University of Louisville

ThinkIR: The University of Louisville's Institutional Repository

Electronic Theses and Dissertations

8-2014

\title{
Culture first, customers second : the case of an organizational learning culture in a successful small business.
}

Devon A. Twyford

University of Louisville

Follow this and additional works at: https://ir.library.louisville.edu/etd

Part of the Education Commons

\section{Recommended Citation}

Twyford, Devon A., "Culture first, customers second : the case of an organizational learning culture in a successful small business." (2014). Electronic Theses and Dissertations. Paper 1471.

https://doi.org/10.18297/etd/1471

This Doctoral Dissertation is brought to you for free and open access by ThinkIR: The University of Louisville's Institutional Repository. It has been accepted for inclusion in Electronic Theses and Dissertations by an authorized administrator of ThinkIR: The University of Louisville's Institutional Repository. This title appears here courtesy of the author, who has retained all other copyrights. For more information, please contact thinkir@louisville.edu. 
CULTURE FIRST, CUSTOMERS SECOND:

THE CASE OF AN ORGANIZATIONAL LEARNING CULTURE IN A SUCCESSFUL SMALL BUSINESS

\author{
By \\ Devon A. Twyford \\ B.A., Sullivan University, 2008 \\ M.S., University of Louisville, 2011

\begin{abstract}
A Dissertation
Submitted to the Faculty of the

College of Education \& Human Development of the University of Louisville in Partial Fulfillment of the Requirements

for the Degree of
\end{abstract} \\ Doctor of Philosophy \\ Department of Leadership, Foundations, and Human Resource Education \\ University of Louisville \\ Louisville, Kentucky
}

August 2014 

CULTURE FIRST, CUSTOMERS SECOND:

THE CASE OF AN ORGANIZATIONAL LEARNING CULTURE IN A SUCCESSFUL SMALL BUSINESS

\author{
By \\ Devon A. Twyford \\ B.A., Sullivan University, 2008 \\ M.S., University of Louisville, 2011 \\ A Dissertation Approved on
}

May 12, 2014

by the following Dissertation Committee:

Rod Githens, Dissertation Director

Donna Pearson, Dissertation Co-Director

$\overline{\text { Brad Shuck, Dissertation Committee Member }}$

$\overline{\text { Kevin Rose, Dissertation Committee Member }}$

William Ryan, Dissertation Committee Member 


\section{DEDICATION}

Jesus - My God, My Savior, My King. May my work always be glorifying unto you. And may work and career never again become idols, as I ever remember that my talent and abilities are evidence of your good grace. 


\section{ACKNOWLEDGEMENTS}

The last few years have been some of the most challenging, and rewarding, of my life. Along the way I've been guided, supported, and loved by some of the best people this world has to offer. My gratitude for their commitment to me, to this journey, is overwhelming. Truly, I owe this accomplishment to them.

Three years ago, Dr. Rod Githens encouraged me to consider a Ph.D. When I told him I was intimidated, and didn't think I could do it, he assured me that I could. His encouragement has buoyed my confidence on more than one occasion. And his commitment to my success has enabled me to accomplish more than I could have imagined. Thank you, Dr. Githens, for believing in me. Thank you for being patient with me as I found my way from practitioner to scholar.

To Dr. Donna Pearson, whose expertise, commitment, and support have been instrumental to my growth as a researcher. The moment I walked into your classroom for the first time, qualitative research came alive to me. I knew that I was home. Throughout this journey, your commitment and support have amazed me time and again. You are unmatched, Dr. Pearson. No matter how full your calendar or how many your commitments, our time together always leaves me feeling that I am your only student. Thank you for all you have done to help bring this project to fruition. I can stand by this work because it was guided by you.

To my committee members, Dr. Brad Shuck, Dr. Kevin Rose, and Dr. Bill Ryan. In so many ways you have served as much more than committee members. Dr. Shuck, 
your presence in my life throughout the last three years has been a constant source of encouragement. Because of your intentional mentorship, I have gained skills that would have taken me years to cultivate otherwise. Thank you for making a place for me in your life. Dr. Rose, our conversations have been life-giving. You've talked me off the ledge more than once, and your quiet wisdom always gives me greater perspective. I'm grateful for you, both as a scholar and as a friend. Dr. Ryan, thank you for asking important questions. From the time I presented this project as an early seed of an idea, your thoughtful questions encouraged me to consider other important angles. Thank you for carving out time to serve.

Most importantly, to my family, without whom none of this is possible. Mickey, you are not only my husband and my teammate in life, but your love, support, and belief in me are ever-present anchors during times I feel I'm drowning. You've put in just as much work over these past three years to make this accomplishment possible as I have. You inspire me to be better just by being you. I love you beyond words. Momma and Daddy, you are responsible for the woman I am. I have never for one second doubted your love for me. If I could see myself through your eyes I am certain I would be convinced that I could conquer the world. Your love and support serve as the foundation from which I draw my strength. Thank you for teaching me that the most important thing in life is family. And, Daddy, I know you wish you had the opportunity to obtain more education, but now I've got enough for both of us. Finally, for my mother in law, whose encouragement never ceases. No matter how many times I uttered, "I can't do this," you were there to convince me that I could. Thank you for loving me as your own daughter and taking this journey alongside me. 


\begin{abstract}
CULTURE FIRST, CUSTOMERS SECOND: THE CASE OF AN ORGANIZATIONAL LEARNING CULTURE IN A SUCCESSFUL SMALL BUSINESS

Devon Twyford
\end{abstract}

May 12, 2014

This dissertation is a case study of a learning culture in a successful small business. It begins with a discussion of the importance of small business to the U.S. economy. The high rate of small business failure is highlighted, along with several factors known to contribute to failure. Of those factors, the limited resource environment within which most small businesses operate is discussed. The reality of limited resources influences small business owner-managers to adopt a risk-averse and conservative approach to business operations. This risk-averse and conservative approach often impacts owner-managers' attitude toward employee learning.

A historical overview of the field of human resource development (HRD) is presented next, including a critical contention that HRD achieves maximum effectiveness when applied with a focus on organizational learning. The conceptual framework used to guide this study suggests that when organizational learning is embraced by a small business, through its central tenets of improving effectiveness, striving for continual learning, and detecting and correcting error, a learning culture can emerge. It is at this point that HRD is viewed as a support mechanism for the learning culture. Instead of 
being viewed as a tool or something to be done, $\mathrm{HRD}$ - formal or informal, intentional or incidental - exists as an outward manifestation of the learning culture.

Several findings from this study are helpful to small business, HRD, and organizational learning scholars and practitioners. First, the organization's learning culture was identified as the greatest contributing factor to business growth. Second, the learning culture was initially established by the owner-manager exclusively. Subsequent recruiting and hiring practices helped identify employees with whom the culture's values resonated, thus creating greater support for the culture. Over time the culture became self-sustaining. At this point, less leadership influence was required to keep the culture alive. Finally, leadership and employee commitment to learning was instrumental to sustaining the culture long-term. 


\section{TABLE OF CONTENTS}

PAGE

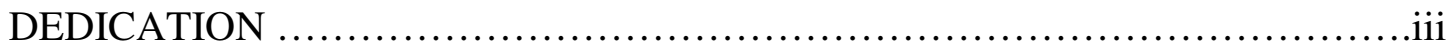

ACKNOWLEDGMENTS .......................................................

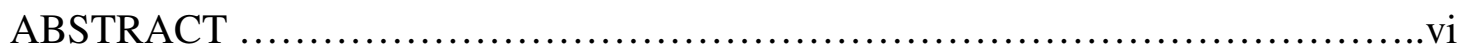

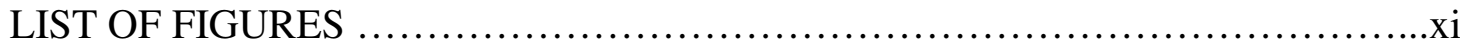

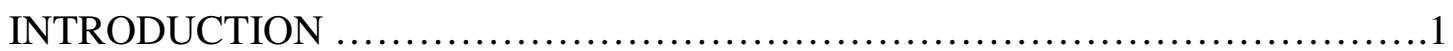

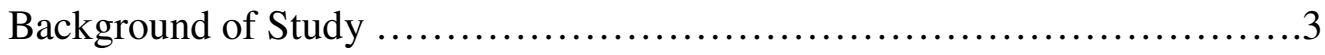

Statement of Problem .................................................... 5

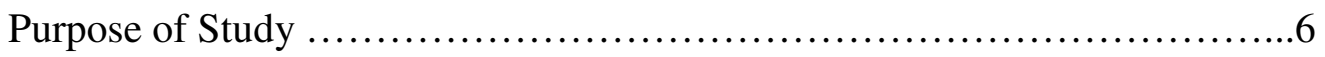

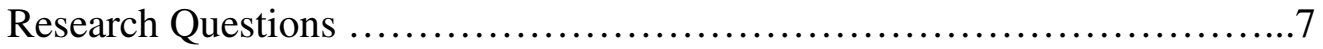

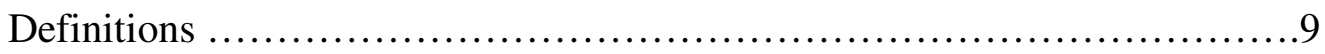

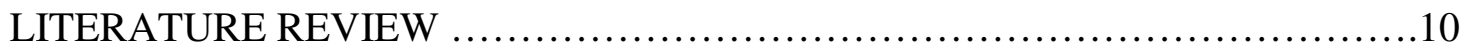

Small Business Context ..............................................11

Human Resource Development ........................................13

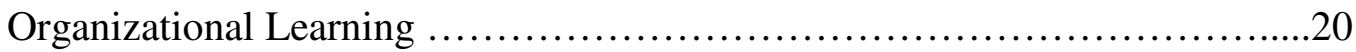

Conceptual Framework ....................................................

Connection of Current Study to Literature …................................33

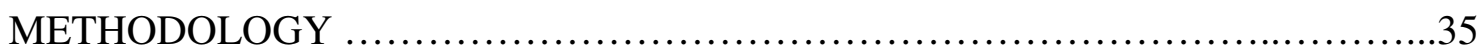

Establishing Positionality and Ensuring Openness ...........................36

Qualitative Research Design ..........................................41

Data Collection ..................................................... 47 


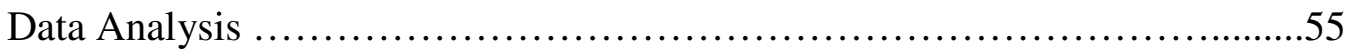

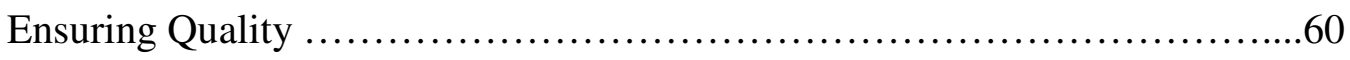

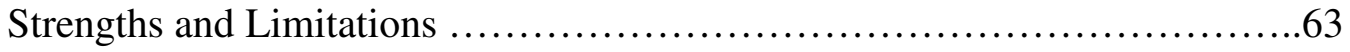

Ethical Considerations .............................................64

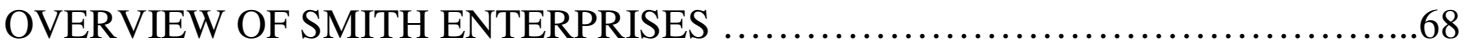

Background and Evolution of Smith Enterprises .........................69

Smith Enterprises' Current Business Structure ...........................80

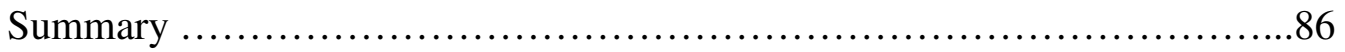

THE ORGANIZATIONAL LEARNING CULTURE ...........................88

Establishing the Learning Culture $\ldots \ldots \ldots \ldots \ldots \ldots \ldots \ldots \ldots \ldots \ldots \ldots \ldots \ldots . \ldots \ldots$

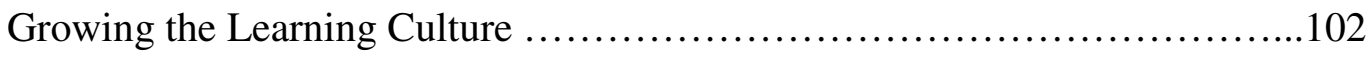

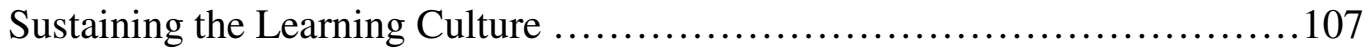

Raising Industry Perceptions .......................................117

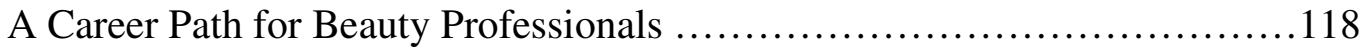

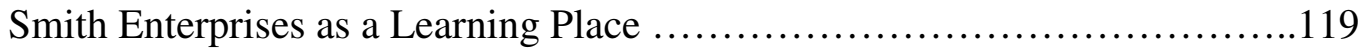

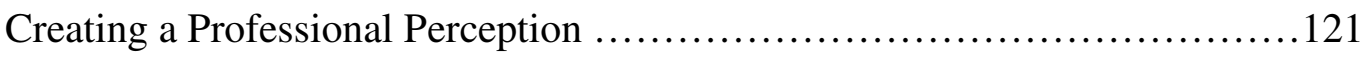

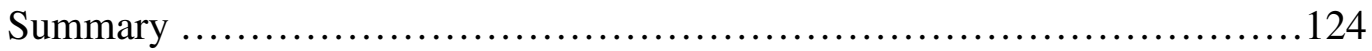

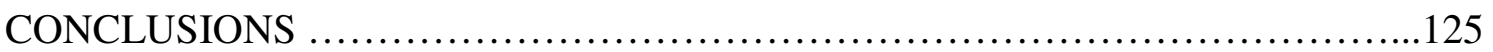

Revisiting the Conceptual Framework ..................................126

Research Conclusions .............................................. 130

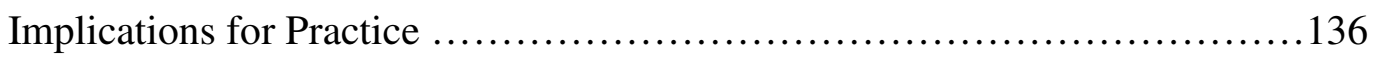

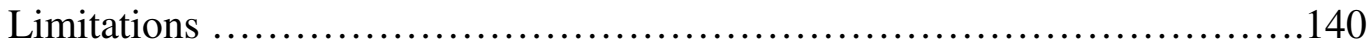


Future Research

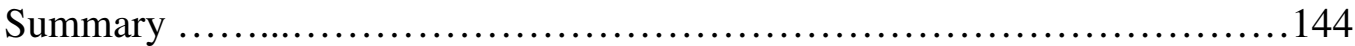

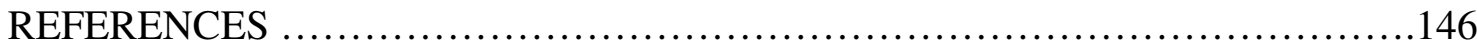

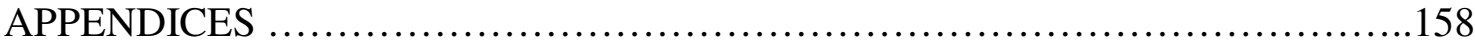

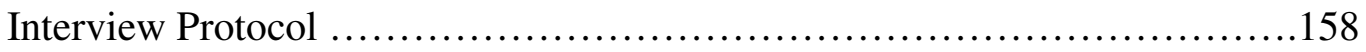

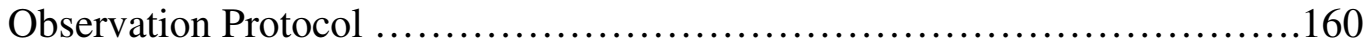

Apprentice Training Modules ...............................................161

CURRICULUM VITAE ................................................... 167 


\section{LIST OF FIGURES}

$\begin{array}{lll}\text { FIGURE PAGE } & \text { PAR }\end{array}$

1. Small Business Organizational Learning Culture Conceptual Framework ............32

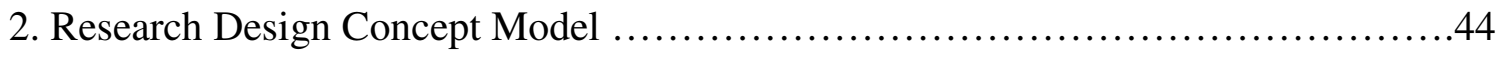

3. Know How Center for Creative Development .................................78

4. Know How Center for Creative Development ...............................78

5. Smith Enterprises, Incorporated Organizational Structure $\ldots \ldots \ldots \ldots \ldots \ldots \ldots \ldots \ldots . .81$

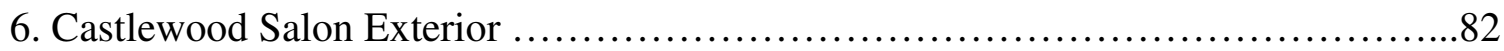

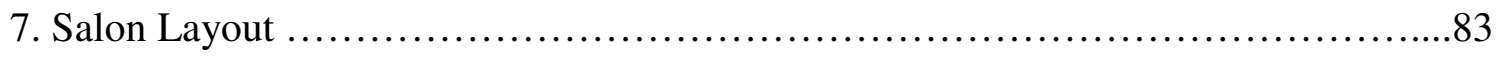

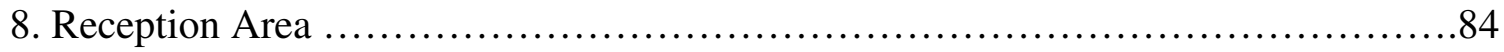

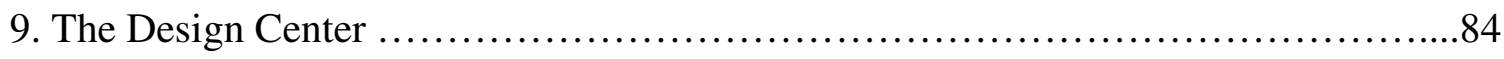

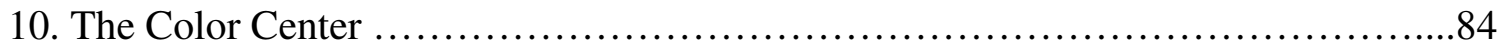

11. Beauty Factor \& Bond for Men Products Manufacturing \& Distribution Facility ...85

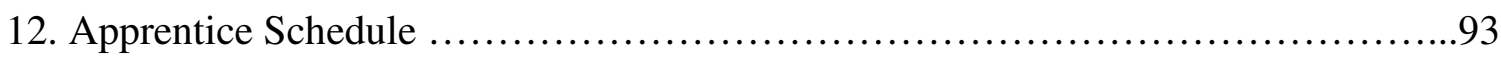

13. Apprentice Final Presentation Standards .................................... 98

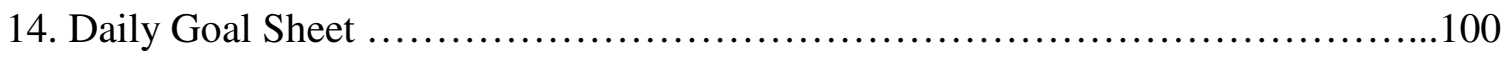

15. Small Business Organizational Learning Culture Conceptual Framework ..........128 


\section{CHAPTER ONE \\ INTRODUCTION}

Small business is vital to the development and success of the United States economy (Hudson, Smart, \& Bourne, 2001; Rasheed, 2005; Robson \& Bill, 2000). As recently as 2012, the U.S. Small Business Administration (SBA) reported that 38 percent of the nation's gross domestic product (GDP) is generated by small businesses. Dobbs and Hamilton (2007) report that 55 percent of product and service innovations are driven by small businesses and 95 percent of all radical innovations have been developed in the small business market. In addition, small businesses represent 99.7 percent of all U.S. employer firms. Research indicates that the greatest public benefit created by small business growth is the contribution to employment (Dobbs \& Hamilton, 2007). Finally, Ayyagari, Beck, and Demirguc-Kunt (2007) suggest that when a country's economy is comprised in large part by small businesses, it is an indication of a successful economy.

The SBA defines small businesses based partly on employment criteria.

According to the SBA, a firm is considered a small business if the number of employees is fewer than five hundred. Based on this information, the SBA reports that 99.8 percent of U.S. firms are considered small. Other criteria that may be used for defining small business ranges from employment statistics, sales volume, or investment quantity 
(Ayyagari, et al., 2007). Regardless of how small firms are defined, it is clear that they represent an important sector of our country's economy. Yet, many fail to succeed past the first few years of establishment. In fact, the SBA (2012) estimates that only $51 \%$ of small businesses survive past the five-year mark. With an almost 50\% likelihood of failure within the first five years of establishment, it is reasonable that there is a body of scholarship that seeks to understand the factors contributing to such a high rate of failure (Balcaen \& Ooghe, 2006; Bates, 2005; Crutzen \& Van Caillie, 2008; Dobbs \& Hamilton, 2007; Gaskill, Van Auken, \& Manning, 1993; Lussier, 1996).

Balcaen and Ooghe (2006) suggest that a strong relationship exists between the size of the business and the likelihood of failure. Failure is more common in younger, small businesses than in larger, more established businesses. Small firms often operate within a limited resource environment and owner-managers' approach to conducting business is primarily pragmatic and reactionary (Choueke \& Armstrong, 1998). These distinguishing characteristics set small businesses apart from their larger organization counterparts. Small businesses often suffer from limited financial resources as well as lack of available external funding opportunities (Rasheed, 2005). Conversely, large organizations have greater access to financial resources including existing capital and external funding opportunities. In small businesses, the challenge of resource constraints, combined with a greater focus on the present state, or the short term, rather than the future state, influence small firm owner-managers to make decisions that provide the most immediate, substantial return (Covin, Green, \& Slevin, 2006). And while all businesses are, or should be, focused on securing returns, for small businesses there is even less room to make decisions that are not immediately profitable or worthwhile 
(Barrett \& Mayson, 2007). Cardon and Stevens (2004) describe the reality inside small businesses as one in which the liabilities of smallness, including limited resources, stymie the ability to seek out new opportunities or even to endure bad markets and heavy competition.

The lack of success of this important sector of our national economy presents a multitude of implications that transcend the basic failure of a business (Crutzen \& Van Caillie, 2008). When a small business fails to thrive, a host of negative, cascading implications is presented including loss of jobs, increased usage of government-based social support programs (e.g., unemployment, WIC), and a community left void of economic and social progress (Wallsten, 2000). Further, customers, suppliers, creditors, and employees all have a stake in the success of a business and can also suffer negative consequences when a business fails (Crutzen \& Van Caillie, 2008). However, Balcaen and Ooghe (2006) suggest that while the mortality rate for small businesses is exceptionally high, failure can be avoided by illuminating certain factors responsible for business collapse that are within management control.

\section{Background of the Study}

To better understand the factors contributing to small business success, we turn our attention to the role of knowledge and learning in organizations. Davenport and Prusak (2000) suggest that understanding the role of knowledge may help answer the question of why some firms are consistently successful. The scholars also claim that organizational knowledge is intimately tied to the success of the business. Relatedly, Torres and Preskill (2001) define a process of organizational learning as continuous growth and improvement of an organization (p. 388). Organizational learning is also 
described as an organization's reaction to changes in its operating environment both internal and external (Graham \& Nafukho, 2007; Wyer, Mason, \& Theodorakopoulos, 2000). This is in agreement with Davenport and Prusak who state that as business environments change over time, the only consistent factor contributing to firm continuity is the way that firms generate and pass on knowledge. This passing of knowledge can be referred to as a learning culture.

Culture is defined by Torres and Preskill (2011) as the way things get done within the context of a certain organization. This includes the "patterns of behavior and thinking practiced and shared between those within the organization" (p. 36). In their research, Torres and Preskill identified the culture of an organization as an essential construct for effective organizational learning practices. In a qualitative study of small businesses, Paige (2002) found that owner-managers had a significant impact on the culture of the organization including how learning occurred. In addition to influencing the culture of the organization, Kitching (2007) suggests that owner-managers have an obligation to serve as enablers of employee learning. It is imperative that owner-managers embrace and set the tone for organizational learning behaviors to ensure that organizational learning becomes an embedded part of the culture (Nafukho, Graham, \& Muyia, 2009). The learning dynamic present within a small business will ultimately determine the growth path of that business (Dobbs \& Hamilton, 2007). It is only through understanding this learning dynamic, along with how and when learning occurs most effectively, that a business is able to obtain and apply the knowledge that will allow them to grow. 


\section{Statement of the Problem}

A small number of studies have investigated both organizational learning and learning cultures within the context of small businesses (Choueke \& Armstrong, 1998; Devins, Gold, Johnson, \& Holden, 2005; Fink, 1998; Graham \& Nafukho, 2008). At present it seems that the field's knowledge is limited to these studies. Relying on these few studies restricts a comprehensive understanding of organizational learning cultures in small businesses. Given the unique context of each small business, what is learned from one study's findings is not always indicative of the experience of all small businesses. This is especially true in qualitative research which does not aim to generalize findings. Wyer et al. (2000) were among the first scholars to ardently suggest further investigation of organizational learning in the context of small business. They present several areas for investigation including how small business owner-managers challenge and adjust their mental models as a basis for a strategic adjustment to markets, products, and processes, the nature of learning interactions with external stakeholders, and how externally revealed fact and insight relating to unexpected unfolding change situations is contextualized into the small firm-specific context.

Further, in 2009 Nafukho, Graham, and Muyia identified a lack of empirical research with regard to mechanisms supporting organization-wide learning in small businesses. They argue that this lack of understanding of organizational learning mechanisms leaves small business owner-managers with no theoretical foundation for use in growing their business. Thus, further inquiry is necessary to identify organizational learning mechanisms that are proven successful in the context of small businesses (Nafukho, et al., 2009). 
A quantitative investigation of seven small businesses conducted by Graham and Nafukho (2008) provided insight regarding organizational learning in the context of small business. The study found that it is imperative for small business owner-managers to understand the culture of their business and how it may or may not promote organizational learning. Graham and Nafukho's findings identified critical variables correlated with culture but the researchers call for additional qualitative research. Using a qualitative approach to inquiry, a more comprehensive understanding of culture and its influence on organizational learning can emerge.

\section{Purpose of the Study}

Using a qualitative approach to inquiry, this research explored an organizational learning culture in the context of a successful small business. By generating a deeper and more nuanced understanding of the learning culture within a successful small business, we better understood how an organizational learning culture contributes to business success.

This study provided an opportunity to make a meaningful contribution to this important body of scholarship. While the literature is brimming with investigation of the reasons why small businesses fail, it is also valuable to understand the factors contributing to small business survival. Of those factors, there is little empirical evidence available with regard to how an organizational learning culture might help small businesses guard against failure. The current study extended the work of such scholars as Dobbs and Hamilton (2007), Torres and Preskill (2001), and Davenport and Prusak (2000). The research extended Dobbs and Hamilton's work by determining the ways the learning dynamic present within a business does influence the growth path of the 
business. It extended the work of Torres and Preskill in determining how an organizational learning culture is an essential construct for effective business practices. And, finally, it extended the work of Davenport and Prusak by determining whether the knowledge that a small business generates and passes on does, indeed, contribute to the success of the firm.

The evidence gathered by this study encouraged critical reflection of the existing theory and research in the area of learning culture and small business. The findings served to both corroborate and stimulate critical questions of the existing body of knowledge. Ultimately, the hope is that evidence-based practices of a successful small business have been illuminated which can contribute to the chance of survival of this important sector. This began with a deeper understanding of organizational learning in small businesses as suggested by Swanson and Holton (2009) in their claim that whole system change begins with a commitment to the in-depth study of a group or groups.

\section{Research Questions}

Using a qualitative approach to inquiry, this research sought to understand an organizational learning culture as it occurred in a successful small business. The following central research question and sub-questions guided this study: How does an organizational learning culture occur in a successful small business?

1. What are the elements of the organizational learning culture?

2. How do employees describe their experience with the organizational learning culture?

3. How does the organizational learning culture contribute to the growth of a small business? 
4. What happens to the organizational learning culture as a small business grows?

The central question sought to understand the organizational learning culture that is present within a small business that has demonstrated sustained growth. In doing so, significant elements of the learning culture were identified to illicit a rich description. Sub-questions examined how the identified learning culture contributed to the growth of the small business under study and what happened to the learning culture as the small business experienced growth. Employee experiences with the organizational learning culture were sought in order to add to the understanding of the phenomenon.

\section{Summary}

This chapter introduces the topic of organizational learning in small business including the research problem, the purpose of the study, and the overarching research questions that will guide the study. Additionally, definitions of pertinent terms are presented at the end of this chapter to aid the reader in understanding important terms that appear throughout the remainder of this document. Chapter Two provides a literature review which expands upon important theoretical and conceptual frameworks that provide context for understanding the topic of organizational learning in small business.

The chapter concludes with an original conceptual model suggesting that cultivation of an organizational learning culture may be an appropriate solution for small businesses looking to achieve growth despite a scarce resource environment. Chapter Three presents the methodology employed to conduct this study including explanation of the study sample, data collection tools, and the analytic method used to interpret data. Chapters Four and Five present the background and evolution of the case organization. Finally, 
chapter Six presents research conclusions, implications, and suggestions for future research.

\section{Definitions}

Throughout this dissertation, the following four terms will be used as defined below: growth, owner-manager, small business, and success.

Growth: In line with the claim that the greatest public benefit created by small business growth is the contribution to employment (Dobbs \& Hamilton, 2007), growth is identified as a consistent uptick in the number of individuals employed by the business from inception to present. Thus, a business that began with two employees and currently employs 23 employees would constitute a business that has achieved growth.

Owner-Manager: Often within small businesses, the owner of the firm is also the acting manager. For this study, the term owner-manager is defined as the highest-ranking decision maker in the business. It is expected that this person will always be the owner, the manager, or both. However, if there is another individual who is responsible for the highest level decision making who is not the owner or the manager, that person will still be identified as the owner-manager.

Small business: The United States Small Business Administration (SBA) defines small businesses as any business employing between one and 500 individuals. However, because existing research lacks investigation of small businesses which fall on the lower end of the small business continuum, this study defines small business as any business employing fewer than 25 full-time individuals.

Success: Success is defined as any small business which has avoided failure (closing) and has continued to operate past the critical five-year mark of inception. 


\section{CHAPTER TWO \\ LITERATURE REVIEW}

This section will expand upon important theoretical and conceptual frameworks that provide context for understanding the topic of organizational learning in small business. The business context of U.S. small businesses is discussed to highlight the limited resource environment within which most small businesses operate. The reality of limited resources may influence small business owner-managers to shun human resource development (HRD). Definitions of HRD, including its activities and its occurrence in small organizations, provide a greater understanding of the state of HRD in small business. The evolution of the field of HRD from operationally reactive to strategically proactive is discussed to illuminate the claim that strategic HRD, with its focus on organizational learning, is the future of the field. A review of important organizational learning scholars and their research contributions provides a comprehensive view of the organizational learning landscape. This information also makes a case for the importance of an organizational learning culture within small business. Finally, an original conceptual model suggesting that organizational learning may be an appropriate solution for small businesses looking to achieve growth and success despite a limited resource environment is proposed. 


\section{Small Business Context}

Small business is considered the economic engine of the American economy (Hausman, 2005; SBA, 2014). Half of the U.S. public sector is comprised of small business, and the major portion of job generation takes place within small businesses (Headd, 2010). They provide between 60 and 80 percent of net new job creation and represent 99.7 percent of employer firms (Dobbs \& Hamilton, 2007; Gu, Karoly, \& Zissimpoulos, 2008; SBA, 2014). The Small Business Administration (2014) also reports that since 1990, large firms have eliminated 4 million jobs, while small firms have added 8 million jobs to the U.S. economy. Due to the impact of small business on the American economy, federal and state government programs, along with private sector programs, have been established to facilitate small business creation and expansion (Gu, et al., 2008).

Small Business Development Centers (SBDCs), a program sponsored by the Small Business Administration, are available in over 900 service sites in the country. The centers provide business training and assistance to both current and prospective small business owners. Training topics include finance, marketing, production, organization, engineering, and technology (Gu, Karoly, \& Zissimpoulos, 2008). Another program, the Service Core of Retired Executives (SCORE), offers consulting and counseling to small businesses similar to that of the services offered by SBDCs. Supported in part by the SBA, and staffed with volunteer business leaders, the program provides an array of services including mentoring, business tools, and workshops (SCORE, 2014). Finally, government programs such as the Self-Employment Assistance program allows unemployed individuals to receive unemployment insurance benefits while starting a new 
business in lieu of searching for a paid job (Gu, et al., 2008). Each of these programs strives to enable and support the success of American small businesses, as they remain an important component of a thriving economy.

Part of the mission of these small businesses support programs is to educate small business owner-managers regarding gaining access to financial capital. In order to establish and grow a business, small business owner-managers must have access to financial capital (Cherubin, 2005). Yet, many face challenges to obtaining access to capital to finance both the startup and growth of the business (Kim, Aldrich, \& Keister, 2006). Small business scholars argue that unless an owner-manager has personal wealth to finance the startup of the business, capital must be obtained from an outside source (Hausman, 2005; Hutchinson, 1999). Kim, et al. (2006) suggest that small business owner-managers are often forced to rely on informal types financing such as loans from family, credit cards, and personal savings. Part of the reason that small business ownermanagers rely on such sources of funding is due to a lack of sufficient understanding regarding available financial sources and the skills to access them (Hutchinson, 1999).

Wiklund, Patzelt, and Shepherd (2009) suggest that, as the most general type of capital, financial capital is most easily converted into other types of resources. Equipment, labor, property, and other resources are more available to a small business when there is greater access to or greater amounts of existing financial capital. Thus, when a small business suffers from inadequate financial capital, they are forced to operate within a limited resource environment (Kim, Aldrich, \& Keister, 2006). This limited resource environment influences owner-managers to adopt a more risk-averse and conservative approach to business operations (Hausman, 2005). 
One example of the type of risk-averse and conservative approach to business operations can be observed through small business owner-managers' approach to employee learning. Research by Hill (2004) illuminated this reality. Hill's findings suggested that small businesses lack expertise, infrastructure, and general resources which larger organizations typically enjoy. Thus, an employee is less likely to receive training if they work in a small business. In fact, it was suggested that in many small organizations, training does not take place at all. But in cases where training does occur, it is likely informal and short-term focused. It is applied almost exclusively to solve immediate work-related problems rather than aiming for the development of people. This approach to HRD is a common shortcoming of many small businesses. As a result, it functions as a roadblock to the growth of the business.

\section{Human Resource Development}

HRD has been defined and conceptualized throughout its history, beginning with Nadler's (1970) classic definition of the field as, "a series of organized activities conducted within a specific time and designed to produce behavioral change" (p. 54). Since that early definition the field has evolved to include not only the fundamental function of training and development but also a more strategic, global outlook. Yet, even today a precise definition of HRD, consistent across various scholars, is elusive (Mankin, 2009, McLean \& McLean, 2001; Swanson \& Holton, 2009). And, at times, the necessity of a definition is even debated (Lee, 2001).

In 2001, McLean and McLean investigated the possibility of developing a definition of the field that represented a comprehensive, global perspective. To do this, they enlisted the participation of HRD scholars and practitioners around the globe. In 
addition to providing many various definitions, the participants also provided descriptions of various activities associated with their definitions of HRD. After summarizing the similarities and differences among the many definitions, McLean and McLean crafted their own original definition of HRD:

Human resource development is any process or activity that, either initially or over the long term, has the potential to develop adults' work-based knowledge, expertise, productivity and satisfaction, whether for personal or group/team gain, or for the benefit of an organization, community, nation or, ultimately, the whole of humanity (p. 314).

From McLean and McLean's definition it is clear that HRD is viewed as both a process and an activity. This perception suggests that HRD is a tool used to develop individuals for the benefit of anything from an organization to the whole of humanity. HRD, according to McLean and McLean's definition is something to be done.

In addition to this comprehensive, global definition, they suggest that the scope of HRD activities reported by participants ranged anywhere from strictly training to activities broad enough to make it possible for "all people to develop their full potential in physical, emotional, spiritual, and intellectual terms, while improving their technical and productive skills, to ensure their full participation in the process of national development" (p. 315). However, while a broad range of activities was associated with HRD, McLean and McLean reported that most fell somewhere within the realm of learning, performance, and change.

This focus on learning, performance, and change can also be found within a definition advanced by Wilson (2005) which defined HRD as, "a title which represents the latest evolutionary stage in the long tradition of training, education and developing people for the purpose of contributing towards the achievement of individual, 
organizational and societal objectives," (p. 25). Wilson also identified the component elements of HRD as training, education, development, and learning. Through his investigation of the ways in which HRD contributes to strategic organizational issues, Wilson identified an important contribution of HRD as enabling an organization to learn

more quickly than its peers. Similar to Wilson's finding, Tseng and Lee (2009) suggested that most definitions of HRD include the need for organizational efforts to result in performance improvement and organization development that enhance the organization's competitiveness and effectiveness. From these more recent definitions it is clear that HRD is more than organized activities aimed at behavior change. While the field may have upheld such goals early on, more recent definitions of HRD indicate a reality in which development of employees is aimed at learning and improvement of both the employee and the organization.

\section{Contingent HRD - The Impact of Firm Size}

As can be seen from the above collection of definitions, there is an abundance of existing literature in the field of HRD. However, Kuchinke (2003) states that current theoretical propositions are not sufficient for understanding the exact nature of HRD in practice. Kuchinke also suggests that HRD activities vary greatly among organizations often based on industry characteristics and the size of the organization. Similarly, several other scholars encourage HRD scholars and practitioners to recognize that small business organizations are all uniquely different and prefer a customized approach to HRD based on their specific business needs (Loan Clarke, Boocock, Smith, \& Whitaker, 1999; Rauch, Frese, \& Utsch, 2005; Sadler-Smith, Down, \& Field, 1999). Because industry characteristics and organization size influence the way HRD is structured in different 
firms, Kuchinke argues that many organizations are continuously adapting, modifying, and altering their HRD practices. Those practices can range from minimal or non-existent to varied, specific, and even strategic-level.

In order to understand the variations in HRD practices among organizations, Kuchinke (2003) investigated the HRD arrangements, strategies, and core processes within various organizations. While the sample represented both large and small organizations, the study found evidence that small organizations often likely avoid investment in HRD activities due to the scarce resource framework within which they operate. This is in agreement with the assertions of other scholars (Hill, 2004; Huang, 2001; Sadler-Smith, Down, \& Field, 1999; Saru, 2007). Thus, based on study findings, Kuchinke developed a contingency framework which consists of the following propositions:

1. The structure and staffing of HRD in organizations will be influenced by industry characteristics, including technical, regulatory, and institutional, and by organization size. Size effects will be industry specific.

2. Organizations will decide on investment in HRD based on cost-benefit considerations and weigh investment in HRD products and services against other forms of building, maintaining, and increasing human capital. Given uncertain returns on investment, organizations will invest conservatively in HRD and focus on system maintenance rather than system change.

3. Organizations will support multistage HRD core processes, such as instructional systems design or action research, by assessing the need for each stage and implement HRD core process steps based on the expected utility of each step. 
Kuchinke's framework contends that small organizations often satisfice rather than maximize employee learning and performance needs. Effectively, HRD in firms with scarce resources is considered, "essential only to the degree that it contributes more efficiently and effectively to performance than other allocations and scarce resources" (p. 305). Thus, harkening back to McLean and McLean's (2001) definition, HRD is seen as a tool that requires the use of scarce organizational resources such as time and money.

Building upon the notion that HRD is seen as a tool which requires use of organizational resources, a number of studies suggest that it is likely that many small businesses are failing to provide the necessary tools to improve employee job performance (Huang, 2001; Sadler-Smith, Down, \& Field, 1999). Improved performance is an unlikely result when HRD practices take the form of inexpensive and inefficiently applied solutions that are short-term focused (Sadler-Smith, Down, \& Field, 1999). Yet, the harsh reality for many small businesses is that a decision to invest even a few hours of time or a few hundred dollars on a specific HRD-related activity could cost the business other opportunities that may be more worthwhile (Patton, Marlow, \& Hannon, 2000). In fact, Patton et al. (2000) suggest that there is little empirical evidence of a direct link between investment in training and development and increased organizational performance. Regardless, if a small business does decide to invest in HRD, it is apparent that to add value, practices must be timely, relevant, and rooted within the daily practices of the business (Hill, 2004). HRD must become part of business as usual, smartly camouflaged within the day-to-day routines of operation.

Rigg and Trehan's (2002) study discovered that identifying HRD using the most basic and traditional definition (training) prohibited a complete understanding of HRD in 
small businesses. Their study added to the understanding of HRD practices within the context of small business. The researchers compared both a traditional interpretation and a discursive interpretation of three companies' HRD practices in an attempt to develop a more holistic perspective. The study revealed that by using a traditional definition of HRD, participants reported HRD activities that were limited to the number of formal training hours in which employees engaged. On the other hand, when the conception of HRD was expanded, participants reported activities that reached far beyond formal training and included the ways in which organizational members developed and altered their working ways.

As a result of their study, Rigg and Trehan (2002) advocate for a learning perspective as it relates to HRD. They argue that this presents the possibility to recognize that development is not simply the result of formalized training practices but that development happens as a result of informal, continuous processes at all levels of the organization. Investigating this learning perspective as advanced by Rigg and Trehan, in the next section we turn our attention to the evolution of HRD from an operationally reactive approach, limited to activities such as employee training, to a more strategically proactive approach, including activities more representative of a learning perspective.

\section{Twenty-first Century Human Resources - From HRD to Organizational Learning}

Ruona and Gibson (2004) argue that it has never been more important for organizations to tap into the strategic potential of their people. In response to this, the scholars suggest that the field of human resources has evolved and is no longer distinguished by the differences in its various functions but instead is operating from an integrated, strategically proactive approach that contributes to organizational 
performance. Through the use of historical analysis, the authors traced patterns of events, forces, and ways of thinking that have impacted the field of human resources from inception to present. Their analysis consisted of a review of over 50 articles and book chapters in the fields of human resource management, HRD, and organization development over the past 50 years. The authors paired Brockbank's (1999) Dimensions of Competitive Advantage for HR Activities model with Ulrich's (1997) Four-factor HR Roles model to develop their own original model that represents the historical context of the field as it evolved from operationally reactive to operationally proactive and then from to strategically reactive to strategically proactive (see Table 1).

\begin{tabular}{|c|c|c|}
\hline Strategic & Support strategy & $\begin{array}{c}\text { Create future, strategic } \\
\text { opportunities }\end{array}$ \\
\hline Operational & Implement the basics & $\begin{array}{c}\text { Improve the basics } \\
\end{array}$ \\
\cline { 2 - 3 } & Reactive & Proactive \\
\hline
\end{tabular}

Table 1. Ruona \& Gibson (2004) Evolution of HRD.

This model, when applied to the field of HRD, traces the history from the early industrial era when training became a central feature in organizations and focused on creating and integrating components of instructional design and adult learning, to the strategically proactive HRD of today which concerns itself with creating a knowledgeable, competent, and agile workforce that uses learning to capitalize on emerging opportunities (Ruona \& Gibson, 2004). This focus on learning at the individual, group, and organizational levels facilitates the development of holistic organizational 
systems that "translate learning into unique and strategic core organizational competencies" (Ruona \& Gibson, 2004, p. 58). Ruona and Gibson suggest that HRD has been an important contributor to the development of organizational learning concepts through which various powerful models for creating a learning organization have emerged. They also propose that it is this focus on organizational learning that has the potential to be the hallmark of strategically proactive HRD. In addition and similar to Ruona and Gibson, Graham and Nafukho (2008) highlight the need to move beyond traditional HRD practices to foster an environment that facilitates organizational learning. By cultivating an environment rich in the specific elements of a learning-oriented culture, Graham and Nafukho suggest that small businesses, in particular, can achieve improved organizational performance.

\section{Organizational Learning}

Though Crossan, Lane, White, and Djurfeldt (1995) claim that no one theory or model of organizational learning is widely accepted, several theories of organizational learning have been proposed by various scholars. Cangelosi and Dill (1965) were the first scholars to advance a definition of organizational learning as a series of interactions between organizational decision makers. Later, Argyris (1977) described organizational learning as an organization's detection and correction of error. Argyris' work resulted in two new terms in the field of organizational learning: single-loop and double-loop learning. More recently, Senge (1991) brought the concept to popular attention through his identification of organizational learning as the Fifth Discipline. Further advancing the field is the 4I Framework of Organizational Learning as proposed by Crossan, Lane, and White (1999) which suggests that organizations can renew themselves by managing the 
learning of employees, groups, and the organization. What follows is an investigation of each scholar's definitions and frameworks in order to provide a comprehensive view of the concept of organizational learning.

\section{Organizational Learning as Decision-Making}

Cangelosi and Dill's (1965) seminal study of organizational learning investigated the learning processes of a team of students acting as complex organizational decision makers as part of a management simulation exercise. The study was the first in the area of organizational learning to suggest that learning occurs at the individual, group, and organizational levels. It was also clear from Cangelosi and Dill's study that organizational learning was not simply a collection of all of the individual learning that occurs within an organization. The study identified four phases of learning and each phase represented the various levels through which the decision makers moved as they monitored their business environment and made decisions based on what they learned. Learning began with individual insights but then progressed to team decisions which ultimately resulted in organizational change.

More recently, scholars such as Huber (1991) have drawn upon Cangelosi and Dill's (1965) framework to suggest that organizational learning is an intentional process aimed at improving effectiveness. Huber claims that effectiveness is improved through the application of new learning which, according to Marsick and Watkins (2001), can occur both informally and incidentally. This is evident in Cangelosi and Dill's findings as group members displayed learning that occurred through individual insights (informal), group discussions (informal), and even mistakes (incidental). This type of learning (informal and incidental) underpins Huber's claim that learning takes place within 
organizations even when organizational members are unaware that it is happening.

Learning need not be formalized, such as through classroom training and other formal development programs, to occur.

\section{Organizational Learning as Error Detection and Correction}

Cangelosi and Dill's (1965) study indicated that learning can occur in response to poor decision making and mistakes. However, it was not until later that Argyris (1977) formally identified this phenomenon through defining organizational learning as the detection and correction of error. Argyris identifies two types of learning that occur within organizations: single-loop and double-loop. According to Argyris, single-loop learning produces changed behavior on the part of organizational members, but does not cause individuals to question the underlying organizational processes and procedures responsible for their behavior. Double-loop learning, on the other hand, not only produces behavior change but also results in organizational members questioning the fundamental processes and procedures of the organization to identify corrections that must be made in order to reduce recurrence of error. The difference between single and double-loop learning can be seen when organizational members not only change their behavior in response to error, but also seek to change the fundamental ways in which the organization carries out its day-to-day operations to avoid the same error in the future.

Double-loop learning is also characterized by a change in one's personal constructs, or ideas about the world, and the frames of reference that support them. For example, Wyer, Mason, and Theodorakopoulos (2000) discuss the external operating environments faced by small businesses as typically uncertain and ever-changing. This type of environment requires highly complex decision-making. Thus, if personal 
constructs prove ineffective for dealing with the environment, the assumptions upon which the constructs are founded must be uncovered, questioned, and then modified. The ability of owner-managed small businesses to identify and cope with open-ended change situations by reconstructing and modifying their existing personal constructs will determine the business's ability to sustain long-term growth (Wyer, et al., 2000).

\section{The Fifth Discipline}

In line with organizational learning scholars that preceded him, Senge (1991) agrees that organizational learning is more than just the cumulative result of the individual learning of organizational members. However, diverging somewhat from earlier scholars he states that organizational learning begins with the individual learning of each organizational member. Senge presents the term personal mastery to describe the discipline of personal growth and learning toward which each organizational member should strive. He claims that this quest for continual learning is the spirit of the learning organization. Similar to the model advanced by Ruona and Gibson (2004) which suggests a dichotomy of reactive versus proactive approaches to doing business, Senge claims that personal mastery entails approaching one's life from a creative versus reactive standpoint.

Senge's (1991) claims echo those of Argyris' (1977) double-loop learning theory. Senge suggests that in order to be considered a learning organization, two conditions must be present at all times. First, the organization must have the ability to design itself according to its intended desires our outcomes. Second, the organization must be able to recognize when its direction is different from the desired outcome and follow the necessary steps to correct the misalignment. It is within this second condition that one 
sees double-loop learning occurring. Not only must the organization recognize error, or misalignment, but it must also question the underlying causes that contributed to such misalignment.

Organizational learning has long been conceptualized by scholars through various definitions and frameworks. From Cangelosi and Dill's (1965) decision-making framework, to Argyris' (1977) error detection and correction framework, to Senge's (1991) framework of personal mastery and keen awareness of desired organizational outcomes, each scholar contributes to the conceptualization of a learning organization. And this conceptualization did not cease with early scholars. Currently, definitions and frameworks of this concept continue. Scholars such as Graham and Nafukho (2007) and Wyer et al. (2000) describe organizational learning as an organization's reaction to changes in its operating environment whether internal or external. The scholars claim that learning opportunity is presented any time that change occurs and, based on how the organization responds to the change, can determine its designation as a learning organization. It would seem that from the work of each of these scholars that the essence of organizational learning is an organization's ability to continually adapt and improve as it moves toward its desired future. Crossan, Lane, and White's (1999) 4I Framework of Organizational Learning, described in the next section, exemplifies this philosophy within a process termed organizational renewal.

\section{I Framework of Organizational Learning}

Crossan, Lane, and White (1999) suggest a framework of organizational learning that addresses the phenomenon of organizational renewal as it relates to learning. Specifically, the authors suggest that strategic renewal requires organizations to explore 
new ways of operating (feed-forward) while continuing to exploit what they have already learned (feedback). This tension between exploration and exploitation is the basis for what is termed the 4I Framework of Organizational Learning. The framework consists of four key premises:

Premise 1: Organizational learning involves a tension between assimilating new learning (exploration) and using what has been learned (exploitation).

Premise 2: Organizational learning is multi-level: Individual, Group, and Organization.

Premise 3: The three levels of organizational learning are linked by social and psychological processes: (a) Intuiting, (b) Interpreting, (c) Integrating, and (d) Institutionalizing (4I's).

Premise 4: Cognition affects action (and vice versa) (Crossan, Lane, and White, 1999, p. 1999).

This framework contends that the processes of intuition, interpretation, integration, and institutionalization are all related through feed-forward and feedback processes across all levels of the organization. The authors also suggest that the interactive relationship between cognition and action is critical to the phenomenon of organizational learning. In fact, it is organizational learning which connects cognition and action - thus, understanding guides action and action then informs understanding through a symbiotic type of relationship.

Intuition, according to Crossan et al. (1999, p. 526), "involves perceiving similarities and differences - patterns and possibilities." This process of recognizing and learning from similarities and differences in experiences is the first step in the 
organizational learning cycle. As individuals develop new insights and ideas based on experiences, those insights and ideas begin to guide their actions and decision-making. However, it is not until those newly discovered insights and ideas are explained through words that they can be interpreted.

Interpretation involves the use of language in enabling individuals to name and explain intuitions that are grounded in feelings, hunches, or sensations (Crossan, et al., 1999). Until intuitions are fully clarified through interpretation, individuals cannot begin to make explicit connections among them. Further, it is through this processing of insights and ideas that shared meaning and understanding is cultivated among individuals in a shared social group. The interpretive process allows groups to develop cognitive maps that are representative of the common domains in which they operate. Further, Crossan et al. suggest that when these cognitive maps move beyond particular individuals to become entrenched within the workgroup, it can be described as integrative.

Integration is described as "coherent, collective action" (Crossan, et al., 1999, p. 528). This coherent, collective action is made possible only through a shared and agreedupon understanding. Just as in the process of interpretation, language plays an important role in integration. Primarily, language provides the means by which groups can preserve that which has been learned. It is through language, primarily conversation, that established meaning is communicated and new learning is advanced. The authors suggest several ways that communication can occur such as through communities of practice that illuminate what actually occurs in practice. Often, what occurs in practice is different from what occurs in manuals or what is taught in formal training. Actual practice is often propagated through stories passed down by community members. As the stories evolve 
among the communities of practice a more in-depth understanding is cultivated and new integration occurs.

Institutionalizing, the final process within the 4I model, distinguishes organizational learning from individual and group learning. The process of institutionalizing is more than "the sum of all of the learning that is present among the individuals within the organization" (Crossan, et al., 1999, p. 529). When the learning that occurs among individuals and groups is embedded within the systems, structures, strategy, routines, and prescribed practices of the organization, we can say that organizational learning has occurred. In fact, institutionalization is a way by which organizations can leverage the learning of its individual members. For organizations that reach the level of institutionalization, there can be some confidence that learning opportunities provided to employees should result in some long-term benefit to the organization even upon departure of the employee. However, the institutionalization of learning can pose some challenges to the organization. According to Crossan et al., as prior learning becomes embedded in the organization and begins to guide the actions and learning of employees, spontaneous individual and group learning becomes less likely.

The tension between feed-forward learning and feedback learning can be a challenge for an organization. Feed-forward learning occurs first on an individual basis and evolves through meaning-making and shared understanding among groups until it is accepted by the organization through institutionalization. Inversely, feedback learning is established learning that has received a certain amount of consensus from influential organizational members and guides the behavior and decision-making of the organization. However, as conditions within the organization shift and evolve, that 
learning which has been institutionalized may no longer be most appropriate. Instead, it may be necessary to shift the focus toward a more individual learning orientation in order to explore new learning opportunities. It is difficult for organizations to manage the tension between exploiting that learning which is established and exploring new learning that has yet to be discovered. Indeed, institutionalized learning can drive out assimilation of new learning. It is within the context of this reality that organizations face challenges to strategic renewal. And, according to Crossan et al. (1999), it is the "individuals, and the social processes and group dynamics through which they interact, that may facilitate or inhibit organizational learning" (p. 534).

A qualitative case study conducted by Crossan and Berdrow (2003) examined strategic renewal within an organization undergoing significant changes. The authors sought to better understand the strategy process through the 4I organizational learning perspective. Their findings indicated that scholars must acknowledge that an organization's context determines its patterns of learning. Crossan and Berdrow's (2003) study argues that while organizational learning processes may not be ideal, they may prove best when considering the context of the organization. This lends support to Kuchinke's (2003) assertion that learning practices may not always align with espoused ideals, rather they are often contingent upon their unique context. Strengthening the argument that the context of the organization matters, we turn our attention to the importance of leader influence on the organization's learning culture.

\section{Owner-Manager Relationship to Organizational Learning Culture}

In their study of three small businesses, Graham and Nafukho (2008) discovered that while the concept of organizational learning initially was not well understood by 
small business owner-managers, as researchers explained its meaning the ownermanagers agreed that this concept was important to success. At the same time, however, the researchers also found that many owner-managers had limited understanding of which aspects of organizational learning should be used, appraised, and audited for deficiencies. This finding is of concern considering that through a meta-analysis of empirical literature supporting the notion that knowledge and small business growth are intimately linked, MacPherson and Holt (2006) identified owner-managers as one of the primary mechanisms by which the accumulation and application of knowledge is achieved.

Spence and Rutherfoord (2001) describe small business owner-managers as the strongest influence on the organization. Given their consistent presence within the business and their close proximity to the day-to-day operations, the owner-manager's influence is powerful in shaping the direction of the organization, including its proclivity for learning (Kitching, 2007; Paige, 2002; Vera \& Crossan, 2004). As such, one of the most important tasks of an owner-manager is maintaining awareness of an organization's external environment in order to recognize the opportunity for learning and growth (Greiner, 1998; Nafukho, Graham, \& Muyia, 2009). Wyer et al. (2000) suggest that small business owner-managers understand their external environments through a process of information gathering and processing that generates new knowledge. Moreover, knowledge, when created, captured, and transferred well can help stimulate and support growth in small businesses (Macpherson \& Holt, 2006). In fact, the knowledge possessed by a business often defines the shape and trajectory of a firm's growth (Macpherson \& Holt, 2006). Further, according to research conducted by Rigg and Trehan (2002), among 
the three small businesses included in the study, there was a strong, shared belief that improvement was a direct outcome of learning.

The opportunity for learning is presented as small business owner-managers monitor their external environments and identify impending change. When information is gathered about the change, translated, and then action is taken to implement new learning, organizational learning occurs (Graham \& Nafukho, 2007; Skerlavaj, Stemberger, Skrinjar, \& Dimovski, 2006; Wyer, et al., 2000). Devins, Gold, Johnson, and Holden (2005) suggest that as learning accumulates in small business, meanings are derived from the learning and become shared among the employees, thus creating the culture of the business. Graham and Nafukho (2008) suggest that culture has an immediate impact on the quality of learning within an organization including the interpretation of employee behavior, and the determination of subsequent behaviors.

\section{Conceptual Framework}

Given the often-limited resource environment of small businesses, it can be difficult for them to take up organizational learning processes as easily or readily as larger organizations having access to more resources (Cardon \& Stevens, 2004; Garavan, Morley, Gunnigle, \& Collins, 2001; Morrison \& Bergin-Seers, 2002; Wyer, et al., 2000). Instead, HRD practices in small business often take the form of inexpensive and inefficiently applied solutions that are short-term focused (Sadler-Smith, Down, \& Field, 1999). According to Ruona and Gibson's (2004) $21^{\text {st }}$ Century HR framework, this type of approach to HRD is considered operationally reactive and is not considered the most effective approach to building the capacity of the organization. 
Instead, Ruona and Gibson (2004) suggest that the future of HRD resides within a strategically proactive orientation which drives the development and adoption of organizational learning practices. And while an operationally reactive approach to HRD may not be considered completely ineffective - Kuchinke (2003) warns against discounting HRD practices that might at first glance seem less sophisticated - it can be argued that organizations benefit from a more proactive and strategic view. Considering Ruona and Gibson's framework, which suggests that a focus on organizational learning is the potential hallmark of a strategically proactive HRD, examination of organizational learning philosophies that might be relevant for small business seems prudent. To that end, Crossan et al's (1999) 4I Framework of Organizational Learning presents opportunity to investigate how organizational learning mechanisms provide the possibility for small businesses to strategically renew themselves in order to attain growth and success.

The following conceptual model draws upon Kuchinke's (2003) Contingent HRD framework, Ruona and Gibson's (2004) Twenty-first Century HR framework, and Crossan, Lane, and White's (1999) 4 I Framework of Organizational Learning to demonstrate how each might contribute to produce a positive future for small businesses looking to embrace a more strategically proactive approach to HRD. When synthesized, the literature suggests that a strategically proactive approach should allow small businesses to harness organizational learning practices which should result in growth and success. 


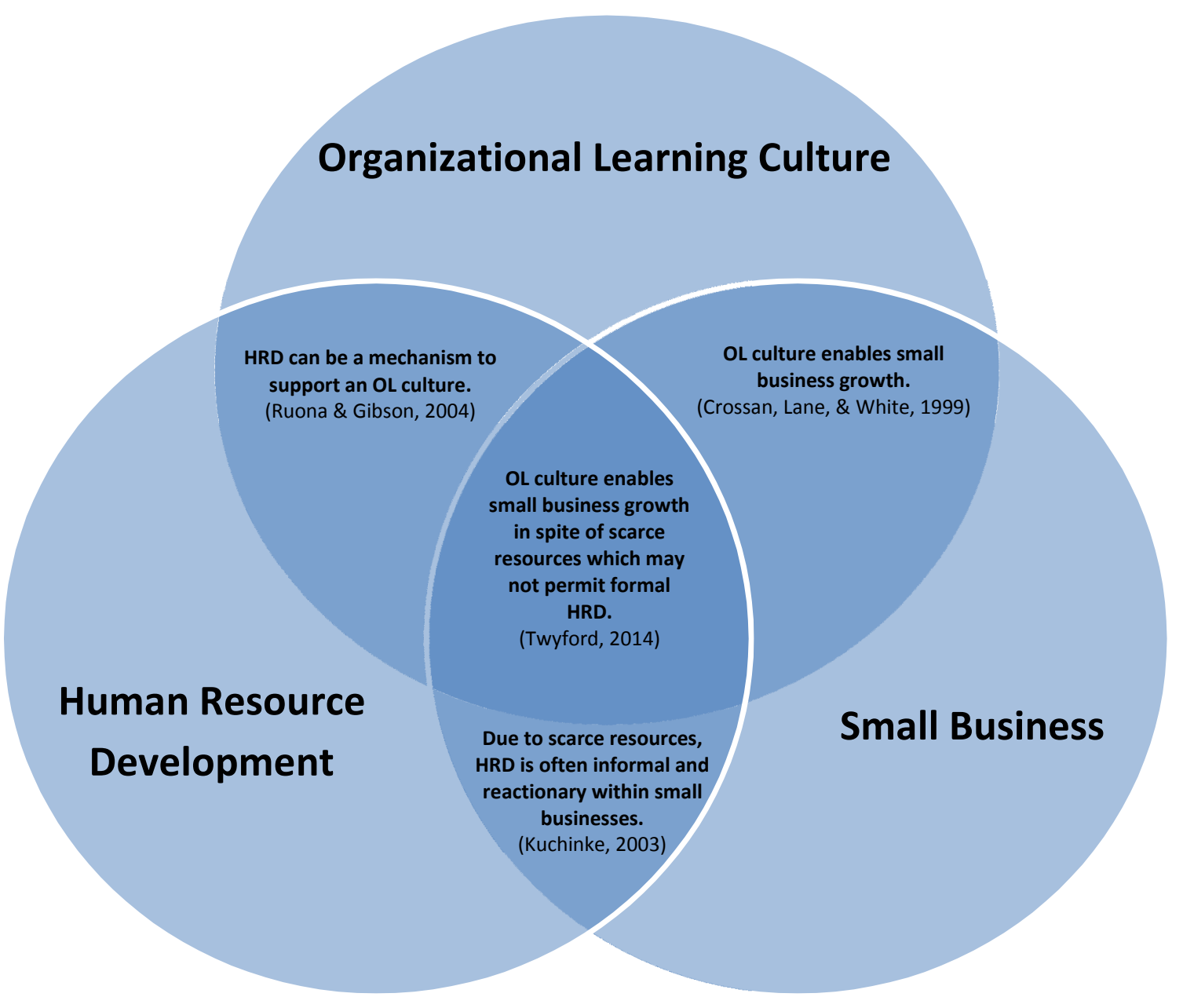

Figure 1. Small Business Organizational Learning Culture Conceptual Framework

Each of the overlapping areas within the conceptual model represents the relationship between two or more of the concepts (human resource development, small business, and organizational learning). As stated earlier, one of the most consistent findings within the HRD in small business literature is that formal HRD activities are often inefficient, short-term focused, or absent from the small business context entirely. It is the case that this type of HRD approach represents a reactive, rather than proactive, approach to improving the capabilities of the small business. Instead, this conceptual model suggests that HRD activities ought to be seen as a support mechanism for an 
organizational learning culture. An organizational learning culture represents an organization's commitment to continuous improvement and renewal. Thus, as the organization strives to improve, its HRD activities, both formal and informal, should reflect and support this mission.

Within this approach to doing business, by creating and sustaining a culture that embraces continuous improvement and learning, it is conceptualized that small businesses can achieve growth in spite of scarce resources. No longer is it important whether resources (money, time, expertise) are available to subsidize formal HRD activities. Instead, it is important that the culture of the business be one in which opportunities for improvement and learning are embraced and capitalized upon. When this type of culture exists, opportunity is unleashed for small businesses to create growth and success despite the scarce resource context within which they operate.

\section{Connection of the Current Study to the Literature}

Senge and Sterman (1992) describe the necessity for understanding organizational learning practices:

The problem lies not in the gap but in failing to recognize and tell the truth about the gap. Until the gap between my espoused theory and my current behavior surfaces consciously, no learning can occur (Senge \& Sterman, 1992, p.140).

Until we further understand the gap between the espoused theories of small businesses and the actual behaviors, we lack knowledge regarding how small businesses creating and sustaining organization learning cultures benefit from organizational learning.

Huber (1991) critiques the organizational learning research and its limited contribution to practice by stating that:

Work on organizational learning has not led to research-based guidelines for increasing the effectiveness of organizational learning. Nor has it been presented 
in forums or media typically monitored by those who guide organizational processes. These two conditions certainly seem deserving of attention and remedial action, as organizational adaptation and innovation, both critical in a rapidly changing world, could undoubtedly be improved if organizational designers and administrators knew more about how organizations learn and about how organizations might be guided to learn more effectively (p. 110).

Huber identifies a need for research-based guidelines that can aid organizational leaders as they endeavor to understand the ways in which their organizations can be strengthened by effective learning. Additionally, Huber's suggestion indicates a need for more empirical work that will contribute toward the development of such guidelines.

Rigg and Trehan (2002) describe our understanding of HRD in small businesses as dominated by "narrow definitions of HRD as training" (p. 395). They state further that the "within the small firms literature intensive studies of the workplace are comparatively rare" (p. 396). Scholars further encourage HRD to be framed as learning so that research can focus on processes through which employees learn and organizations promote that learning (Beaver \& Hutchings, 2005; Rigg \& Trehan, 2002). This study aimed to illuminate the learning practices of a successful small business in hopes of offering more effective guidance to organizations seeking to cultivate an organizational learning culture to improve growth and success. This research built on research conducted by Graham and Nafukho (2008) in that it identified elements of organizational learning in one small business. 
CHAPTER THREE

METHODOLOGY

This research sought to understand organizational learning as it occurred in a successful small business. Using an embedded single-case study approach, the following research questions were asked:

How does an organizational learning culture occur in a successful small business?

1. What are the elements of the organizational learning culture?

2. How do employees describe their experience with the organizational learning culture?

3. How does the organizational learning culture contribute to the growth of a small business?

4. What happens to the organizational learning culture as a small business grows?

Creswell (2013) suggests that a researcher's philosophical assumptions should be considered and made transparent prior to beginning a qualitative research study. These assumptions shape how the research problem and the subsequent research questions are formulated. In addition, philosophical beliefs influence how a researcher sets out to answer the questions they have formulated (Creswell, 2013).

Given the broad nature of the research questions, this study operated from a social constructivism framework. Creswell (2013) explains that questions developed based on a 
philosophy of social constructivism should be broad, general, and as open-ended as possible. The experiences of the participants in the case examined in this study were subjective and constructed within the operating norms unique to their specific work environments. Glesne (2010) explains that constructed realities are not only viewed as existing in the mind of the individual participants but also as social constructions of the language and thought of the wider society. Therefore, it is important to access the perspectives of multiple members of the same social group regarding a certain phenomenon. This study examined the experiences of the small business owner-manager and the employees (social group) regarding the learning culture embedded within the business and how that learning culture contributed to business growth.

\section{Establishing Positionality and Ensuring Openness}

Reflexivity can be understood as giving voice to the researcher's own experiences, biases, and the ways in which certain points of view have been avoided or suppressed (Gergen \& Gergen, 2000). It is unreasonable to expect that a research project is completely void of researcher influence. Therefore, reflexivity allows the qualitative researcher to acknowledge that while the story being told is indicative of participant experience, the dialogue is constructed through shared conversation between participant and researcher. Reflexivity also encourages the researcher to openly acknowledge and challenge personal values, potential biases, and historical and geographic situatedness (Gergen \& Gergen, 2000).

As a former OD practitioner employed by a small-medium sized business, I witnessed an organization's growth over a ten-year period. I observed the organization as it evolved from a reactive approach to learning to a proactive approach. When operating 
from a reactive approach to learning, organizational leaders requested employee training any time mistakes occurred or employee performance was identified as below target levels. However, as the organization grew and discovered better ways of doing business, organizational leaders began embracing a more proactive approach to learning. Rather than only responding to mistakes and below-target performance, top leaders identified learning needs proactively based on the mission of the organization. It was this experience that allowed me to observe the transformative power of a learning culture. The shift in the organization's culture facilitated the achievement of important business goals and helped move the organization forward on a rapid growth trajectory.

Even as the organizational culture was shifting to embrace learning, the organization was operating within a very limited resource environment. It was difficult at times to influence key stakeholders to embrace this learning philosophy. Many believed that it required too much time or financial resources to shift from a reactionary culture, in which change was only deemed necessary in reaction to a problem, to a culture in which change was proactively sought in order to avoid problems. Due to my personal experience, it is easy to assume that most, if not all, small businesses operate in a limited resource environment. However, while literature offers an abundance of evidence that this is often true, it is not necessarily true for every small business.

My former experience as an OD practitioner in a small business has influenced my assumptions about the operating environment within small businesses. These assumptions have led me to believe that the term "small" implies that a business has few financial resources, little or no knowledge of sophisticated organization development systems and processes, and limited experience with business development. While my 
personal experience underpins my desire to support small businesses as they work toward developing a culture of organizational learning, I have to remain aware that each business is unique and may not fit my pre-defined assumptions. Assumptions had the potential to limit my openness to the emerging phenomenon within the small business I studied. Therefore, while in the field, it was important for me to spend time reflecting critically on my observations, interview interpretations, and document selection. I had to remember to continually ask myself what I knew and how I knew what I thought I knew. This was necessary to ensure that I avoided allowing my past experiences to influence the way in which I viewed the case.

Dahlberg, Drew, \& Nystrom (2001) state that human science researchers "explore and describe phenomena of the world as it is experienced by humans," (p. 95). However, as cohabitants of this "lifeworld," researchers must acknowledge that our mere presence influences participants' describing and understanding of the world (Dahlberg et al., 2001). Therefore, as much as possible, we must suspend our influence on these descriptions and understandings in order to capture and represent the truest descriptions and understandings of our research participants. One way this can be done is through bracketing which is defined as, "holding the phenomenon up for serious inspection," (Janesick, 2000, p. 390). Bracketing facilitates the researcher's openness to the emerging nature of the research.

While the nature of openness is a worthy stance toward which to strive, Dahlberg et al. (2001) describe our human aversion to making ourselves available to the phenomena as it presents itself. What we attempt to do instead is make sense of and ascribe meaning to various objects or events under investigation. Further, openness 
requires "consideration of our own contributions to the research including our own personality and style and the way in which we are affected by the research project," (Dahlberg, et al., 2001, p. 99). Taking into account my own personality traits, including my desire to develop solutions quickly, the suggestion provided by Dahlberg et al. resonated strongly. It encouraged me to build in ample time for rumination of the information I gleaned from my participants. This made it easier to illuminate my own prejudices through clear, critical thinking and increased my sensitivity and responsiveness to my participant cases (Dahlberg, et al., 2001).

Self-reflection is also critical to maintaining an open stance. It requires examination of one's thoughts, reactions, emotions, and assumptions. As a researcher I required myself to step back from the research from time to time in order to re-evaluate myself, my assumptions, and my experiences in order to hedge against emerging presumptions. Maintaining a journal throughout the research process provided a way for me to reflect on and evaluate my assumptions and experiences. Further, building in time between data gathering periods allowed me to remain open to discovery and maintain a curiosity about the research. This encouraged appreciation of the findings as they emerged organically.

Dahlberg et al. (2001) also describe several approaches to relationship building that can increase and maintain openness. They suggest that a deep understanding between people emerges when two people take the time to understand one another. It was expected that this relationship would be established during the initial data gathering process. As a growing scholar-practitioner, I desired this deep understanding between myself and my study participants not simply for the sake of the research, but for the 
longer term working relationship that might result from the research process. A deep understanding led to trust that will hopefully encourage them to feel comfortable calling on me in the future. My desire was to deliver a tangible product at the conclusion of the research that accurately represented the work that the participants contributed to the process.

Finally, Dahlberg et al. (2001) suggest several tangible actions that researchers can take to facilitate an open stance and deep, genuine understanding between study participants and the researcher:

- Openheartedness - By revealing my own background through self-disclosure, I can increase the trust in the relationship by taking the risk to share my own story. However, it is important that I monitor the amount of information that I share with participants to ensure that they do not feel pressure to share information of their own that might be beyond their comfort level or an undue influence to be like me.

- Questioning - It is important to challenge assumptions as data is collected. The longer I work in the field, the more difficult it can be to recognize and challenge assumptions. As such, recording insights and returning to them at a later time will allow me to view the recorded insights with a refreshed mind. It is important to remember that effective reflection requires some degree of distance.

- Reflection - Not only does reflection require distance but it can be enhanced by involving an unbiased third party, especially if the person is a more 
experienced researcher. Reflecting with a "critical friend" can help shed light on collected data.

- Suspension of pre-understanding - Pre-understanding includes prior experiences with the phenomena under study, prior research about the phenomena, or any other influencing constraints that may impact the researcher's outlook. Dahlberg, et al. (2001) suggest that openness is always constrained by pre-understanding. While this may be true, it is possible to at least lessen the impact of pre-understanding by remaining aware of it and continually challenging assumptions and insights.

\section{Qualitative Research Design}

Qualitative inquiry allows researchers to embrace the idea of multiple realities as we examine a particular phenomenon (Creswell, 2013). As opposed to a positivist viewpoint, which assumes an objective reality, an interpretive approach embraces the subjective reality as experienced by each participant. The belief that it is through the subjective experiences of people that knowledge is discovered suggests that conducting research in the field or context in which participants live and work is ideal. This provides the researcher opportunity to observe and interact with participants to better understand their experiences.

In addition to seeking to understand the subjective realities of study participants, qualitative research design considerations should be led by the purpose of the study. While every research method, including both quantitative and qualitative approaches, can be used for any and all research purposes - exploratory, descriptive, and explanatory the key is to understand the purpose of the research well enough to determine the best fit 
between the research purpose and the method (Yin, 2009). There are numerous approaches for qualitative inquiry and each provides unique value to the research process. It is incumbent upon the researcher to identify the most appropriate qualitative approach for the research problem being studied.

\section{Embedded Single-Case Study}

Creswell (2013) defines case study research as, "an approach in a real-life, contemporary bounded system (a case) is explored over time, through in-depth data collection involving multiple sources of information," (p. 97). The more that research seeks to explain some present circumstance, such as how or why some social phenomenon works, the more relevant the case study method becomes (Yin, 2009, p. 4).

This research was conducted as an exploratory, embedded single-case study. Yin (2009) suggests that some questions are exploratory in nature. For these types of questions an exploratory case study can lead to the development of pertinent assertions based on the case findings. Stake (2006) suggests that a case study should summarize not only what was done to obtain answers for identified research questions but also what subsequent assertions might follow based on findings. An embedded single-case study allows the researcher to understand the essence of a phenomenon across the different contexts of subunits within the case. The case selected for this study contained clear subunits within the main case, making the embedded single-case study design an appropriate choice.

For the purpose of this research, the case study approach provided the best opportunity for understanding how a learning culture in a successful small business impacted business growth. By examining the case within its real-life context, the 
researcher was able to make observations and draw conclusions that aided in developing answers to the research questions. It was expected that the small business owner-manager would at times be unable to explain how the learning culture present within the business contributed to the growth of the organization. It was also expected that the culture could be so entrenched and even taken for granted that it goes unnoticed by the organization as they go about the business of growing and improving. However, by using the case study method, which provides a unique strength in its ability to process a full variety of evidence including documents, artifacts, interviews, and observations (Yin, 2009), a comprehensive understanding of the case was produced. This contributed to the uncovering of valuable information with regard to learning cultures in small businesses.

\section{Unit of Analysis}

Yin (2009) presents rationale for conducting a single-case study which argues that this design is appropriate under several circumstances. In particular, Yin suggests that single-case design is appropriate where the case represents an extreme or unique case. That is, the case is so uncommon that its existence is worth documenting and analyzing. The case selected for this study was chosen based on evidence of its organizational learning culture and consistent business growth since inception, which included the cultivation of several separate lines of business. The case exemplified a small business within which a learning culture had been fostered and the results of which have influenced business growth. This is uncommon among the small business community which is known to typically conduct business from a reactionary stance, with little focus on long-term endeavors such as culture and employee development. 
Yin (2009) states that the selection of a study's unit of analysis should occur when primary research questions are accurately identified. Thus, considering the primary research questions of this study, it seemed appropriate to classify the business as the unit of analysis. More specifically, Yin (2009) suggests that further clarification of the unit of analysis is important once the general definition of the case has been established. To that end, while the business remained the main unit of analysis, several subunits were identified. Each subunit represented a business line of the main organization. Further, within each subunit, the phenomenon of learning culture remained the focus. Based on Yin's Basic Types of Designs for Case Studies (2009, p. 46), the following concept model visually depicts the research design:

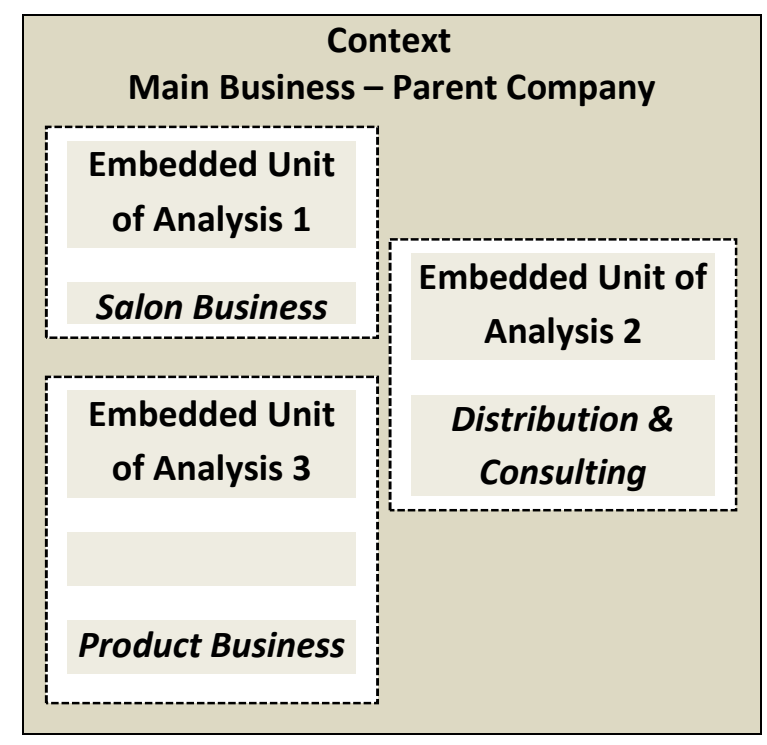

\section{Figure 2. Research Design Concept Model}

Yin suggests that the dotted lines between the context and the individual subunits signal that the boundaries between the case and the context are not likely to be sharp. This reflects the desire to analyze the contextual conditions in relation to the "case." 
Creswell (2013) states that data collection is a series of interrelated activities that gather good information to answer the research questions. These activities must begin with the identification of appropriate sites which will produce rich information. Purposeful sampling is used in qualitative research in order to identify samples that provide the most opportunity for data gathering with regard to the research question under investigation. In addition to being purposeful in selecting the sample to be studied, Creswell (2013) suggests several different types of sampling strategies that build upon purposeful sampling.

\section{Instrumental Case, Stratified Sampling}

This study sought to understand the impact of organizational learning culture on the growth of a successful small business. Rather than selecting the cases randomly or based on convenience, it was important to purposefully select a case that was anchored in the research question and within which it appeared that an established culture of organizational learning (the phenomenon) was already in place. According to Creswell (2013), this sampling approach I have selected for this study is best described as instrumental case sampling. Instrumental case sampling facilitates logical generalization and maximum information application to other cases (Creswell, 2013). Thus, while qualitative inquiry does not aim to facilitate generalization of findings, the findings that are gathered from instrumentally selected cases should provide an abundance of information from which to develop new knowledge about learning cultures in successful small businesses. This new knowledge can then be applied to other similar cases. In the same vein, Patton (2001) describes instrumental case sampling as the process of selecting 
a small number of cases that are likely to yield the most information about the phenomena.

Qualitative research scholars such as Creswell and Patton suggest that it makes sense to select cases in which the phenomenon being examined is evidently present. Therefore, a purposeful sample of an instrumental case was selected for this study. Within the case, to ensure that I gained the insights of both the owner-manager and a broad scope of employees of the business, I took a stratified approach to sampling employees. This provided opportunity to hear from employees regardless of organizational role. In addition, it was expected that within the different business contexts that the experiences of organizational learning culture could be different. Thus, the sampling scheme also provided opportunity to explore the research questions more comprehensively as the gathered data represented the richness and diversity of multiple contexts.

\section{Case Selection}

The case was drawn from the population of small businesses considered successful in the Louisville, Kentucky region. It is understood that qualitative research outcomes do not strive to be generalizable (Creswell, 2013; Yin, 2009). Instead, qualitative research strives to provide a rich understanding of a phenomenon with as much depth as possible (Creswell, 2013). Yin (2009) states that case study research allows researchers to retain the holistic and meaningful characteristics of real-life events. Further, when research questions focus on the what, how or why of a phenomenon, such as the research questions posed by this study, case study research becomes a preferred 
method. These types of questions deal with operational links that must be traced over time, for which the case study allows.

The case selected for this study was identified by the researcher and the study advisor as a successful small business that exhibited a culture of organizational learning. Based on criteria provided by the Small Business Administration (SBA), the term "successful" can be defined as a small business that has avoided failure, continuing to operate past the critical five-year mark of inception. Additionally, while the SBA defines small businesses as employing 500 or fewer employees, there are undoubtedly major differences in both the external and internal operating environments of businesses employing 300 to 500 employees versus businesses employing 1 to 50 employees. Because existing research appears replete with investigation of small businesses that fall on the larger end of the small business continuum, the intention of this research was to understand organizational learning cultures in very small businesses. Thus, the criterion of 25 or fewer employees was established. Finally, because this study sought to understand the impact of organizational learning culture on the growth of small business, the term "growth" was also clarified. In line with the claim that the greatest public benefit created by small business growth is the contribution to employment (Dobbs \& Hamilton, 2007), growth in this case was identified as a consistent uptick in the number of individuals employed by the business from inception to present.

\section{Data Collection}

Data collection took place over the course of a four month span. Entry occurred during the month of September 2013 and the research concluded during the month of December 2013. During this time multiple methods of data collection were used. Yin 
(2009) states that no single source of data collection has a complete advantage over the others and that the sources are highly complementary. For that reason, a well-designed case study will use as many methods of data collection as possible. I collected data through interviews, observations, and document analysis which allowed triangulation of data (Glesne, 2010). Furthermore, observing and interviewing the owner-manager along with employees allowed multiple perspectives to emerge which also facilitated triangulation. Each type of data collected served to contribute to the illustration of the impact of organizational learning cultures in small businesses.

\section{Interviews}

Kvale (2008) proposes that the purpose of qualitative research interviews is, "to understand the themes of the lived daily world from the subjects' own perspectives," (p. 24). And, while interviews somewhat mimic everyday conversations, there is a specific approach and technique of questioning to ensure a professional nature. Phenomenological interview techniques, in particular, seek to describe rather than explain or analyze and include description, investigation of essences, and phenomenological reduction (Kvale, 2008). Because this research endeavored to understand the phenomenon of learning cultures in small businesses, a phenomenological interview technique was used.

Kvale (2008) describes investigation of essences as, "shifting from describing separate phenomena to searching for their common essence" (p. 27). Kvale further explains that considering the phenomenon in all its possible forms allows the researcher to determine that which remains constant among the many variations. This is the essence of the phenomenon. Once the essence is discovered it is important to suspend judgment 
of or bracket one's pre-existing knowledge of the phenomenon in order to arrive at an unbiased description of the essence of the phenomenon.

Interviews endeavored to understand the themes of the lived everyday world from the subjects' own perspectives (Kvale, 2008). As a researcher seeking to understand a certain phenomenon based on participant interviews, I was responsible for accurate interpretation of the meaning of participant perspectives. As such, I relied on Kvale's (2008, p. 28), "Twelve aspects of qualitative research interviews:"

- Life World. The topic of qualitative interviews is the everyday lived world of the interviewee and his or her relation to it.

- Meaning. The interview seeks to interpret the meaning of central themes in the life world of the subject. The interviewer registers and interprets the meaning of what is said as well as how it is said.

- Qualitative. The interview seeks qualitative knowledge expressed in normal language, it does not aim at quantification.

- Descriptive. The interview attempts to obtain open nuanced descriptions of different aspects of the subjects' life worlds.

- Specificity. Descriptions of specific situations and action sequences are elicited, not general opinions.

- Deliberate Naiveté. The interviewer exhibits openness to new and unexpected phenomena, rather than having readymade categories and schemes of interpretation.

- Focused. The interview is focused on particular themes; it is neither strictly structured with standardized questions, nor entirely "nondirective." 
- Ambiguity. Interviewee statements can sometimes be ambiguous, reflecting contradictions in the world the subject lives in.

- Change. The process of being interviewed may produce new insights and awareness, and the subject may in the course of the interview come to change his or her descriptions and meanings about a theme.

- Sensitivity. Different interviewers can produce different statements on the same themes, depending on their sensitivity to and knowledge of the interview topic.

- Interpersonal Situation. The knowledge obtained is produced through the interpersonal interaction in the interview.

- Positive Experience. A well carried out research interview can be a rare and enriching experience for the interviewee, who may obtain new insights into his or her life situation. (Kvale, 2008, p. 28)

Interviews were conducted weekly on Tuesdays and Wednesdays, which are the slowest business days for the organization. I interviewed multiple individuals, including the owner-manager and employees, at each selected site in order to understand the phenomenon of organizational learning culture in small businesses. Creswell (2013) suggests that it is inadequate to study only a few sites or individuals but that, instead, it is necessary to collect extensive detail about each site. To accomplish this it was necessary to interview a minimum of ten employees from the salon business, eight employees from the product lines business, and two employees from the distribution and consulting business. Participants were chosen based on their current role within the organization. A variety of participants was chosen to ensure that all perspectives were represented. 
Because no unforeseen circumstances had arisen, such as the need to interview previous employees involved in a certain learning situation or event, only those individuals employed by the business at the time of investigation were involved.

Yin (2009) describes interviews as "guided conversations rather than structured queries" (p. 106). The interviews were semi-structured and included questions that were developed based on existing literature and under the guidance and feedback of the research advisors. An interview protocol (Appendix A) was created to support the semistructured approach but also included open-ended questions to allow me to probe for further information. An example of a semi-structured question included "How do you relay new learning to your team?" while an example of an open-ended question included "Could you explain that further?” As my guiding philosophy suggests, I was interested in gathering each participant's unique experience with, and understanding of, the phenomenon of organizational learning from the perspective of their specific situation. Because it is likely that an employee's position influenced his/her perceptions and experiences, I purposefully selected interview participants to ensure that I had a representative sample of all employee groups.

By conducting interviews across multiple units of analysis it was possible for the complexities of the phenomenon to emerge. Creswell (2013) suggests that researchers must allow room for illustration of the issue. For example, the various nuances, complexities, and contexts surrounding a phenomenon will only be revealed through a detailed description of the contexts which can be constructed, in part, using interview data. 


\section{Observations}

Angrosino and Mays de Perez (2000) suggest that, "traditional ethnographers have believed it both possible and desirable to develop standardized procedures to maximize observational efficiency," (p. 676). This type of organized approach tightens the focus of the observations so that the researcher is able to focus on elements such as gestures, social interactions, and scenes within the observed environment that best represent the phenomenon being examined. This was achieved through the development of an observation protocol (Appendix B). Additionally, conducting a member-check between researcher and participant to confirm that the observations of the researcher were indeed correct increased the credibility of the findings. This was done by meeting every two weeks with salon leaders and certain employees who were pertinent to the observation to discuss questions and seek confirmation. Both an observation protocol and member-checks were used during the observation process.

Observations of normal business operations took place at each site once per week for approximately four hours at a time. During these observation periods I observed stylist operations, front desk operations, and manufacturing and distribution operations. Educational events were observed on four separate occasions spanning multiple business days. I also spent two full business days shadowing two particular apprentice employees to better understand their experience as apprentice assistants. I determined that I had a sufficient amount of observations when I reached the point of saturation. That is, when no new or relevant information emerged through observations, the decision was made to conclude the observation process. The final total included ten observation periods. Yin (2009) argues that because a case study should take place in the natural setting of the 
case, opportunity for direct observation is created. This component of the data collection process ensured that I was able to better understand the culture of organizational learning and how corresponding behaviors manifested within each small business. Direct observation data contributed to study findings by allowing me to gain a personal perspective through the lens of a nonparticipant observer. This is different from the perspective provided by interview data which provided the unique perspectives of each participant.

Observational approaches are strengthened by a researcher's acknowledgement of the possibility of the observer's influence on what is being observed (Angrosino \& Mays de Perez, 2000). While adhering to rigorous standards can alleviate some degree of bias, observation remains somewhat influenced by the presence of the researcher. In fact, Angrosino and Mays de Perez (2000) suggest that the achievement of the delicate balance between participation and observation should remain the ideal for researchers. The conditions within the business, including the close proximity within which the employees work to one another, were such that acting as a complete observer was impossible. I was known to the participants due to my obvious presence. Thus, it was important to strive for balance between participation and observation.

Meaning reconstruction took place during and after observations were complete. As observations were made and documented, meaning was ascribed by placing words on things such as timing, tone, gestures, and postures of each participant act (Carspecken, 1996). As the researcher it was incumbent upon me to question the meanings I ascribed to the observations I collected. Carspecken (1996) defines the hermeneutic process as what takes place when one formulates possible meanings simply by virtue of being a 
communicative being that can imagine him or herself in the situation being analyzed.

Further, the hermeneutic circle (Carspecken, 1996) includes several features which aid in more accurate meaning reconstruction:

- Intersubjectivity which encourages the researcher to "take the position" of the observation participants in order to understand the impressions of meaning possibly experienced by them;

- Recognition of meaning through position-taking which employs cultural typifications considering tacit generalities typical of a culture;

- Normative reflection which requires reflection upon the conditions of our own recognition of meaning;

- The normative circle which often includes a process of making tacit comparisons between the normative realms with which we are familiar and the normative realms which participants claim as valid;

- Personality factors which require attention to individualized mannerisms, vocal tones, facial expressions, and other features that are indicative of the personality of the participant rather than the culture (pp. 99-102)

Employing these features of the hermeneutic circle ensured a more accurate depiction of the participants of the study and their subjective experiences.

\section{Document Analysis}

Finally, pertinent documents were collected and analyzed to strengthen the findings from the other sources of data collection. These included staff meeting minutes, employee coaching sheets, apprentice training schedules, education events documentation, apprentice final presentation guidelines, apprentice daily schedules, daily 
goal sheets, and performance review forms. Yin (2009) states that the most important use of document analysis is to corroborate and augment the data that is collected through other means such as interviews and observations. The types of documents that were collected during the research were records of strategic business plans that shed light on an organizational learning orientation, documentary evidence of training and development, and other documents, including staff meeting minutes and job coaching documentation, that provided depth of understanding regarding the organization's proclivity for organizational learning.

During interviews information was documented through the use of a recording device (according to participant agreement) and a notepad to make necessary notes as the interview progressed. All recorded interviews were transcribed into digital format. During the observation process I used both the observation protocol and an additional notepad for any peripheral notes. All documented material was also transcribed into digital format.

\section{Data Analysis}

Dahlberg et al (2001) present an analysis technique known as whole-parts-whole. This technique suggests that the analysis of data has a tripartite structure that moves fluidly between the whole, the parts, and back to the whole. The authors suggest that producing meaning from the analysis of text requires the researcher to understand each part in terms of the whole as well as the whole in terms of its parts. Maintaining an open stance toward the text allows the researcher to follow its movements and conclude the analysis in a "harmonic whole" (Dahlberg, et al., 2001, p. 186). This requires the 
researcher to decide when to end the process as it could go back and forth between the whole and its parts indefinitely.

The whole-parts-whole process begins with an initial reading which provides familiarization and a sense of the data as a whole. At this stage there should be no intention to produce any meaning from the data. Dahlberg et al (2001) maintain that the researcher must be immersed in the text and curious enough to want to understand and $b e$ surprised by the text. Naturally, as the understanding of the whole is developed, different parts begin to emerge. This signals the beginning point of actual data analysis. During this phase, it is suggested that the researcher devote a segment of every page to recording the emerging meanings of each part as they are analyzed. The analysis is deepened by questioning the text in such ways as what is being said, how it is said, and what the context and meaning is.

Once the parts are identified and described they can be organized in certain order to see and understand patterns or clusters of meanings that can be conveyed in a logical way (Dahlberg, et al., 2001). During this time it is imperative that the researcher remain open to discovery. It could happen that understanding and interpretation of certain parts may change once they are arranged or considered alongside other parts. New discoveries during this process must influence the previous descriptions.

When each part has been sufficiently described and its meaning analyzed and recorded, the researcher once again considers the text in its entirety. However, now there is a greater and broader understanding than when the researcher initially read the text. The meanings of each part are synthesized into a structure that binds them together, thus moving from a concrete understanding to a more abstract level of understanding 
(Dahlberg, et al., 2001). This type of analysis strives to communicate the basic structure of a phenomenon as well as its inevitable variations.

In addition to whole-parts-whole analysis, within-case analysis provides a detailed description of the case including the specific themes within the business and across the sub-units. This type of analysis often begins with triangulation of data and persists through data coding and thematic analysis. Ryan and Bernard (2000) suggest that themes are abstract constructs that are identified before, during, and after data collection. The authors recommend sources for theme identification including literature reviews and the researcher's own experiences. However, most often themes are developed inductively from the data text. To analyze the data within this study, both the whole-parts-whole and within-case approaches to analysis were used.

\section{Data Management}

Yin (2009) proposes database development as a tool to support the data gathering process. Development of a case study database occurs as the researcher decides how to organize and document the data collected from the research. The database serves to house the raw data entered by the researcher each time data collection is undertaken. It is developed in a formal, presentable manner so that it can be easily reviewed by other investigators, if needed (Yin, 2009). For this reason, a case study database significantly increases the reliability of the case study (Yin, 2009). I organized the case study notes and documents retrieved in such a way that they could be easily and systematically retrieved. In particular, once notes were typed into a digital document and copies and annotations of retrieved documents were made, all files were organized into specific categorized folders and stored on a hard drive. A spreadsheet was developed to 
communicate the logic and system of the digital folders and to communicate what notes and documents were located in each folder.

\section{Triangulation}

Stake (2000) proposes that to reduce the likelihood of misinterpretation, researchers should use various procedures including redundancy of data gathering. Multiple sources of data including interviews, observations, and document analysis facilitate triangulation which can be understood as, "a process of using multiple perceptions to clarify meaning, verifying the repeatability of an observation or interpretation," (Stake, 2000, p. 443). Yin (2009) suggests that data triangulation addresses the potential problems of construct validity because multiple sources of data provide multiple measures of the same phenomenon. Because this study was designed to collect all three of these types of data, repetition of observations and interpretations was recognized in the interview transcripts, observation protocols, and document analysis.

\section{Manipulation of data}

Once the analysis process begins, Yin (2009) suggests that researchers can overcome the stalling process that is common to the beginning stages of data analysis by beginning to manipulate or "play" with the data that has been gathered. This is a preliminary form of data analysis and can aid in the early stages of developing codes and themes for the research findings. During the manipulation, researchers can put the information into different arrays, create various data displays, create a matrix of different categories, and put information into chronological order or some other sort of temporal scheme (Yin, 2009). The aim of data manipulation in the early stages of the analysis 
process is to aid in dictating a general strategy for further data analysis. This process allows for the emergent phenomena to show itself.

\section{Coding}

Creswell (2013) describes the process of coding data in qualitative research as "aggregating the text or visual data into small categories of information, seeking evidence for the code from different databases being used in a study, and then assigning a label to the code," (p. 184). Coding was relied upon as one of the main strategies for data analysis in this study. Text from interviews and observations was combined with descriptive text of relevant documents to develop codes that were representative of the various text segments found within the data. Coding was also helpful in reducing the findings to allow the researcher to focus on data that were useful while eliminating data that were not. Coding required me to use an iterative approach as I reviewed and re-reviewed the data numerous times in order to develop categories of information that were representative of the data (Creswell, 2013).

\section{Themes}

Themes are categories of information developed from study data that are combined into broad units of information to form a common idea that cuts across all of the data sources (Creswell, 2013, p. 186). Theme development moves beyond coding as it requires deconstruction of the text to look for categories or dimensions of information (Creswell, 2013). Theme development also requires an inductive-deductive logic process as the researcher builds themes from the bottom-up. By working back and forth between the themes and the raw data contained in the database, the researcher is usually left with several different major themes occurring within the data. The process of developing 
themes was used as part of the analytic strategy of this study. Codes were analyzed for similarities that served to contribute to the larger framework of theme development. Collaboration between both the researcher and the participants allowed participants to take part in shaping themes that emerged (Creswell, 2013). This ensured that the themes were truly representative of the realities of the cases. The intention was to reduce the data to major themes that were written into the case study report.

\section{Interpretation of Themes}

For this study I anticipated that the interpretation of themes would be based partially on existing theoretical propositions. Because both the objectives and research questions of this study were informed by the existing research on organizational learning in small businesses, my intention was to loop back to these theories in order to make sense of the data. Yin (2009) suggests that propositions developed as a result of the existing literature should help focus attention on certain data and ignore certain other data. Further, Yin (2009) suggests that theoretical propositions that stem from how or why questions can be particularly helpful in guiding case study analysis in this way. While it can also be argued that too much development of theoretical propositions can inhibit the researcher's ability to maintain openness to the emergent nature of the data (Creswell, 2013; Glesne, 2010), guiding propositions provided a useful framework for analyzing data.

\section{Ensuring Quality}

In qualitative research, credibility suggests that an explanation fits the description given to it by the researcher (Janesick, 2000). Lincoln and Guba (1985) suggest that credibility can be achieved through cross-checking the work using approaches such as 
member-checks and audit trails. Member-checks should be done by allowing the research participants to review the material to ensure it is representative of their actual experiences. Outside individuals can also serve as feedback providers through membercheck to lessen the effect of researcher bias (Janesick, 2000). While it can be argued that there is no single correct interpretation of participant experiences, implementing approaches such as member-checks increases the credibility and, thus, the trustworthiness of the research data.

Lincoln and Guba's (1985) recommendations of five techniques to ensure quality and credibility are arguably some of the most formative in the field of qualitative inquiry. They suggest the following:

- Prolonged engagement;

- Peer debriefing;

- Identifying negative or deviant case analysis;

- Benchmarking;

- Member checking (p. 114)

To ensure quality I satisfied the requirement of prolonged engagement by spending significant time in the field with my chosen case participants. Beginning in September 2013 and lasting through December 2013, interviews and observations were conducted and document attainment occurred. This provided sufficient time for the participants to share their experiences and for observations of various types to unfold.

Debriefing was important as I sought to ensure that hidden biases and taken for granted perspectives were uncovered. I discussed the findings of my study as they emerged with my study advisors. Their feedback pushed me to test and defend emergent 
themes in order to determine whether the hypotheses made sense to someone uninvolved in the carrying out of the research.

Seeking negative or deviant case analysis is similar to identifying rival theories (Yin, 2009). This process involves identifying portions of the data that either does not support or that distinctly opposes the explanations that are emerging from the analysis of the data. The value of representing dissenting voices or perspectives is found in the strengthening of the explanations that support the majority of the data findings. This allowed me to establish credibility for my findings as I was able to show that I have considered negative or deviant portions of the data and that those portions of the data did not dissuade my final conclusions.

Benchmarking encourages the researcher to reserve parts of the research in an archival fashion for later comparison. By reserving a portion of the research findings for later comparison the researcher is able to reinforce final conclusions. I reserve three interviews for later coding once the research was complete. I then reviewed the interviews to determine whether or not they fit within the themes identified.

Finally, member checking provides opportunity to ensure that researcher and participant understanding are aligned. As data were collected and conclusions, interpretations, and categories were established, I checked with participants to ensure that descriptions and experiences were accurately recorded and accurate meaning ascribed to the findings. Lincoln and Guba (1985) argue that member-checking is one of the most important techniques for establishing credibility in a study. 


\section{Strengths and Limitations}

One of the potential strengths of this study is also one of the most significant weaknesses. Yin (2009) suggests that case study provides opportunity to understand a real-life phenomenon in-depth. In particular, where a case represents an extreme or unique case, a single-case study design is justified and valuable. However, while this study presented opportunity to understand the organizational learning culture of a successful small business, a unique condition for a small business, it was also weakened by the potential vulnerability of being a single-case study. That is, the potential that the case may have turned out not to be the case it was thought to be at the outset (Yin, 2009). However, given the opportunity to examine multiple embedded subunits within the case along with the purposeful, instrumental sampling strategy, it was determined to be more valuable to investigate a single case, in which the research phenomenon was clearly present, than multiple cases in which the research phenomenon may or may not be present. It could be challenging to identify small businesses wherein an organizational learning culture is established so the choice to be satisfied with one instrumental case was made. Stake (2006) identifies three criteria for selecting cases for research:

1. Is the case relevant to the quintain? Stake (2006) describes a quintain as the larger phenomenon of which the study findings are indicative.

2. Do the cases provide diversity across contexts?

3. Do the cases provide good opportunities to learn about complexity and contexts?

Stake (2006) asks us to consider whether the case is relevant to the quintain. By selecting a case wherein a culture of organizational learning was established, this study was able to 
uncover significant data to ensure the quintain is better understood. In addition, the case provided diversity across its multiple subunits. The diversity and complexity that was found in such differing contexts served to strengthen the findings.

\section{Ethical Considerations}

Regardless of the approach selected for qualitative inquiry, qualitative researchers face inevitable ethical issues that arise during data collection in the field and during the analysis phase (Creswell, 2013). While there are several strategies to cultivate and maintain openness in the research process, absolute objectivity is impossible as a person living in the world (Dahlberg, et al., 2001). Simply given our existence in this world we are imbued with meaning which renders absolute objectivity impossible. As such, it is critical that researchers step back from their investigation and self-reflect in order to increase the likelihood that an open stance is maintained. Dahlberg, et al. (2001) define self-awareness as "keeping a critical eye on oneself," (p. 139). Given my passion for this topic and my desire to contribute something back to my participant sites, I had to work diligently to keep a "critical eye" on my assumptions and insights to ensure I maintained an open stance.

\section{Avoiding Bias}

Creswell (2013) suggests potential strategies for avoiding unintentional bias.

First, I ensured that interviews and observations were recorded using electronic audio devices, protocol documents, and field notes. Further, within 24 hours of completing interviews and observations I recorded my personal reflections in a journal. Relevant information, including pertinent quotes, was recorded for inclusion in field notes later. This facilitated avoidance of bias as I reported raw information. Further, while 
interviewing participants it was important that I resisted the urge to enter into my participants' descriptions and sharing of experiences. This attitude of discovery provided some measure of protection against data contamination that would likely have occurred if my stance was dogmatic or my biases unchecked.

\section{Risk-Benefit Analysis}

In order to avoid exploitation of my case participants through the extraction of data with no benefit in return, it was important that I acknowledged beneficence, respect, and justice. Beneficence requires consideration of how to maximize the good inherent to a study and minimize any harm that may be done. Through this consideration of both risk and benefit, I was able to determine those elements which will ensure a successful study for both researcher and participants. Respect requires protection of the autonomy of the individual participants along with treating each participant courteously. It also requires protection of any vulnerable participants and confidentiality of all data. Finally, justice requires reasonable research procedures that are non-exploitive and that fairly administer the costs and benefits to groups who bear the risks.

Because this study calls for investigation of a topic that is not particularly exploitive, there are few associated risks. However, that does not mean that risks were completely absent. The biggest risk associated with this study was the inconvenience imposed upon the small business participants. In particular, small businesses often operate with limited staff. When employees were absent from the job site it was difficult for work to be conducted as usual. As such, allowing employees to take part in interviews away from the job site was somewhat difficult. To mitigate this risk, while still maintaining the integrity of the study, interviews were conducted on-site but not within 
the context of the daily work. Additionally, while all effort was made to protect the privacy of participants, it was acknowledged that it was impossible to ensure total privacy. Based on the close proximity within which the participants worked to one another, participation in interviews was difficult to conceal. However, privacy was respected and every effort was made to conduct the interviews quickly, discreetly, and with minimal disruption to the work that was required to be completed. For participants willing to do so, opportunity to participate in interviews after working hours was made available. However, it was not possible to compensate employees for their participation after hours.

To maintain confidentiality several steps were taken. First, informed consent, developed under the direction of the University of Louisville Institutional Review Board informed participants of the nature of the study in order that they could choose whether or not to participate. Next, all identifying characteristics of the research participants and the research site were changed. Personal identifiers, such as names, were replaced with pseudonyms. This ensured that no connections can be made between the study data and the actual case being examined. Finally, all data was kept in a secure location only accessible to the researcher. Physical data such as handwritten notes was stored in a locked location while all digital data was stored in a password-protected location and backed up to a password-protected hard drive. Data was stored in a safe location immediately following each visit to the study site.

To buffer the risk of inconvenience, this study offered many benefits for the researcher, participants, and the scientific community. As a researcher in the area of small business and organizational learning this study benefitted not only my personal research 
agenda but, more importantly, the knowledge that I was able to feed back to the small business and organizational learning community. The motivation to conduct this study came from a desire to contribute to the growth of small businesses. To that end, it was important to understand how this particular business's organizational learning processes contributed to business growth. It is only through a well-developed understanding, both of the strengths of the business that enable success and the areas of weakness that constrain success, that scholars and practitioners can begin to provide guidance to these constituents. Participants of this study benefitted from an understanding of specific best practices within their own business that were illuminated by this study. By bringing attention to those things which are done well, participants were able to ensure that evidence-based practices are proliferated. Finally, the scholarly community benefitted from a study which sought to understand exactly how an established culture of organizational learning can contribute to the growth of small businesses. Given the dearth of research within this particular area, the scholarly community stands to gain much through the findings of this study. 


\section{CHAPTER FOUR OVERVIEW OF SMITH ENTERPRISES}

This embedded case study research was conducted within Smith Enterprises, Incorporated, a beauty industry business located in a mid-sized U.S. Midwest city. I came to be a client of Castlewood Salon, the salon business of Smith Enterprises, after seeing Bill Smith, the salon's founder, on a local television talk show highlighting successful local businesses. As both a student of organizational development and a client of Castlewood Salon, I began to see evidence of an organizational learning culture. Examples of these early observations were the salon's appointment of a Director of Education, artifacts representative of a commitment to learning such as fabric swatches displayed next to each stylist's station used to help clients understand hair texture, and apprentice assistants that spend their first year completing an apprenticeship training program before they are able to graduate to a stylist position. Upon determining that the salon offered sufficient evidence of a learning organization to warrant a case study, I pursued the opportunity.

During the summer of 2013, I met with the salon owner, the salon Director of Operations, and the product line Director of Education to determine the possibility of establishing a research partnership to study the organization's learning culture. Salon leaders agreed to open their environment to be studied including access to employees for interviews, the salon and its educational events for observation, and organizational 
records for viewing. Once approved by the dissertation research committee, a research protocol was established and approved by the University of Louisville's Institutional Review Board. The research began mid-September 2013 and concluded mid-December 2013.

\section{Background and Evolution of Smith Enterprises}

When I entered into the process of developing this case in 2013, Smith Enterprises, Incorporated had just been established as a parent company for the three business entities owned and operated by Bill Smith. Castlewood Salon had been in operation for 22 years, Beauty Factor and Bond for Men hair product companies had been in operation for 12 and 8 years, respectively. Fresh Allure Consulting had just been established in 2013. The following case history was elicited primarily through interviews with Bill Smith. However, interviews with three long-time employees align with the history provided by Bill. Additionally, several artifacts within the business lend support to the historical context provided by Bill and his employees.

\section{Bill Smith, Founder}

Smith Enterprises was founded by Bill Smith who comes from a long line of beauty professionals. The son of a hairdresser and the nephew of a beauty school instructor, he was exposed to the industry for many years before his decision to pursue hairdressing as a career. Yet, the early exposure also caused Bill to initially dismiss the possibility that he may someday follow in his family's footsteps. It was not until he faced an impending high school graduation and a lack of desire to pursue college that he decided to enroll in his aunt's hairdressing school. It was during this early experience as a beauty school student that Bill first discovered the possibility offered by the hairdressing 
industry. More than the "eight dollar haircuts" and "roller sets" that Bill recalls watching his mom do during his childhood, he discovered the world of competitive platform artistry as a beauty school student.

In the hairdressing industry, a platform artist works on stage at events such as beauty trade shows and industry educational events to train, inspire, and educate show participants on the latest trends and techniques within the industry. The platform artist showcases their own skills and abilities in order to provide opportunity for others to learn. In addition, a platform artist can also choose to participate in competitive events that allow them to obtain professional awards that provide career advancement opportunities. Because Bill attended a beauty school whose owner participated in competitive platform artistry events, he was provided the opportunity to compete as a platform artist. At only 19 years old he placed seventh out of 60 participants in his first platform artist competition. This early experience exposed Bill to the possibility that hairdressing could be more than cutting hair as a way to make a living:

And I remember thinking, whoa, that was good. That was fulfilling. And because of that, that's where my switch was flipped and the world of possibility came on. At that moment, I realized I could go to work, have a job, cut some hair, have some money in my pocket, or I could go do that. I could go around the world and I could do this kind of stuff...I could be on the stage doing cool hair in front of hundreds and thousands of people anywhere. That is where the career thought got a hold on me in the industry.

This experience not only influenced Bill to adopt a career mindset as it related to his work, but it also opened the door to what he still refers to as possibility thinking. This 
shift in thinking would serve to influence the culture that he would go on to later implement in his own salon business.

Following his graduation from beauty school, Bill began his first job working as a stylist in a salon. His early career work in this salon allowed him to gain knowledge and skills that added to what he had learned both in beauty school and during his time as a competitive platform artist. This first experience working in a salon also encouraged his desire to think more broadly, and with more possibility, about both his career and the hairdressing industry as a whole. That salon owner was instrumental in Bill's early career by introducing him to the work of author, sales person, and motivational speaker Zig Ziglar. After closing the salon one evening the group of employees rode to dinner with the salon owner. During the drive she played one of Ziglar's messages. Bill found himself compelled by the message and he began his journey as a "student of Zig Ziglar." He would go on to embrace and implement many of Ziglar's philosophies in his own career.

\section{The Beginning: Castlewood Salon}

Establishment. The experience of working as a stylist, combined with the mentoring of the salon owner and an entrepreneurial spirit, influenced Bill's decision to pursue salon ownership. After five years of working as a stylist, he ventured out on his own and opened Castlewood Salon in 1992. He was young and inexperienced as a business owner, but with a desire to direct the course of the career he envisioned for himself. Salon ownership allowed him to direct his future and bring his vision to life. However, his first attempt at ownership failed to bring forth his vision into reality.

During the early years of Castlewood Salon Bill operated his business on a booth rental basis. This structure required the stylists he employed to pay a monthly rental fee 
for the space they occupied within the salon. And while Bill spent time and money marketing the salon, stylists also worked to recruit their own clients. Bill recalls that stylists came to view themselves as independent contractors, which promoted a culture wherein Bill was able to exercise only minimal influence on employee job performance. It was difficult to persuade stylists to implement performance feedback or to make any other type of change, such as participating in job training, that was requested. He also struggled to gain support from stylists regarding his vision for the future of the salon. According to Bill, the structure of the salon enabled him to operate the business profitably, but it was apparent that business growth was stymied due to the limited leadership influence that he could exercise. Subsequently, employee development and the strategic direction of the business suffered.

Failure. Within the first few years of establishment Castlewood Salon experienced failure. Bill lost all of the stylists who were not producing enough income to sustain their salon space rental. As his pool of stylists dwindled, so did business income. Thus, Castlewood Salon was closed. Bill spent time following the salon's closure reflecting on this experience, along with his knowledge of business leadership and ownership. After a year of introspection and reflection regarding the reasons his first attempt at business had failed, he decided to re-open the salon. He recalls, "I was like, I'm going to study relentlessly to figure out what I need to know and how I need implement it." And while he implemented changes to the salon's operations, he kept the same business model as he had prior. Once again the salon operated within a booth rental structure and stylists paid a monthly rental fee in exchange for space within Castlewood Salon. A team of stylists was hired and the salon experienced a quick increase in both 
clientele and business income. However, it was not long before many of the original problems, such as stylist reluctance to participate in job training and embrace the strategic direction of the organization, began to resurface.

Bill found himself once more with limited ability to influence the performance of the stylists and the strategic direction of the organization. It was not long, two years to be exact, before Bill once again faced the reality that the salon could not achieve sustainability by continuing to operate within the current structure. Stylist performance suffered as Bill's limited influence impacted his ability to improve the knowledge and skills of his stylists. Certain that the booth rental structure was detrimental to his ability to influence the strategic direction of the organization, Bill decided to implement a different organizational structure.

\section{Changing Course}

Bill Smith had worked hard to design, market, and staff his business to enable growth and financial success. Yet, after all of this effort, the salon failed to be successful. It took some time, but eventually Bill recognized the weakness in his business model:

Because we hadn't created a learning environment, these people didn't know how to take care of the clients anyway. So we had a big army of clients rolling in but the people weren't prepared [to serve them]. And because the people were not prepared to handle the business, we were toast. We put the cart before the horse. This new awareness led Bill to consider changing the business structure within Castlewood Salon.

Changes to Castlewood. This change to the business structure required transitioning from a booth rental structure to a commission-based structure within the 
salon. This gave Bill greater influence over the performance and development of salon stylists. Because stylist income would now be tied to performance, he could ensure greater employee motivation to learn and grow and perform according to standards. The hope was that rather than operating as independent contractors, stylists would see themselves as bona fide employees of Castlewood Salon, committed to the success of both their own careers and the strategic direction of the organization.

Moving from an independent contractor mindset to that of a commission-based employee was not an easy transition for many stylists. In fact, after Bill announced the change, there was an exodus of all but one stylist. While some fallout was expected, Bill did not expect that he would be left with only one stylist. Yet, determined that this new model was the best decision for the salon, he remained steadfast even though it meant starting over with only one person. At this point, Bill and the single stylist began to operate the salon according to the new system. Bill worked to run the business while simultaneously taking clients alongside his one remaining stylist. He slowly began developing the criteria for the specific type of employee that he thought would be successful in helping the organization grow in the direction of his vision.

As the employment criteria began to materialize, Bill began cultivating his workforce through a series of rigorous recruiting and interviewing activities. The first major change came in the form of hiring only those individuals who had never once worked for any other salon. Bill was determined to "grow his own" employees. That is, he would begin with a fresh slate - those individuals having no salon experience - and he would train and develop his workforce specifically according to the organization's mission and vision. 
Bill began his recruiting efforts within local beauty schools. His desire was to reach students who were close to graduation who might be interested in working with his salon. This practice proved successful in identifying and hiring young talent, and over ten years later is still a mainstay in his recruiting efforts. As part of the reorganization of the salon, Bill decided that there would be a distinct separation between the roles of stylist and front desk employee. And while only those individuals having no prior salon experience were considered for stylist positions, there were no such criteria for front desk employees. Bill did not foresee it being a detriment to the business if front desk employees had prior experience in salon work.

The decision to separate the roles of stylist and front desk employee was made based on prior experience that evidenced the difficulty of having employees work within two different, unrelated roles. The organizational setup of Castlewood Salon, which remains today, consisted of apprentice assistants, stylists of varying experience levels, front desk employees also known as "Hair Traffic Controllers," a Salon Director, and a Director of Education. Based on level of experience, stylists operated as stylists, master stylists, or designers. Bill served as owner/operator of the salon as well as a designer level stylist.

Emanating from this shift in how the salon operated was an opportunity for Bill to have greater influence over employees' acceptance of and compliance with the strategic direction of the organization. Rather than being largely self-directed and operating as independent contractors, Bill desired employees who would work together as co-learners and teammates toward the goals of the organization. Thus, hiring employees unshaped by prior salon experience, who accepted employment under the agreement of spending the 
first year in a "student learning" mode, allowed Bill to shape a culture that valued growth and learning and that embraced the vision of the organization. From this vision a program was developed that has been, according to both Bill and salon employees, a cornerstone of employee and organization success.

During Bill's prior experiences operating Castlewood Salon he recognized that, even though demand for services was high and the salon was profitable, the employees were not adequately skilled to meet the demand. This was attributed to a lack of training provided to salon employees upon hire. Employees were being hired with prior experience as stylists, with the expectation that the prior experience would serve to make them successful at Castlewood Salon. No specific training was provided by Bill or others within the salon. The degree to which employees received technical job training was informal and "as needed." It was provided by other, more experienced stylists upon Bill's request. After experiencing business failure within the salon, Bill recognized that the lack of training and development of employees was a detriment to business success.

Implementing apprenticeships. The apprentice training program became a cornerstone of the new way of doing business for Bill and the employees of the salon. Whereas prior there was no formal training and development, now a program existed in which all new employees participated for the first year of employment. The program was designed to teach technical and business skills necessary to becoming a successful stylist within the salon. There was a major emphasis on professional skills such as stylist and client dialogue, professional appearance, and even professional speaking. New stylist employees entered the salon on the first day of employment as an apprentice assistant and remained in this role throughout the first year of their work. 
Upon implementation of the apprentice training program, the benefits of a highly skilled workforce were clear. In addition to increased employee skill level, the apprentice training program facilitated the proliferation of a culture of learning among salon employees. Specifically, a commitment to learning and growth was a core value that Bill desired to see manifested within the culture of the salon. Thus, requiring new employees to spend their first year of work in a learning role not only communicated, but also upheld, this core value as important. The apprentice training program provided the means to reinforce the elements of a culture which valued learning within Castlewood Salon.

Adding new product lines. It was not long before Castlewood Salon was experiencing sufficient business growth that enabled Bill to expand into other areas of the hairdressing industry. In 2001 he expanded into product manufacturing with a line of hair care products for women. The product line, Beauty Factor, was created to be used in Castlewood and other salons as well as for retail purchase. Four years later in 2005, Bond for Men was created as a line of hair care products for men. This product line was also created to be used in Castlewood and other salons as well as for retail purchase. The manufacturing facility for both product companies was established within twenty miles of Castlewood Salon in a warehouse facility in southern Indiana.

Along with the ability to provide hair care products to salons, Bill used the Beauty Factor and Bond for Men companies to offer education opportunities to those salons which carried the products. Similar to Bill's desire to educate his own workforce within Castlewood Salon, he also desired that the salon industry, as a whole, be better equipped for success. Thus, much of the education offered to his own employees was now being offered, for a fee, to those salons carrying his products. This was not only an income 
opportunity, but also an opportunity to provide both technical skill and business education to other salons in the industry. With all that had been learned over the course of his business failure and then subsequent success, Bill knew he had something to offer other salons looking to succeed in the industry.

Educating. The education classes were all provided at the Know How Center for Creative Development (Figures 3, 4). This space was purchased and renovated and located two doors down from Castlewood Salon. The facility offers a lifelike salon setup that can be used for training demonstrations as well as tables, chairs, and audiovisual elements needed for classroom trainings.

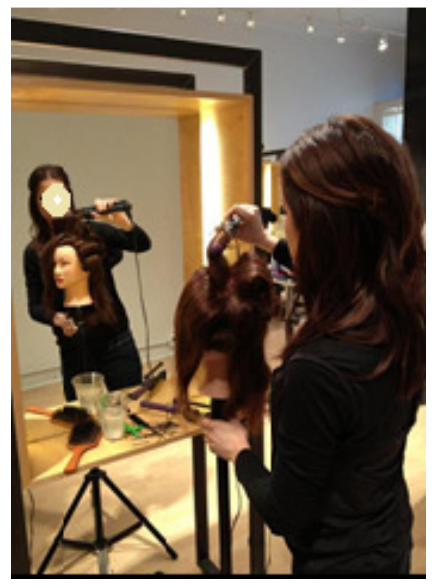

Figure 3. Know How Center for Creative Development

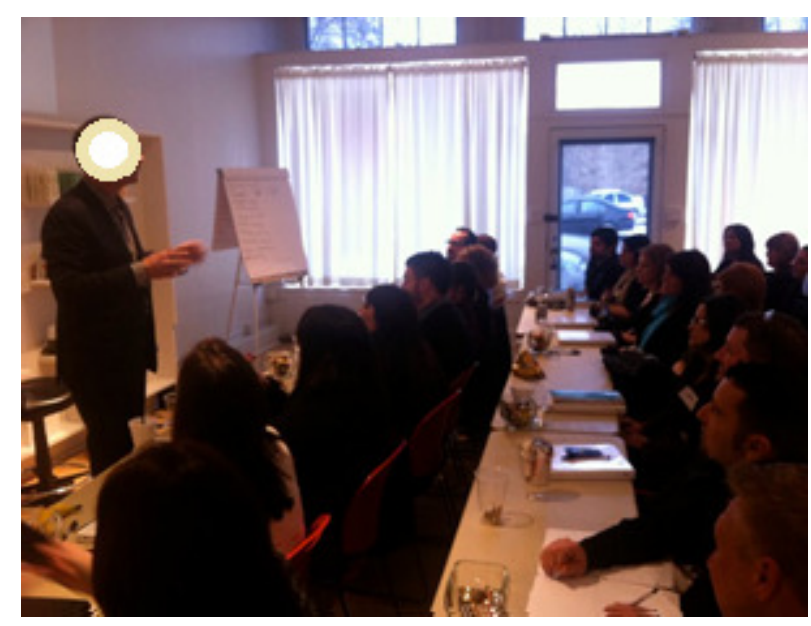

Figure 4. Know How Center for Creative Development 
Along with the opportunity to produce income and educate other salons, this new venture provided opportunity for employees of Castlewood Salon. In addition to Bill himself, stylists and front desk employees were offered the opportunity to become educators with Beauty Factor and Bond for Men. This was a mutually beneficial model for the business and its employees. Employees were offered the opportunity to develop additional skills in public speaking and training, while the product companies were able to benefit from using salon employees to provide training. Because the product companies were an extension of Castlewood Salon, employees could be essentially shared between the two businesses.

The opportunity to train other salons was also used as a motivational tool for employees of Castlewood Salon. The opportunity to become an educator for the product companies was not offered to all employees of the salon. Rather, it was an opportunity that was earned as employees worked to develop and hone their knowledge of the techniques and business practices in place at Castlewood Salon. Their role as an educator for the product companies was separate from their role in Castlewood Salon. It was common that employees worked a full schedule within the salon throughout the week and worked as Beauty Factor and Bond for Men educators on the weekends.

Beauty Factor and Bond for Men product companies provided education opportunities to client salons as a benefit of carrying the products. However, the use of a third party distribution channel limited the relationship between the product companies and the client salons. Up to this point the relationship between the product companies and the client salons was indirect - salons that carried the products may or may not choose to attend education events offered by the product companies. And while the education 
events offered by the product companies stood to help salon clients build technical and business skills, only through a more direct relationship could Bill get close enough to salon owners to make a significant impact on how the salon business operated.

Direct distributing. Bill saw an opportunity to develop this relationship with client salons by distributing his products directly, rather than through a third party distribution company. If he could gain access to salons as a distributor, he was sure that he could build a relationship that would open up opportunity for business consulting. To that end, Fresh Allure Consulting was established in 2013 to serve both a distribution and consulting function. According to its mission statement, Fresh Allure Consulting is "dedicated to the advancement and prosperity of the professional stylist, independent salon owner, and the professional salon industry as a whole. This is accomplished by providing world-class business consulting, technical training, inspiration, and professional salon products."

\section{Smith Enterprises Current Business Structure}

At the time of this case study in 2013, Smith Enterprises, Incorporated was established to operate as a parent company for the separate business entities that Bill Smith had established: Castlewood Salon, Beauty Factor and Bond for Men products, and Fresh Allure Consulting. While each business remained a separate entity for legal and accounting purposes, they were all organized under the parent company of Smith Enterprises, Incorporated. Figure 5 demonstrates that rather than the establishment of a parent company first with each business entity trickling down subsequently, Smith Enterprises, Incorporated began with Castlewood Salon and grew to include the multiple other business entities. Today, Smith Enterprises' revenue is divided as follows: 
Castlewood Salon (60\%), Beauty Factor and Bond for Men Products (30\%), and Fresh Allure Consulting (10\%). Bill Smith is also involved as co-owner of Main Street Barber Shop located in the same Midwest city. He acquired the business in 2010. While this business is not organized under Smith Enterprises, Incorporated, his role as co-owner of Main Street Barbers provides additional evidence for the business growth trajectory experienced by Bill over the course of his career.

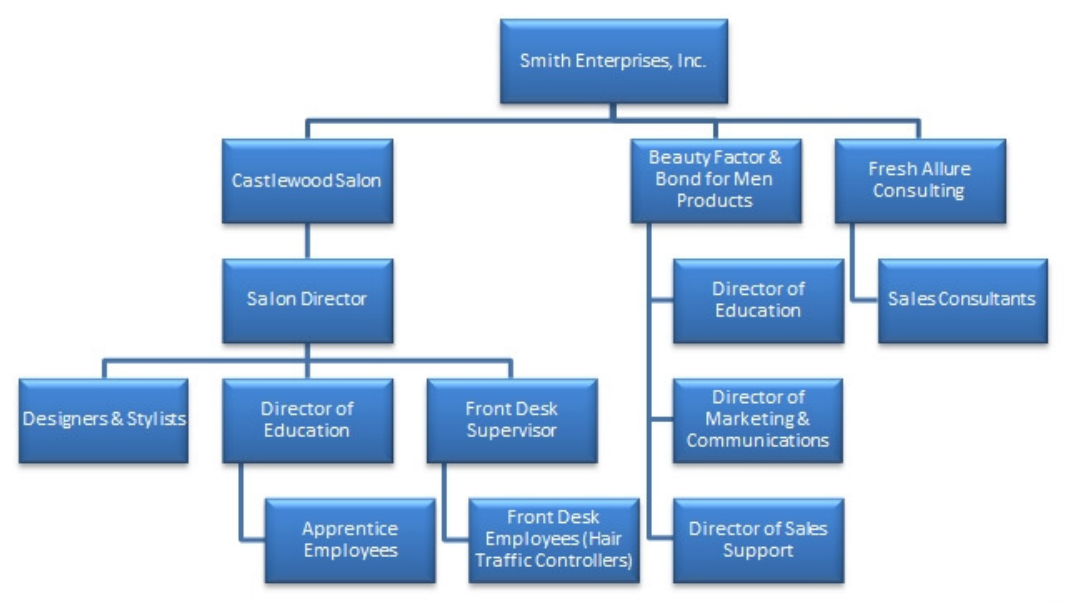

Figure5. Smith Enterprises, Incorporated organizational structure

The individual businesses intermingled somewhat based on similar business philosophies which emanated from Bill Smith who owned and operated each business, and crossover of some employee roles. Bill states about the structure:

The philosophies [of the companies] do intermingle because it's all from me. So you'll see when we're teaching [with the product companies], it all has to do with that same philosophy [of the salon].

What follows is a current description of each of the business entities included with Smith Enterprises. 


\section{Castlewood Salon}

Castlewood Salon operates from one location in the mid-sized U.S. Midwest city. Currently, this is the only location for the salon. As a full-service salon it offers haircutting, styling, coloring, makeup application, and product retail services. The salon is staffed with 25 full-time employees, including the salon owner, a Salon Director, a Director of Education, twelve stylists, three designers, two front desk operators, and five apprentice assistant staff members. The gender breakdown of employees is $95 \%$ female and 5\% male. Within a fifty-mile radius of the salon there are more than 500 other fullservice salons currently in operation.

The salon is situated within three turn of the century style houses that have been renovated and combined to create one complete structure.

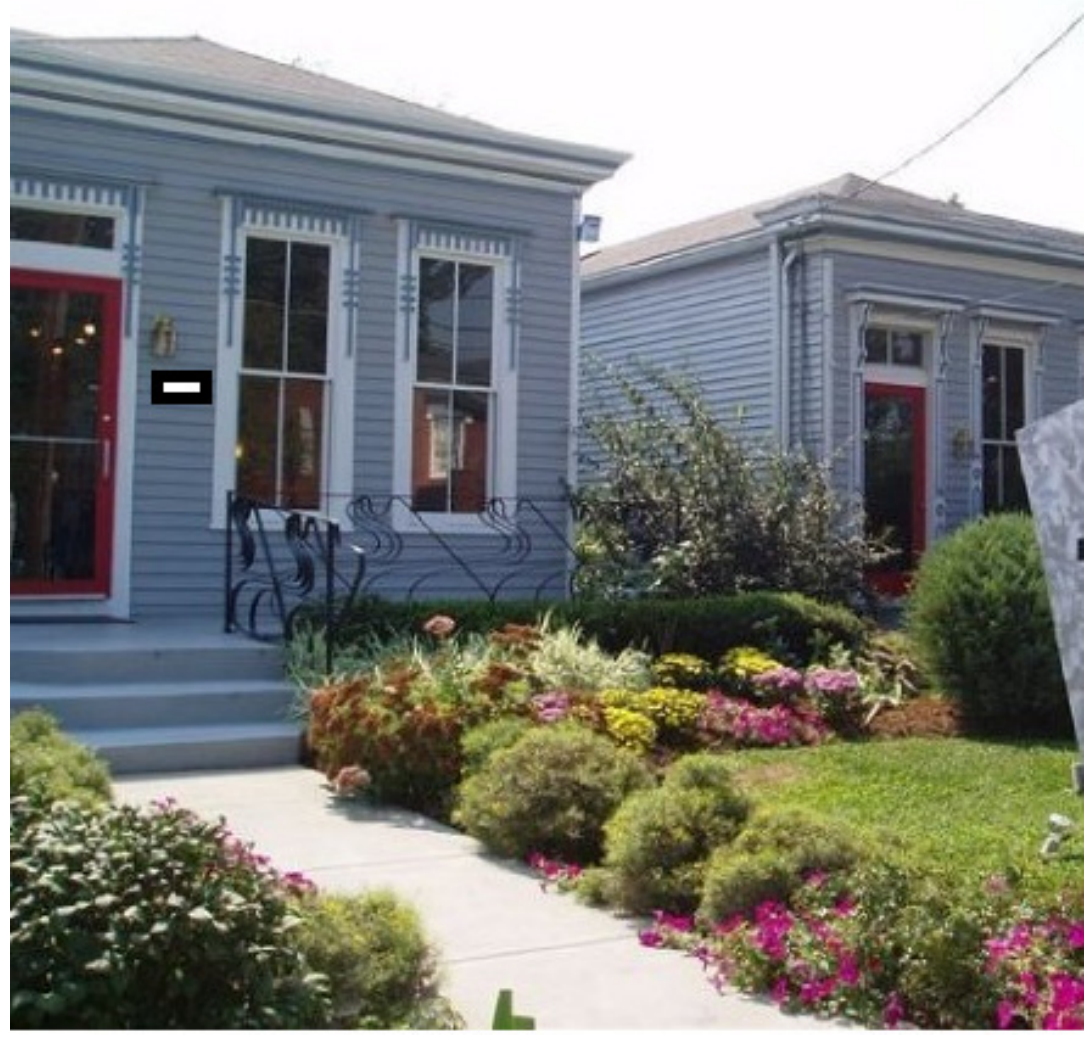

Figure 6. Castlewood Salon Exterior 
The salon environment is comprised of a reception area, changing rooms for clients to obtain protective smocks, a makeup application area, and separate areas designated for shampooing, haircuts (The Design Center), hair coloring (The Color Center), and styling. There is also a dispensary, which contains all supplies, and a laundry area. Finally, an upstairs loft space serves as an office area for Bill and the Salon Director, Lana. This is also where all one-on-one staff meetings and formal coaching sessions take place. A full layout of the salon (each elongated section being a former house), including pictures of various areas, is presented below.

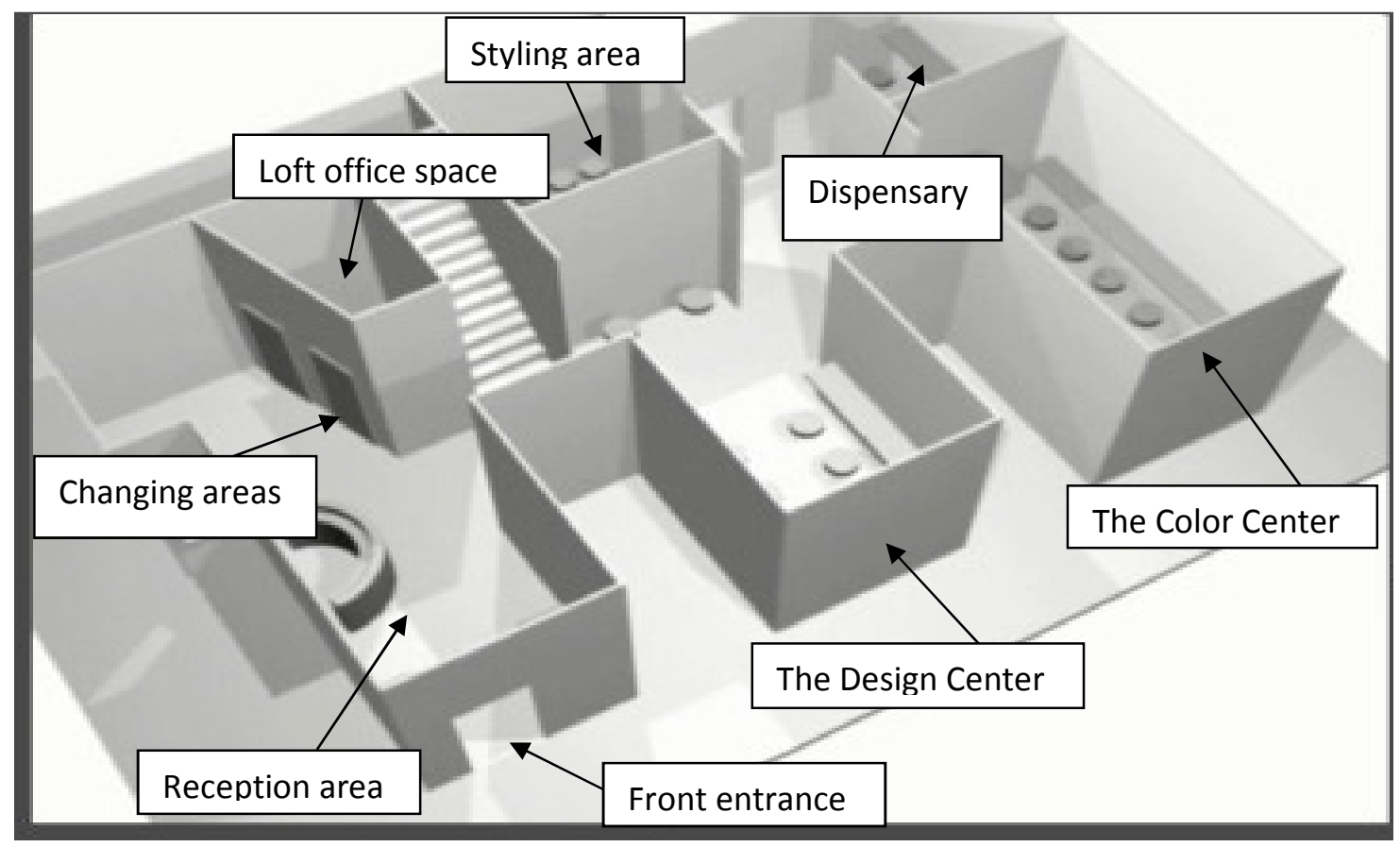

Figure 7. Salon Layout 


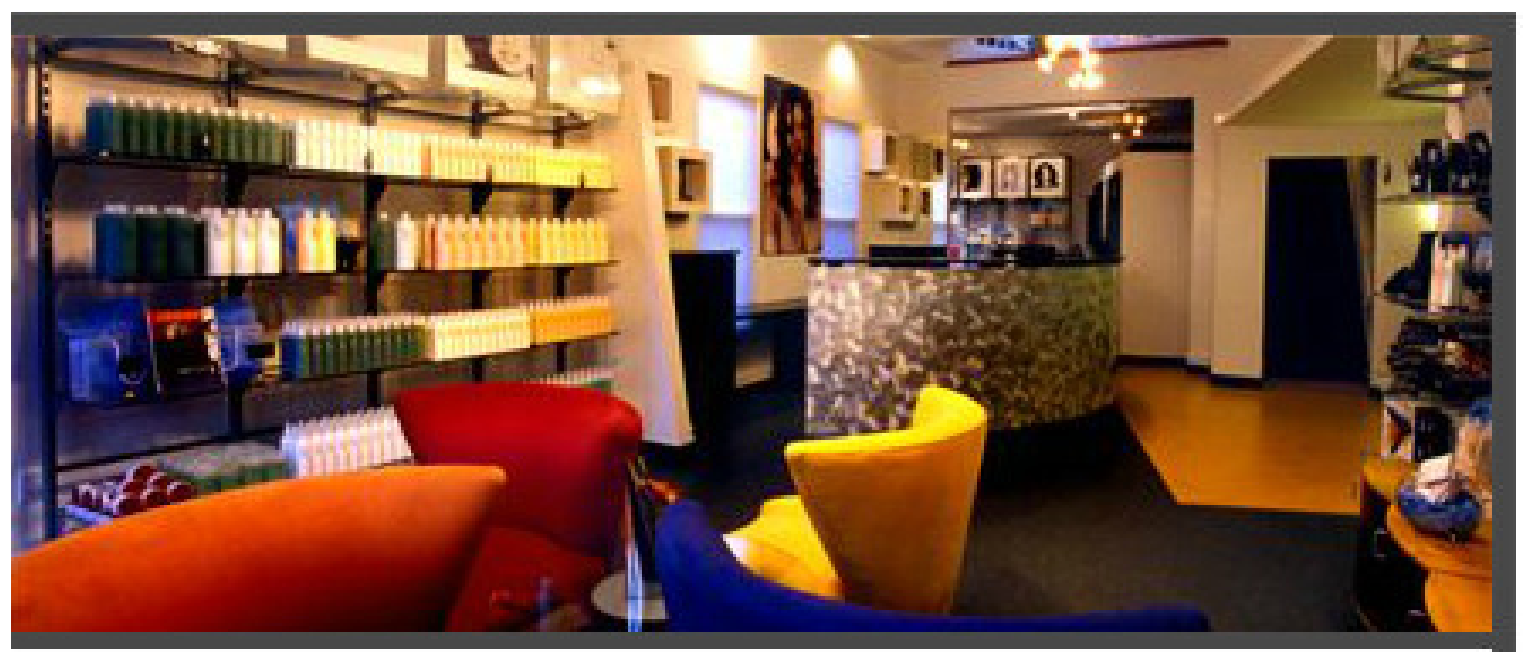

Figure 8. Reception Area

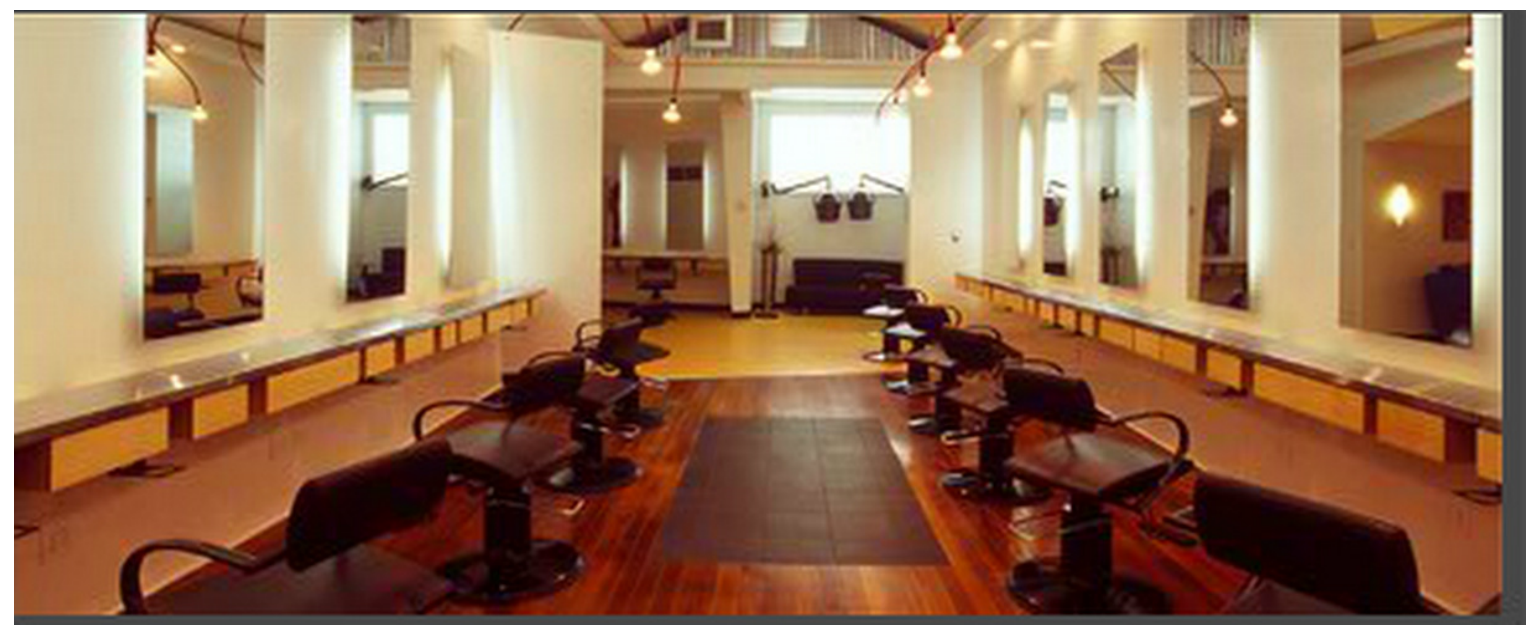

Figure 9. The Design Center

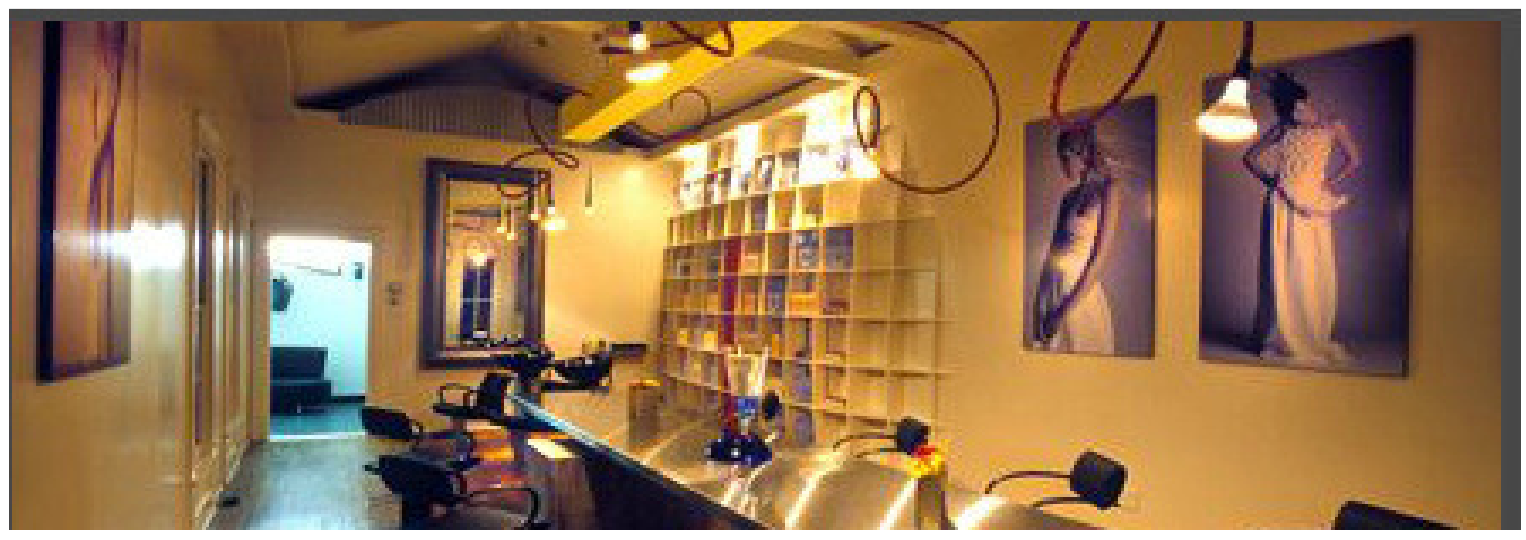

Figure 10. The Color Center 


\section{Beauty Factor and Bond for Men Products.}

Beauty Factor and Bond for Men product lines were established in 2001 and 2005 , respectively. The businesses operate within a single warehouse facility in a nearby city (Figure 11). The products are manufactured and distributed from this location. The business is comprised of a Director of Education, who also serves as a senior stylist in Castlewood Salon; a Director of Marketing and Communications, who is employed exclusively by the product lines; a Director of Sales and Distribution Support, whose role spans both the product lines and Fresh Allure Consulting; and seven educators who work primarily as stylists and front desk operators within Castlewood Salon. The product companies also provide technical and business education that is offered to client salons throughout the mid-south and southeast United States.

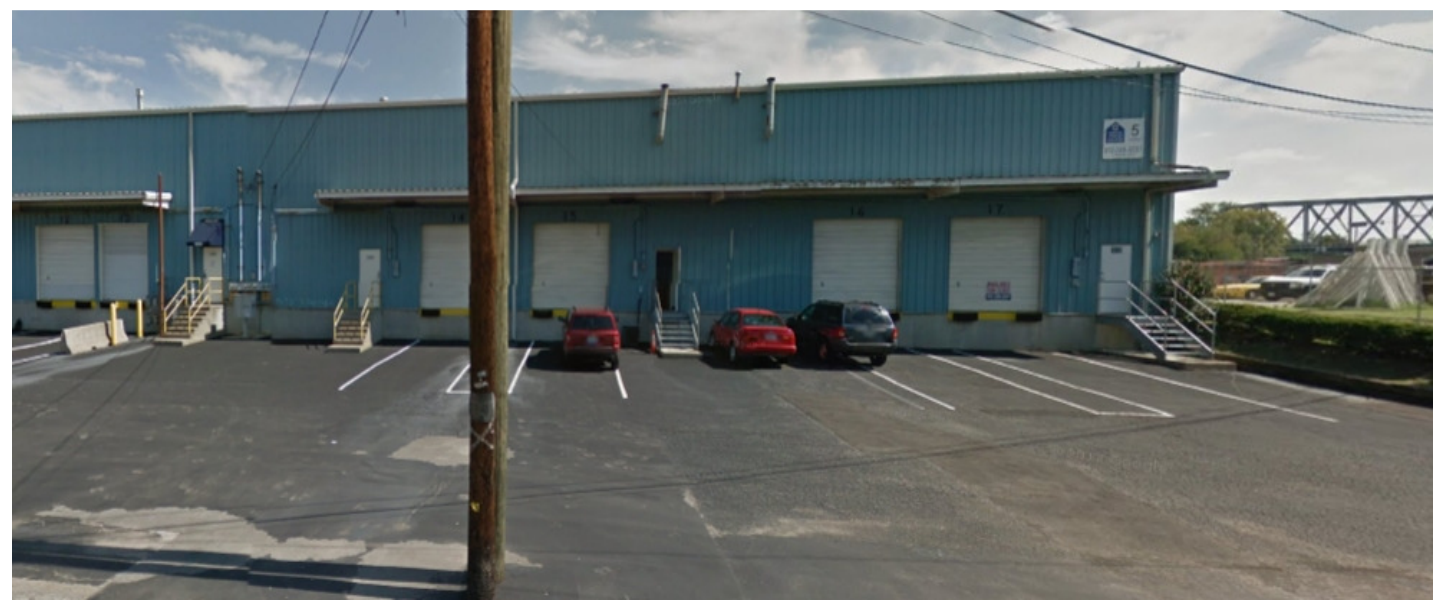

Figure 11. Beauty Factor and Bond for Men Products Manufacturing and Distribution Facility Fresh Allure Consulting.

Fresh Allure Consulting was established in 2013. The business serves as both a distribution channel for Beauty Factor and Bond for Men products, as well as a consulting company. Fresh Allure Consulting operates from the same warehouse facility as Beauty Factor and Bond for Men products. Employees of Fresh Allure Consulting 
include one sales consultant, who is exclusive to Fresh Allure Consulting, and five other sales consultants whose primary roles are within Castlewood Salon. Bill Smith is also involved with Fresh Allure Consulting as a business management consultant. Sales consultants work with client salons, which carry Beauty Factor and Bond for Men products, to identify business consulting needs. Sales consultants identify themselves as "salon guidance professionals fully devoted to the advancement of the professional beauty industry." The consulting team boasts over 55 years of combined experience in salon ownership, management, distribution, manufacturing, and hairdressing. Consulting services include bi-weekly or monthly personalized business coaching sessions, personalized goals and contests to support salon success, and a myriad of personalized classes focusing on marketing and branding, stylist success, apprentice training programs, salon owner leadership classes, and team building.

\section{Summary}

The evolution of Smith Enterprises began with Bill Smith, founder. As a young beauty school student, Bill was compelled by the possibility that hairdressing could offer a broader and richer career than what he had first imagined. To chase this possibility, he established his own salon business early in his career. However, due to inexperience and a lack of knowledge, his first two attempts at business ownership ended unsuccessfully. Because Bill treated his business failure as an opportunity for learning, he reestablished his salon a third time and changed the business structure entirely. This shift in structure provided Bill more influence over employee performance and the strategic direction of the organization. It also enabled him to pass on his value of learning to employees. Soon after this shift, intentional hiring practices were implemented along with the development 
of an apprentice training program. These practices produced a well-trained and highly skilled workforce. As a result, business growth and success were achieved. Bill was able to expand into other areas of the beauty industry, including hair care products, business education, product distribution, and business consulting. Most importantly, a culture of learning was proliferated throughout each of the businesses. 


\section{CHAPTER FIVE \\ THE ORGANIZATIONAL LEARNING CULTURE}

Your company culture should be so vivid that some people are repelled by it. Only when it's strong enough to repel can it also attract. (Marcus Buckingham)

This embedded case study was bound by the organizational context of Smith Enterprises, Incorporated. This includes three distinct business entities: Castlewood Salon, Beauty Factor and Bond for Men hair products, and Fresh Allure Consulting. The study's central research question, guided the inquiry: How does an organizational learning culture occur in a successful small business? The following story describes the organizational learning culture that exists within Smith Enterprises, Inc., the establishment of which began in Castlewood Salon.

\section{Establishing the Learning Culture}

\section{Recruiting and Onboarding}

Bill and other salon leaders within Castlewood Salon spend a significant amount of time recruiting current beauty school students for work within Castlewood Salon. This is a strategic decision to identify potential employees with whom the organizational culture resonates. This increases the potential for a good fit between the employee and the organization. Bill recounts the details of how they speak to the students when they visit the various schools:

You as a student have spent ' $\mathrm{x}$ ' amount of dollars to go to this beauty school to pass your test and get your license. So how much was that? 18 grand? 15 grand? 
25 grand? Depending upon the school, it's going to be a substantial amount of money. So you've spent that much money to go to beauty school to get your license to come into the workforce. Now, I've got a question for you. How many of you have ever heard of the great Vidal Sassoon? How much do you think it would be worth to study under someone like Vidal Sassoon for a year? You can't put a price on that. How many of you have ever heard of Paul Mitchell? THE Paul Mitchell. Not the product company, but Paul Mitchell? How much would it be worth to study under Paul Mitchell? If you can't put a price on that, what would it be worth for...someone like myself, at Castlewood Salon, to teach you how to make over \$100,000 dollars a year? Shouldn't you be paying us? And [it's at that point] the light switches.

The purpose of this presentation is to, in Bill's words, "thin the herd." He says that when this scenario is presented to the students, only a small portion of them relate to this type of career thinking. But because so much of Castlewood Salon's culture is built on career thinking, they must recruit the kind of employees with whom this message resonates.

During the interview process, potential employees are evaluated on their ability to articulate their career goals and how working at the salon fits within those goals. Salon leaders seek those individuals who appear to think long-term about their career, as opposed to those whose only interest is how much they will be paid. A common phrase used by those who participate in the hiring process is, "It's not about what you'll make at Castlewood; it's about what you'll become at Castlewood." Salon leaders suggest that the biggest indicator of a potential good fit for the salon is someone who is coachable, with 
enough passion for their career to sustain them through the tough first year as an apprentice. Lana, Castlewood's Salon Director, explains it this way:

Everyone is told upfront that the goal is to continue to improve. So when you are asked to do things, I don't expect you to necessarily do them perfectly right away. But if you don't make the effort to improve, that's when we're going to have a problem. So if you can't put forth any effort, with all the effort we're putting into you, then that is [seen as] disrespectful, and you're not going to grow here. It's all based on if you are putting in the effort to improve. It's an improvement effort.

Lana goes on to explain that even if people do not innately embrace this sort of incremental improvement mindset, it is expected that they make the choice to embrace the commitment to learning and growth that is part of working at Castlewood Salon. Employees are expected to incorporate enough of the organization's values to enable them to work in the manner required of the salon. If not, their career within the salon will not prosper.

\section{Staffing Structure}

As employees are hired at Castlewood Salon they occupy one of two roles stylist or front desk employee. Front desk employees, also known as Hair Traffic Controllers, are able to begin work immediately and learn on-the-job from the Front Desk Manager. Hair Traffic Controllers are responsible for client relations as well as developing the work schedule of all salon employees. The front desk employees develop work schedules for salon employees because they are exclusively responsible for client scheduling. In addition to receiving incoming phone calls and scheduling service appointments, they work with first time and returning clients alike to ensure that they 
schedule appropriate services for the client's visit. Hair Traffic Controllers are located directly across from the salon's front entrance in the reception area. They greet each person into the salon, by name if they know them, check them in for their service, offer a beverage, guide the client to the changing room to obtain a smock, offer a seat if the client arrives prior to appointment time, and follow each service experience by thanking the client and accepting and processing payment.

Unlike front desk employees who can be hired regardless of past salon experience, stylists are typically hired directly from beauty school. Only those individuals who have no prior experience working in a salon can be considered for employment as a stylist at the salon. This requirement is based on Bill's intent that every employee learn Castlewood's systems without influence from past experiences. He wants each stylist to follow and believe in Castlewood's approach to doing business. He also wants new employees to understand the importance placed on learning. Bill states, "We want to set the stage for them to understand that they are a student as they enter our doors. They are not employees. They are students. It just happens they're going to get paid while they're a student."

\section{Apprentice Training Program}

Each stylist that is hired to work at Castlewood Salon must participate in a yearlong apprentice training program. The program is designed to teach the skills needed to operate at the level required by Castlewood Salon. One senior stylist describes the apprentice program as "building confidence through giving them [apprentice employees] education and experience." The program is considered mutually beneficial for salon employees and the business. During a "Salon Success Factors" business workshop hosted 
by Beauty Factor products, Sarah, Director of Education for the product lines, described to participants the mutual benefit of the apprentice training program. She explained that stylists benefit from the program through the opportunity to educate apprentice employees. In her words, "When you teach someone, you see them learn and it brings you satisfaction. Also, to teach it [skill] well, you have to do it [skill] really well." Describing how the program is beneficial to the business she stated, "As employees become more profitable, the salon becomes more profitable and grows."

Purpose. While each new employee is likely a recent graduate of beauty school and state-licensed to begin cutting hair, the skills amassed in beauty school are typically insufficient to perform the level of work that the salon is known for, according to Bill. To that end, the apprentice training program provides technical skill building. However, it also provides opportunity for employees to assimilate the cultural elements of the organization during the yearlong program. One senior apprentice employee described the apprentice program to me during an observation period: "In our apprentice program we have classroom training. We also learn through the work we do when assisting senior stylists. The classroom training is for learning technical skills. Assisting on-the-job is more for learning the business and the culture." A conversation with Bill later that day echoed this apprentice employee's sentiment. According to Bill, "It really is the savvy that they are gaining through the apprentice program, as much as it is technical skill."

Duration. An employee's apprenticeship period lasts for one calendar year. During that first year they are not permitted to accept clients, but are only able to assist established stylists with their clients. According to the Salon Director, this element of the apprentice training program separates design (haircutting and highlighting) from labor 
(salon upkeep, hair shampooing, hair color application). Stylists are responsible for design whereas apprentice employees are responsible for labor. This serves to improve efficiency, as those with certain skills focus solely on the work for which their skills qualify them. An apprentice begins each workday with a personalized schedule developed for them by the front desk employees. The schedule is based on the salon's master schedule of clients for that particular day. Figure 12 shows an example of an apprentice's daily work schedule.

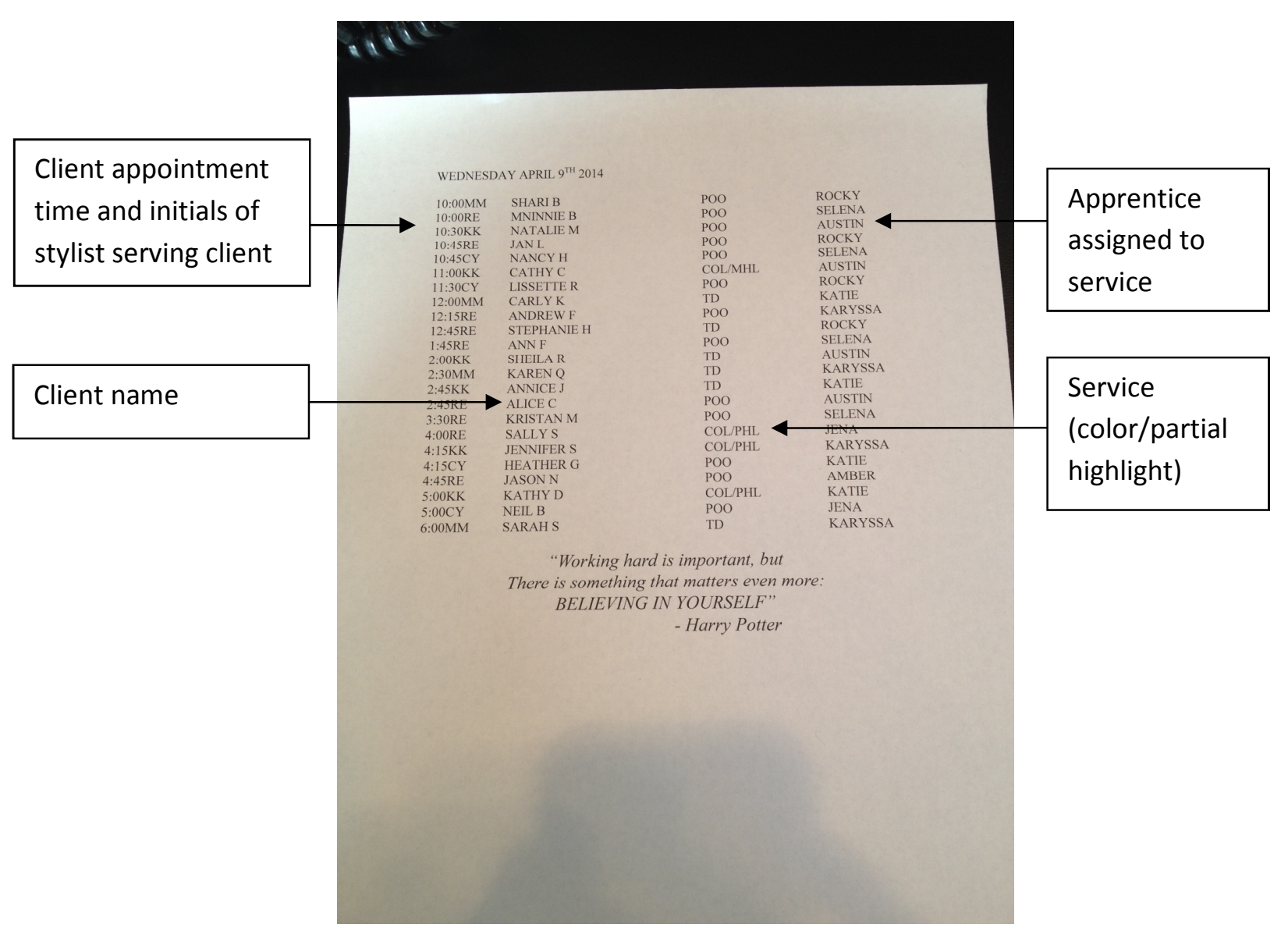

Figure 12. Apprentice Schedule

Progression of apprenticeship. Each apprentice is assigned to specific services based on the length of time they have spent in the apprentice program. Due to the nature of the apprentice program, employees progress through a series of training and on-the-job 
experiences that prepare them to gradually assume more responsibility and exposure to salon clients. Bill describes the model:

To really do it correctly, we start out taking each individual and training them on all the nuances... and the behaviors that we expect to happen here before they are ever allowed to touch a customer. So, in particular, culture is developed before they touch customers. So culture is first. Customers are second.

During the first thirty days of the program, apprentice employees are assigned no other duty than to care for the salon environment. This includes cleaning, organizing product displays, laundering smocks and towels, and keeping salon supplies stocked. This time spent taking responsibility for the salon environment is intended to help them understand the importance of maintaining the salon's standards of presentation. Also, during this time Bill and other salon leaders are able to evaluate a new employee's willingness to care about and take responsibility for even the smallest details of the salon. During one observation period I spoke with an apprentice employee who was nearing the end of the program. She told me that apprentice employees are reminded of the importance of caring for the salon environment when salon leaders tell them, "To be sure we can trust you with clients, we have to first be confident that we can trust you with the salon environment. So even the way you mop the salon floors tells us something about you."

Following the initial thirty day period, an apprentice employee is permitted to begin assisting senior stylists with clients. By the time they reach the thirty day mark, in addition to the work they have been doing in the salon, they have received at least four weeks' worth of classroom training that prepares them for their careers as stylists. The classroom training begins immediately upon being hired, is led by more senior salon 
employees, and starts with foundational skills such as stylist/client dialogue. Classes are held weekly, on Tuesdays, at the Know How Center for Creative Development.

Classroom training is bolstered by the fact that apprentice employees are simultaneously observing what they are learning in the classroom as they work daily in the salon. For example, apprentice employees observe how stylists interact with their clients and how the dialogue between stylist and client should sound. They are also provided time to practice these skills in the weekly classroom training sessions. So, once they are released to begin interacting with clients, they have received training to perform these duties successfully.

In the beginning stages of assisting stylists with clients, the apprentice employee provides all hair shampooing services. This is one duty that is performed exclusively by apprentice employees. Bill describes the philosophy behind this as freeing stylists from the duty of hair shampooing to perform other types of work, such as haircutting, that apprentice employees are not yet permitted to do. He states that this separation of duties contributes to the efficiency of salon operations. Next, following additional training, apprentice employees are approved to begin mixing and applying hair color. At this point, according to the established apprentice training schedule (Appendix C), it is likely that the apprentice employee has observed color mixing and application during their work in the salon. In fact, during one observation period I watched as a senior stylist talked to an apprentice employee as she [stylist] mixed a client's hair color formula. She explained to the apprentice the process of combining certain amounts of various color formulas to achieve the color mix she desired. One month later, as I was once again observing, I noticed the apprentice employee mixing color formulas for the stylist on her own. This 
type of progression is what salon leaders suggest prepares the apprentice employee to assume additional duties as they become more skilled. Appendix $\mathrm{C}$ presents the full apprentice training schedule.

Apprentice employees are permitted to apply hair color for clients, but they are not permitted to apply highlight color. I asked about this after I realized that I had not observed apprentice employees applying client highlights, but I had observed them applying allover hair color. I was told by Lana that highlight application is considered a "creative endeavor." According to her, the process of placing the highlights in a client's hair is something that one must "have an eye for," so that the highlights appear naturally occurring in the hair. She told me that cultivating an "eye" for this takes time and practice. Thus, employees are limited to application of allover hair color during their time as an apprentice. They are trained to perform highlight application, as well as provided time to practice on models and mannequins, but they must wait until they have graduated the program to provide this service to actual clients. With allover hair color application being a more straightforward process, according to Lana, apprentice employees are permitted to begin this work within the first few months in the program.

While apprentice employees are not permitted to apply client highlights, they do assist stylists with the application of highlights. They stand next to stylists and act as a second pair of hands for supplies. This limits the number of movements required of the stylist. Efficiency was observed, and confirmed by salon leaders, to be an important element of the culture at Castlewood Salon. They explained that any opportunities are taken to limit the time it takes to complete a certain job. Having an apprentice available to gather supplies, as well as to act as a second pair of hands, allows the stylist to limit 
movement between supplies and the client's hair. Salon leaders also see this as a learning opportunity for the apprentice as they can observe how the stylist places highlights within the client's hair. It helps them cultivate their "artistic eye" for highlight application and prepares them for graduation from the apprentice program.

In addition to the experience received inside the salon, weekly classroom training provides opportunity for apprentice employees to practice new skills. Apprentice employees are required to recruit individuals on which they can practice their newly learned skills. Twice a month they bring their own "model" and perform various haircut, color, highlight, and styling techniques. This hands-on experience helps prepare them for working with salon clients. As they near the end of their year spent as an apprentice employee their skill level should be comparable to the stylists within Castlewood Salon. This is measured using a set of standards to which their graduation demonstrations must adhere. An example of the standards is presented in Figure 13 below. 


\section{Final Presentation}

- You must perform the following on a live model

- Image Profile

- With all the required steps including BeautyFactor brochure

- Color service

- Color

- Highlights

- Both

$\circ$ Haircut

- Must be a modem LOOK above the shoulders

- Blowout

- Make-up Application

- You will present your model to a panel of judges

- Discuss the services you performed on the model

- Demo dialogue for after service

- Referral at the chair- (asking what their friend's hair is like)

- Referral at the chair- (asking for referrals)

- Referral at the desk-(explaining new client packet)

- Reschedule

- Retail

- After this portion is complete, your model will leave.

- You will then present your mannequin to the judges.

- Complete the look that you have chosen for your mannequin.

- Now perform your prepared presentation.

- Discuss what your apprenticeship has done for you

- Discuss what going on the floor means to you

- The judges will follow up with questions

\section{Figure 13. Apprentice Final Presentation Standards}

In regard to the skill progression of employees, as an outside observer, it was easy for me to discern between those apprentice employees who were new to the program and those who were more experienced. It was not just the duties they were performing in their work that set them apart, but it was the confidence with which they performed their work. The more experienced employees posed fewer questions and exhibited greater poise as they went about their day. 
Assimilation. Not only does the apprentice training program provide opportunity for employees to grow in knowledge and skill during their first year of employment, it also provides opportunity for the employee to become accustomed to the culture of the salon. As an outside observer, this was one of the most surprising elements of the apprentice training program. Before I observed the program firsthand, I assumed that I would observe apprentice employees learning technical skills while on the job. However, what I actually observed was very little technical skill building but a considerable amount of cultural assimilation. On one occasion, I observed a more senior apprentice employee approach a stylist with a question about a client. I noticed that the employee did not approach the stylist at their chair where they were working with a client. Instead, she stood off to the side and waited for the stylist to acknowledge her. At that point, the stylist excused herself from the client and came over to the apprentice employee to answer her question. Conversely, on another occasion I noticed a brand new apprentice employee, employed less than thirty days, hurry over to a stylist's chair to ask a question. While this was not in keeping with protocol, the stylist simply excused herself and the apprentice from the client and began to discuss the employee's question. I later asked about this observation and was told that, during a break in clients, the stylist talked with the apprentice employee to ensure he understood to not interrupt a stylist who was working with a client. This was viewed by the stylist as a learning opportunity for a newly hired apprentice and not out of the ordinary.

While some elements of the culture are taught inside the classroom, there are still some that are taught through employee experience on the job. For example, one element of the organizational culture, goal setting, is discussed in classroom training sessions. 
Apprentice employees can observe this cultural element during their on-the-job experience, through artifacts such as the daily goal book into which all employees must input daily productivity (Figure 14). However, the concept of goal setting could be taught exclusively in the classroom setting alone if on-the-job observation was limited. Yet, another cultural element, professionalism, is more nuanced and, thus, more difficult to capture in a classroom setting apart from on-the-job observation.

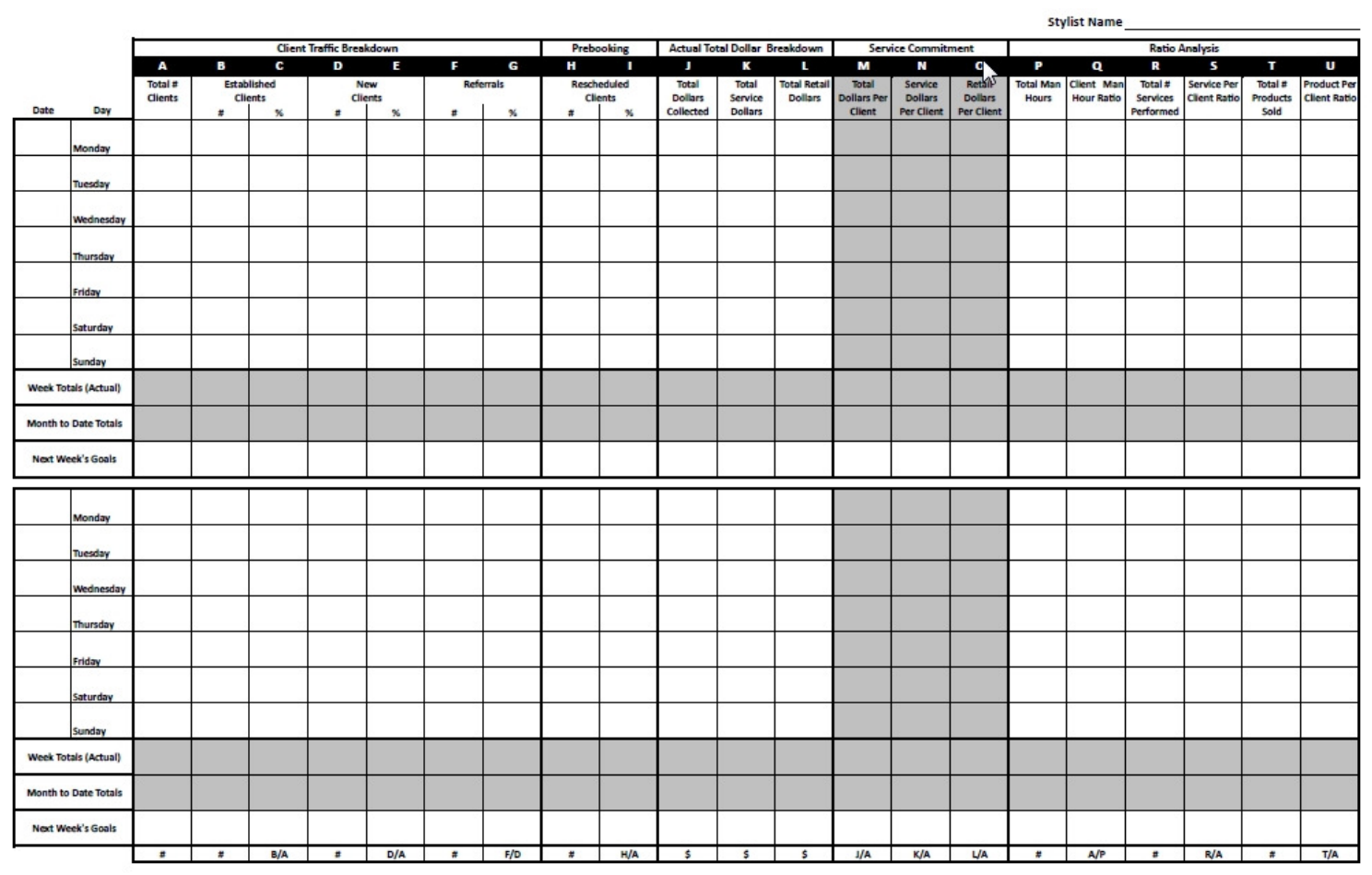

\section{Figure 14. Daily Goal Sheet}

\section{Transition to Stylist: Controlling the "Black Hole"}

Upon graduating from the apprentice training program, each employee is

promoted to the role of stylist. However, employees do not immediately spend all of their time in this new role. Instead, they ease into the new role to enable them to build their client base enough to warrant full-time work. During this transition phase, employees are initially only permitted one day per week to work in the stylist role. The other four days 
are spent maintaining their role as an apprentice assistant. Bill describes this transition from apprentice to stylist as creating a potential psychological black hole. That is, as an employee transitions out of a role in which they were highly involved and directed as to what to do each day, into a role in which they receive much less direction and fewer tasks, the individual's mind can become disengaged. Bill describes this transition in detail:

They have one day to start building customers. The rest of the time, they're still in training assistant role. So we give them that one day to start [working on] their friends and families and then the rest of the time I keep them busy. I never let their brain take off into the black hole - I'm controlling the black hole. Then as soon as I see a little bit of action happening, I'll go and open another day for them. And usually I'll do the front and the back of the week. So we'll open a Saturday next. And usually what happens is they take off on those two days really good. Then I go ahead and open the rest of it. That gives them the opportunity to start getting a little experience and keeps them engaged and they don't lose their extra $\$ 100$ in gratuities because they're still participating [as an apprentice when they're not working as a stylist]. And it's expected that no matter what, if they have some free time, say a couple customers had to reschedule or cancelled or whatever, they're expected to pitch in and assist for the rest of their careers. The apprentice training program serves as a mechanism for not only preparing new employees for success in Castlewood Salon, but also as a means by which the organizational learning culture is grown and sustained. 


\section{Growing the Learning Culture}

\section{The Spirit of Castlewood Salon: It's What We Are.}

In many ways, the apprentice program epitomizes the spirit of Castlewood Salon. Because stylists comprise the bulk of the employee base, and each stylist is required to participate in and graduate from the program, participating in the apprentice program permeates the experience of each employee. Lana, the Salon Director, states it this way: Even though we're much more than just an apprenticeship program, the apprenticeship program...we all did it. So that's our core. The front desk are the only people who didn't go through that. So all of us are a direct product of the apprenticeship program. It [the apprentice training program] really is what we are and what makes us different.

This common experience seems to influence the way that employees view one another. Those currently participating in the program are able to look to senior stylists who have graduated the program to see what they can become. The program provides hope, and an implicit guarantee, that if apprentice employees work hard and embrace the culture, they too can be as successful as the stylists that have come before.

\section{Commitment to Training: We Learn First}

The apprentice training program, while described by employees as the spirit of Castlewood Salon, is but one outward manifestation of the organization's learning culture. Castlewood Salon's leaders are committed to upholding a learning culture because they believe that it contributes to employee and business success. Bill describes this commitment: 
If we...spend the bulk of our focus on training and enlightening the employees, everything else will take care of itself. A lot of times the small business says, "We're going to do marketing or we're going to advertise and we've got to get customers, customers, customers, customers." But because they haven't created a learning environment, these people don't know how to take care of the customers anyway.

Refraining from allowing new employees to be "put on the floor," or allowed to serve in a stylist capacity upon hire, is another outward manifestation of leadership's commitment to the organization's learning culture. Even in situations where the salon may be shortstaffed of stylists, refraining from allowing apprentice employees to work in stylist positions before the completion of their yearlong training program demonstrates commitment to preparing employees to be fully capable before releasing them to do the work.

Bill attributes the growth of Castlewood Salon, and subsequent businesses that were established due to the success of Castlewood Salon, to the establishment of an organizational learning culture:

If someone asks what we do, I tell them we train, train, train, train. And we're relentless about the training. It's because of this that the culture flourishes. And at the end of the day, if you're not willing to create an environment of learning right off the bat, then you are destined for massive mistakes that are going to put you right out of business. So, we come in it from a thought pattern of learning first, then into selling. We learn first. 
This commitment to the learning culture includes providing employees proper training regarding how things are expected to be done before employees can interact with clients. Delaying short-term gains - abstaining from allowing apprentice employees to work with clients immediately upon hire - provides greater probability for the long-term success of both employees and the business. This is a lesson that Bill claims he learned from previous failures.

\section{Establishing an Organizational Learning Culture - Pumping the Well}

Establishing the organizational culture of Castlewood Salon required intentionality and commitment. But because Bill had experienced business failure due to, according to him, having no intentional organizational culture, he remained committed to the work it would require. As a self-proclaimed student of Zig Ziglar, Bill compares his experience of establishing the organizational culture of Castlewood Salon to Ziglar's story of pumping an old, unused well:

Zig Ziglar said it best, I keep referring to him, but he was a very important part of my life when I first discovered him. He talks about it like a well, an old well, on a farm with a big old pump on it. He says a lot of times if it hasn't been run for a while, you'll start pumping and you'll pump for a while and nothing will happen. And you keep pumping and pumping and pumping and nothing is happening. And you've got sweat rolling off your forehead, and nothing's happening, and you're just pumping and pumping and you think it's dry. You keep pumping and pumping and pumping and then all of a sudden the water starts to roll. And when the water comes out now all you do is [use] one finger and the water continues to roll. In the beginning, the genesis of all companies should be based purely around 
training, and purely around education and learning. That's the only thing they should spend any of their energy on the first six months.

After the initial establishment of the culture, Bill continued to develop the culture through the hiring and promotion of employees who embodied and embraced the organizational culture. Specifically, he looked for those who showed interest in continual learning and growth. This served as a way to preserve the organizational culture. Once again, Bill describes:

Once it's been created... [and] it's a lot of work to create and most people miss the boat because they're not willing to put that work in... [but] that's when it starts to live on its own, you sit back and just direct.

The work of establishing and nurturing the culture in the beginning stages of the organization's life cycle paved the way for a culture that currently requires little oversight from organizational leaders.

\section{Fostering Good Habits - Beating the Drum}

In the early years of the organization, Bill identified the type of culture he wanted to create. Yet, it took the business failing before he realized that it would be necessary to create the culture first before focusing heavily on the primary work of the business. Once Bill realized this, he began the work of building the culture. As the owner and sole leader, his vision, energy, and passion were required to establish the culture. But, slowly, as he hired employees to join his team, he reinforced the organizational culture through a process he calls "beating the drum." This term is used repeatedly by Bill, the Salon Director, and the Director of Education to describe how the organization's values and by extension, the culture, are reinforced and achieved. Bill claims that, over time, beating the 
drum, or reminding employees through words, actions, and processes, became less necessary as employees moved from a state in which accountability was necessary, to a state in which behaviors occurred routinely. It is at this point that the employees begin to "carry the culture torch" on their own.

I observed an example of an outcome of "beating the drum" within the salon. I noticed that employees were diligent to ensure that the door to the dispensary was kept closed. As they entered and exited the area where smocks and towels are laundered, hair color is formulated, and refreshments are stored, they closed the door behind them each time. I sensed an intentionality with which employees ensured that the door was kept closed. When asked about this observation, Bill suggested that what I observed was the result of years of reiterating the importance of keeping that area of the salon out of sight of clients. As he and others in leadership positions kept "beating the drum," it became habitual. Now, employees ensure that the door is kept closed without being reminded.

\section{Reinforcing Good Habits - Eliminating the Need for Constant Leader Presence}

As the organizational culture continued to evolve, and additional leaders were appointed, it was less necessary for Bill to be involved. Sarah, a senior stylist at Castlewood Salon and Director of Education for the product lines, explained it as follows:

There's been times where Bill, specifically, before there was a really great system underneath him, was still the guy doing everything. He also started [new] companies, so he would be gone for days. We would make it through, but then when he would come back we would have to talk about this or deal with that, and it was stressful on him. You could see it. And it was stressful on staff, and it just 
didn't work. So even though he was an amazing leader, just him not being there [was a problem]. But, you can't have the leader role be over everything. That doesn't work. That's not sustainable. That's not a good business when it is stressful on the owner all the time. That's how you begin it maybe, but that's not how it grows.

As a result of organizational growth, a Salon Director was appointed. Yet, even in the absence of Bill or other organizational leaders, employees continued to operate in a manner consistent with organizational values. Thus, the initial work that Bill did, such as establishing the culture and recruiting employees with whom the organizational culture resonated, produced a culture that thrived even without constant reinforcement from leadership.

\section{Sustaining the Learning Culture}

\section{The Role of Leadership in an Organizational Learning Culture - Lead, not Do}

For years, Bill maintained his role as a hair stylist while maintaining his leadership role. This caused him to sacrifice time that should have been committed to strategic leadership issues for the tasks required of his stylist role. From this experience, Bill says he learned that a leader should "lead, not do." As an example, he discussed:

I don't want to be the technician. I want to be the leader, and I want to grow others. At the end of the day, the decision has to be made to decide what is [my] role. Am I going to do the work of the business or am I going to create the business for others to flourish in? When [an entrepreneur or a leader is] focused on cutting hair themselves, then the business suffers because they are chasing two rabbits. They need to relinquish some of that and take the stuff that they don't 
know anything about, which is why they continue to cut hair as opposed to working over here [broadening their skills], and embrace the learning process so they can learn how to be a business owner instead of just cutting hair.

During an observation within the salon, I recognized the value of Bill, as a leader, extricating himself from the work of the business. He mentioned that he would be retiring as a stylist in order to focus solely on the strategic direction of the businesses. However, while I was aware of this, it was not until I saw him at work as a stylist that it was clear that his contribution to the business is greater when working in a more strategic capacity. It was as if his span of influence was so limited while working as a stylist. Yet, I questioned whether or not it was in the best interest of the business for him to retire from his "product," or his work as a stylist. However, I recalled a conversation with Bill when he described the importance of "training up" others in the work of hairdressing. He described this as necessary to freeing him, and other leaders, to increase their span of influence and ability to lead the organization forward.

\section{Leading the Learning}

Bill talks about his own personal commitment to learning and how that has impacted his ability to lead well. Each day he endeavors to learn through reading, listening to audio books, and reflecting on the day's experiences. He relies heavily on the teachings of Zig Ziglar, but also incorporates other business authors such as W. Randall Jones, Jeffrey Gittomer, and John Maxwell. Each of these authors provides what Bill describes as bread for the head. He explains that his habit of daily reading and listening to audio books gives him "fuel for the mission." He attributes his ability to sustain energy as a leader to a personal commitment to learning. 
Bill also encourages his employees to do the same thing, thus creating an environment in which employees are seen as co-learners. Bill and other salon leaders assign themselves and employees specific reading material on a routine basis:

I think about where they are and I pick the elementary stuff, not literally but figuratively. I pick the stuff that I think that their mind needs first. So, depending upon where that person is, I will put them on a certain read. Gittomer has one called The Little Golden Book of Yes and that's a gentle, funny read about attitude and about thoughts. So we start there and then we encourage from there on different levels. It depends on where it [skill level] is.

Further, Bill discussed the need to implement what is learned:

So to me, education is paramount but education is only a slice. Implementation and action are the real deal. Studying is half the answer. The other half is living it [through] implementing it.

One specific example of putting learning into action was revealed through a discussion with Castlewood's Salon Director. She described the evolution of the Apprentice Training Program and how it came to include its current elements. She discussed the years spent implementing various learning models and tweaking them as they proved effective or not. In addition, she and Bill spent time learning about an apprentice training program used by Vidal Sassoon. They implemented some elements of that program into their own training regimen. But, over time, as they learned more, through experience and reading for themselves, the program evolved into its current state. Still they do not stop looking for ways to improve the program. They continue to learn from it and implement changes as necessary. 


\section{Inspiring Employees}

During interviews, employees described their support for the mission of the organization and for Bill's leadership. Several employees shared that they trust that Bill cares for them, as individuals, but also that he balances that care with ensuring business success. One employee explains:

We know that he cares for us. He's our boss. He wants to see us succeed. But we know that, ultimately, he has a business that he has to run. And for his wellbeing, he needs the business to succeed. So we know that what he's implementing is best for us because, if we do well, then he's going to do well.

When asked about striking a balance between employee development and business development, Bill stated that he does not see this as a balance to be achieved. Instead, he views the two concepts as not mutually exclusive. He shared a Zig Ziglar quote to illustrate his point: "You don't build business. You build people and they build the business." Candice, a front desk employee, described the trust that employees have in Bill's commitment to employee success:

I would say we know that he's been in the industry... he has knowledge and he's built this...empire. We trust him, and we trust that what he's doing is [good] for us. The main thing is that we all believe in what Bill stands for.

\section{Employee Experience of an Organizational Learning Culture - In Their Own Words}

The interpretive approach adopted by this research study embraces the subjective reality as experienced by each study participant. It is through the subjective experiences of people that knowledge can be discovered. Based on this interpretive approach, it was necessary to understand the phenomenon of an organizational learning culture from the 
perspective of the organization's employees. Exploring this phenomenon from multiple perspectives produced a more accurate depiction of the organization's culture. Employees identified four major themes as they described the organizational learning culture: employees are encouraged to take initiative to improve themselves personally and professionally, being coachable is necessary to ensure personal and professional growth, change is oft-occurring and embraced, and because the organization's culture has led to success for the employees and the business, it must be protected so as not to forfeit continued success.

\section{Employee Experience of the Learning Culture}

Assuming responsibility. While the culture of the organization encourages, supports, and provides learning and development opportunities, each employee is expected to take initiative for their own professional growth and career development. Jessica, a senior stylist, states that while there is opportunity available within the organization, it does not come easy. I witnessed an example of this phenomenon during one observation period. It suggested to me that employees avoid being sedentary and find ways to stay busy. I observed an apprentice employee finishing a client's color application. After finishing her work with the client, she moved immediately to cleaning windows and doors. There was no break between the technical work of completing color application and the more ordinary work of caring for the salon environment. It seemed this employee had no hesitation to stay busy, whether with a technical task required for her future job as a stylist, or with the more menial work required as an apprentice. She stayed continually occupied with work. When I shared my observation with a senior employee, she explained, "Success isn't just handed to you [here]. You have to try hard - 
this perfect system and everything still comes with the expectation that you're going to try hard." In an attempt to further understand what motivates employees to exert this type of consistent effort, I asked Candice, a front desk employee, for her perspective:

The people here want to be on top of their game. We are influenced by seeing anything successful, or seeing anything like continuous learning, and being as good as we can be, and continuing to get that way. It's a lot of "I wanna, I wanna, I wanna."

From my observations, the culture seems to encourage employees to take initiative to learn and grow. While opportunities exist to support employees' career development, I observed both implicit and explicit messages that communicate that employees should take ownership of their own professional development. Bill states, "Not only do you want to train them, but you want to create them to be hungry for learning. That hunger for learning and wanting to grow is a byproduct of the leadership's tenacity in training."

Being coachable. Employees described the organizational culture as one of "coaching and being coachable" many times throughout the interview process. Informal coaching was observed on several occasions within the salon setting. As employees worked on various tasks, they either asked for feedback when they were unsure about the correct decision to make, or they would receive feedback from other employees who noticed them struggling to perform. Lana, Salon Director, described the coaching process:

There is formal coaching that happens through quarterly performance reviews, but...the most important is the informal coaching. It [informal coaching] is less about that it's time to review everybody, and more about, I want to sit down with 
you because I see something I want to coach you through. Whether it's that there are some great things going on, and I want to coach you to motivate you to go further; or there is something that we need to address that is incorrect, and I need to work with you on it. To me, informal coaching sessions actually mean a little bit more than the formal coaching. Informal coaching is extremely random but it occurs when necessary. "When necessary" seems like not very often but it's actually very often. So if even one instance occurs and there needs to be coaching, someone usually gets involved in that situation. I would say there's a lot of coaching that happens on a very regular basis.

According to organizational leaders, coaching often happens from leader to employee. However, at times, employees also coach one another. Lana describes this phenomenon: What's neat is even if it's not a leadership person coaching somebody else, coaching still happens. When situations arise, instead of me always trying to address them, I will help others see how they might address the situation. So we coach on coaching a lot, because our motto is to develop more leaders, not followers. We coach people to coach. But what happens is, because we're all close and our environment doesn't have room for error, the people around you will naturally coach you. So you have employees who may have worked at the salon two or three years who are not in a leadership role, but they will end up coaching each other. So, even though we don't tell them to do that, everybody is aware of holding everybody accountable.

Observing daily operations within the salon, I witnessed employees demonstrating the peer-to-peer informal coaching. On several occasions I observed employees talking to 
one another regarding mistakes that they had made or questions they had. Their peers were quick to step in to coach them based on their own prior experiences, or to encourage them to talk with someone in a leadership position.

Embracing change. Many employees throughout the enterprise discussed change as an inevitable part of the everyday experience in the organization. According to employees, when change occurs, the positive aspect of the change is communicated to staff. The benefit of the change for employees is also presented with the hope that early identification of the benefit of the change will increase employees' openness to the change. Finally, employees said that Bill never uses the phrase "because I said so." As one apprentice employee explained:

He presents us with why it is great instead of just saying, "It's my salon and we're using this color." He's definitely not that kind of boss. I would say that the main thing [he does] is explain why this [the change] is happening and what it will do for us. He's really good at showing people how this is going to benefit them and why this is important.

Several employees revealed throughout the interview process that sometimes change is negotiable and, other times, it is not. According to the employees, when change occurs that they do not agree with, they are encouraged to share their perspective and suggestions. The purpose of this is to ensure employees have a voice in the change process through suggestion-making. However, change is also so oft-occurring, employees said that they have become somewhat accustomed to it. However, even when they may not agree with the change or be excited by it, their attitudes typically remain positive. A senior employee comments: 
When we changed colors last time, one of the girls told me that she was so irritated because we were changing colors. She didn't want to deal with the new color because it was going to be hard. And then she said, "Now that I've gone through it, I've learned so much about color, and I like this stuff." But I think the thing is, I never knew that she was having a problem. I didn't know because she kept that negative under wraps and just got over it because she knows that that's not an acceptable way to be.

During an observation period, I had the opportunity to have lunch with some employees within the break area of the salon. At the table were employees from the salon and one of the product line businesses. The employees discussed an upcoming change to the way in which education opportunities would be offered to outside salons. I observed one employee expressing concern about the change. Another employee chimed in to support this person's concern by agreeing that the change was going to require extra effort. However, this employee shifted to presenting the change in a positive light by highlighting the growth opportunity available for employees. A third employee began to state the positive elements of the upcoming change, such as the ability to increase personal income and the opportunity to travel to a major hair show in Paris. The concerned employee considered these suggestions. She also thanked them for their willingness to share their thoughts. The conversation was lighthearted, but conducive to substantive discussion. I did not observe tension or hesitation on the part of the concerned employee when sharing her apprehension. The other employees validated the concern. However, they also worked to embrace the change. 
Protecting the culture. Establishing a strong organizational culture, underpinned by the core values of learning and growth, was important to Bill Smith when he set out to create a successful organization. Now, the organization's culture is so strong that it requires less work from Bill and other organizational leaders to maintain the culture. The organization's culture has developed a self-protecting mechanism. Meaning that, it is no longer necessary for leaders to step in to resolve something that goes against the values of the culture. Instead, those things tend to resolve themselves among employees. Sarah explains:

What's happened over the years is we have just personally become very protective of that [culture]. I mean, if someone comes in with a nasty attitude, and they are not willing to learn, it is almost like you go back to junior year of high school, and no one talks to you. I mean, seriously, we're not putting up with it. Do you know how much money some of us make? Do you know how much we have on the line and how many houses some of us own? And how important...we've got kids in college and we're pregnant... you're messing with my income with your attitude. It has been inbred in some of us older ones [senior employees] to the point of we will fight for it. Most of the time we don't have to. But the moment we have to, we would fight for it. We would have each other's back for it. What's best for the salon? Because if this place isn't jammin', if clients don't come in and feel chill and comfortable in a positive, happy, pretty environment, then none of this works. And one person with a snarky face walking through or doing shampoos will kill it. Let alone, what it can do in the break room or the 
dispensary behind-the-scenes. So, personally, we've all become very protective of that positive culture, the willingness to learn culture.

The self-protective nature of the organizational culture was mentioned several times by various employees during the interview process. While not everyone used the term selfprotective, it was described as a culture in which being coachable is important to ensure that, "we're not going to get someone in here who thinks they know it all and doesn't want to do it this way," with the phrase this way referring to the existing culture. This statement from the Director of Education alluded to the importance of protecting the culture that is in place. Additionally, a senior stylist commented, "At Castlewood it's all about...growing and goals and just being the best in the game. And we all try to teach the younger ones why we think the same way." The desire to teach new employees why existing employees think the "same way" indicates a desire to protect the culture that is already in place.

\section{Raising Industry Perceptions - We Can All Get a Piece of the Pie}

Part of the formal mission statement for Beauty Factor products is "to raise the image of the beauty professional in modern society." This mission statement exemplifies Bill's commitment to raising the standard of the hairdressing industry through not only his own salon, but through those with whom he is involved. His product, manufacturing, and consulting businesses serve as mechanisms to allow him and his salon employees to make an impact on the industry in a positive way. Employees of the salon are expected to commit to the learning culture, and are given opportunity to participate in the other areas of business to contribute to the improvement of the industry through education and consulting. The product line offers additional career opportunity as Bill describes: 
Part of what helps us over here at the salon is the fact that I am still engaged in the product side of it as well. That is an avenue of career development that these other salons can't bring to the table. There is a career path that is presented to every employee from the day they begin the job. It is available to every employee, but they must be willing to step up to the plate and work hard. I'll show them the career, but how far they want to go is up to them.

During one particular observation period, Bill discussed a news story regarding a celebrity who paid $\$ 2,000$ for a haircut. He talked about how great this was for hairdressers and for the salon industry, as a whole. He described how prices "trickle down" from metropolitan areas to create the possibility for those in smaller, outlying areas to charge more for haircuts. Rather than complaining about pricing being limited by geographic regions, Bill encouraged the group that the "pie" is so big that they could all get a piece of it, as long as they were committed to working for it.

\section{A Career Path for Beauty Professionals - See Where Your Career Can Go}

This type of possibility thinking is what Bill says he hopes to inspire in current beauty school students with whom he and other salon leaders interact during their recruiting efforts. His vision comes full circle from the classroom to implementation when Bill is able to take new graduates as employees in the salon. By supporting their learning and growth, eventually they have the possibility to help raise the perception of the industry through the education they provide to other salons. One employee explained it as, "While our company grows, his other company is growing and the other one is growing. You can see where your career can go, as well." 
Bill says that because the salon promotes a career-thinking mentality, employees have the opportunity to develop their skills and ability more quickly than if the salon promoted a job-thinking mentality. This idea harkens back to Bill's early career experience when he was exposed to the possibility that hairdressing could be more than cutting hair to make a living. And to help others see the possibility that lies within choosing a career in the hairdressing industry is, according to Bill, the right thing to do.

[I do this] to leave a mark, for lack of a better way of saying it. I made a decision early on that I could either cut hair and earn a really handsome living - way over six figures - or I could create an organization to where I truly develop just absolutely outstanding hair designers. And then, through that, I can move my philosophy of things that I have learned into a larger arena - and then the product company comes into play and that makes the arena even way larger - so it allows me to do what I believe is the right thing for my industry. And when you run your business correctly, you can truly contribute to society. And you can truly make a difference in lots of lives.

The ability to provide a career path for his employees allows Bill to alter the perception of the hairdressing industry. Throughout conversations with both Bill and his employees, it was clear that this commitment to shift the perception of the hairdressing industry, from one of negative perception to positive, is a high priority.

\section{Smith Enterprises as a Learning Place - Beyond the Beehive}

As the culture within Castlewood Salon has grown and thrived, other opportunities have emerged simultaneously. The Beauty Factor and Bond for Men product companies eventually created an opportunity for Bill to establish an in-house 
distribution and consulting company. These additional ventures provided opportunities for employees within the salon to learn and grow and expand their horizons beyond that of their primary role within the salon. Many of the stylists within the salon work with the product and consulting companies to educate other salons regarding technical skills and general business principles. Castlewood Salon does not keep their operating details secret or exclusive. Instead, they believe in proliferation of those practices throughout the industry to allow other salons to achieve success as they have. This benefits both the organization and the industry as a whole. The beauty industry, in particular hairdressing, is plagued by the perception that those doing this type of work lack intelligence and choose their profession based on limited options for other types of work. According to Bill:

The industry has been perceived as being dummies for so long that some stylists come in thinking they're a dummy. When we look at the way the media has portrayed the hair industry we see the example of the popular film Grease. There was a scene where the young lady was called a "beauty school dropout." So what happened is that particular movie suggested that the poor kid couldn't even make it in hairdressing so she should get back to high school. Right? They made it funny. They made it cute. They made a pink beehive. It was ridiculous, and it was a slap in our face, in my opinion.

Because the industry has struggled with negative perceptions throughout its history, as Castlewood Salon imparts specific principles that have contributed to its success, it serves to raise the performance and, thus, the perception of the industry as a whole. 
Though in the beginning Bill was operating only a salon, he knew that his vision included, "going from Bill who has a little salon in Louisville who is a killer haircutter, to Bill the speaker, the leader, the trainer, and the product manufacturer." The salon's organizational learning culture has been an important element in achieving this vision. As employees in the salon developed their skills and improved their abilities, other opportunities began to materialize. As Bill established the product companies, he provided salon employees opportunities to educate client salons. Castlewood Salon itself became a learning mechanism, both for employees working within the salon, and for those salon owners and employees coming in for various training programs offered by the product company.

\section{Creating a Professional Perception}

As evidenced by things like the mission of the product companies and the professional atmosphere that meets each person as they enter Castlewood Salon, the goal of having beauty professionals viewed as highly skilled and professional is important to Bill's mission. He is adamant that being a hairdresser is often perceived by society as a kind of second-class career, and it is not often someone's first choice of career. This belief seems to fuel Bill's determination to help people believe in themselves when they have chosen this field. To counteract the popular notion that beauty professionals lack professionalism, Bill has demonstrated a commitment to providing training and learning that not only teaches technical skill so that the stylist can be the best in their field but also business acumen that allows the stylist to be a top professional. Part of this comes from elevating the employee's self-esteem. Bill describes this process: 
The bulk of the young people that come into the hair industry usually don't feel that they're worthy of college or smart enough for college. Or there wasn't any money for college or it was like, "I gotta do something for crying out loud, so I'll be a beautician." At the end of the day I come from the school of Zig Ziglar. He said the number one disease in the world is lowered self-esteem. If we can lift people's self-esteem, we will conquer all. And that has been with me my whole life [since] I first heard it. And he's right. So, for every young person that comes in there that's unsure of herself or won't look people in the eye, or who is scared to talk, we conquer that.

One employee, when asked to describe the culture of the salon, stated, "We want to be looked at in the same manner as doctors and lawyers.” This type of statement was common among the descriptions of the culture provided by employees, evidencing a commitment to the type of professionalism that one might typically expect from a career other than hairdressing. Employees are expected to act in a professional manner rivaling that of doctors, lawyers, and other professionals. One employee states the following:

I think that, in general, our goal is... really it's about the reputation... making not just our salon's reputation... because our salon has a good reputation... and it shows that salons can have good business and can be professional and all of those sorts of things. So I think we're really influenced by wanting the professionalism in the salon world and, even though we're just one salon, if we can do it then obviously it's going to change people's perception and the reputation of our industry. 
Employees of Castlewood Salon demonstrated support for educating other salons in the name of raising the perception of the industry. Dana, the front desk supervisor at Castlewood, reflects, "Where we differ here is that we not only want to make sure that our staff is well educated but we want to make sure that all the other salons are educated, which I think is great."

During one of the many educational workshops offered by Beauty Factor products that I attended, Bill led the participants through a chant that encourages them to consider their value in contemporary society. He asks participants to repeat the phrase, "Without us," loudly after each statement he makes. The chant proceeds as follows:

There would be no weddings... WITHOUT US!

There would be no Hollywood films made...WITHOUT US!

There would be no proms...WITHOUT US!

There would be no funerals...WITHOUT US!

There would be no commercials made...WITHOUT US!

This commitment to raising the perception of the beauty industry is evident in all that Bill does with both his own employees and those with whom he consults. This vision is much bigger than his own success or that of his employees. He demonstrates commitment to his industry and longs to see the day when the beauty professional is admired and viewed within society as a professional person worthy of the respect of others for what they contribute to society. At the end of an interview, Bill closes with this:

I'll close on this, I love it. I heard a successful salon owner speaking to a group of business owners and he said, "You know, when I wake up in the morning I think 
of how exciting would it be for one of these young people to choose hairdressing over law school." And I'm just like, yeah man.

\section{Summary}

Bill Smith's commitment to the value of learning influenced the organizational culture of each of his businesses. The learning culture was established in the early years of Castlewood Salon. It was identified as the main influence on the salon's growth and success. It continued its influence on the subsequent business entities established as a result of that growth. While Bill was responsible for the initial establishment of the learning culture, as he recruited employees with whom the cultural values resonated and as those employees were developed within the culture, it became self-sustaining. Less leadership influence was required to keep the culture alive. As the culture proved successful in enabling business growth and success within Smith Enterprises, Bill and his employees began conveying this information to others in the hairdressing industry. Through the education and business consulting elements of Smith Enterprises, Bill and his employees are able to educate other salons regarding how an organizational learning culture can facilitate business growth and success. 


\section{CHAPTER SIX}

\section{CONCLUSIONS}

Davenport and Prusak (2000) suggest that understanding the role of knowledge in organizations may help answer the question of why some firms are consistently successful. Similarly, Ellinger, Ellinger, Yang, and Howton's (1999) study findings suggest that there is a positive association between the concept of an organizational learning culture and a firm's financial performance. To add to this body of scholarship, this study sought to understand an organizational learning culture within a successful small business. The study was guided by the following central research question: How does an organizational learning culture occur within a successful small business? Subquestions explored (a) the specific elements of the organizational learning culture, (b) employees' description of their experience with the organizational learning culture, (c) how the organizational learning culture contributes to business success, and (d) what happens to the organizational learning culture as the business grows.

Swanson and Holton (2009) claim that whole system change begins with a commitment to the in-depth study of a group or groups. It is hoped that the in-depth study of this research case of Smith Enterprises will provide specific evidence of practices that may help other small businesses experience whole system change. This final chapter begins with a review of the study's conceptual framework followed by conclusions from 
the study. Attention is then turned to the implications for HRD practitioners. Finally, limitations of the study are discussed and directions for future research are suggested.

\section{Revisiting the Conceptual Framework}

Scholars of HRD advocate for a strategic approach, which shifts the perspective of HRD from training to learning (Graham \& Nafukho, 2008: Rigg \& Trehan, 2002; Ruona \& Gibson, 2004). According to Ruona and Gibson's (2004) $21^{\text {st }}$ Century HR model, this shift in perspective moves HRD practices from an operationally reactive state to a strategically proactive state. In an operationally reactive state, the organization is likely implementing basic employee training, at best. However, in a strategically proactive state, the organization is more likely working to create future, strategic opportunities, such as those that embrace a more holistic view of employee learning. This strategically proactive approach to HRD is often termed organizational learning.

It is common for small businesses to adopt an operationally reactive approach to HRD (Choueke \& Armstrong, 1998; Covin, Green, \& Slevin, 2006). The limited resource environment within which many small businesses operate, along with limited knowledge of HRD practices on the part of the owner-manager, may deny employees the necessary tools to improve job performance (Sadler-Smith, Down, \& Field, 1999; Huang, 2001). This short-term focused approach to HRD results in inexpensive and ineffectively applied solutions that do little to improve performance (Sadler-Smith, Down, \& Field, 1999). A decision to rely on the job itself to serve as the means by which a new employee learns is but one example of this type of approach to HRD (Huang, 2001). In many instances HRD is dismissed by small business owner-managers as unnecessary or unattainable (Hill, 2004). 


\section{Elements of the Conceptual Framework}

The conceptual framework used for this study draws upon Kuchinke's (2003) Contingent HRD framework, Ruona and Gibson's (2004) Twenty-first Century HR framework, and Crossan, Lane, and White's (1999) 4I Framework of Organizational Learning. Kuchinke's (2003) framework offers one especially salient point that is relevant to the conceptual framework. He contends that small organizations often satisfice rather than maximize employee learning and performance needs. Said another way, rather than attempting to identify the best possible alternative in terms of employee learning, small organizations typically invest conservatively, if at all. Ruona and Gibson (2004) suggest that it is a focus on organizational learning that has the potential to be the hallmark of strategically proactive HRD. Finally, Crossan, et al. (1999) assert that to achieve growth through the process of strategic renewal, a business must explore new ways of operating (feed-forward) while continuing to exploit what they have already learned (feedback).

Building upon the work of these scholars, the conceptual framework designed for this study suggests that small businesses can move toward a more strategically proactive approach to HRD, through a focus on organizational learning, regardless of limited resources. If organizational learning is embraced by a small business, and its central tenets such as improving effectiveness (Huber, 1991), striving for continual learning (Senge, 1991), and detecting and correcting error (Argyris, 1977) upheld as core values, an organizational learning culture can emerge. It is at this point that HRD can be viewed as a support mechanism for the organizational learning culture. Instead of being viewed as a tool or something to be done, HRD - formal or informal, intentional or incidental - 
exists as an outward manifestation of the learning culture. A more in-depth discussion of the framework can be found in the literature review section of this study.

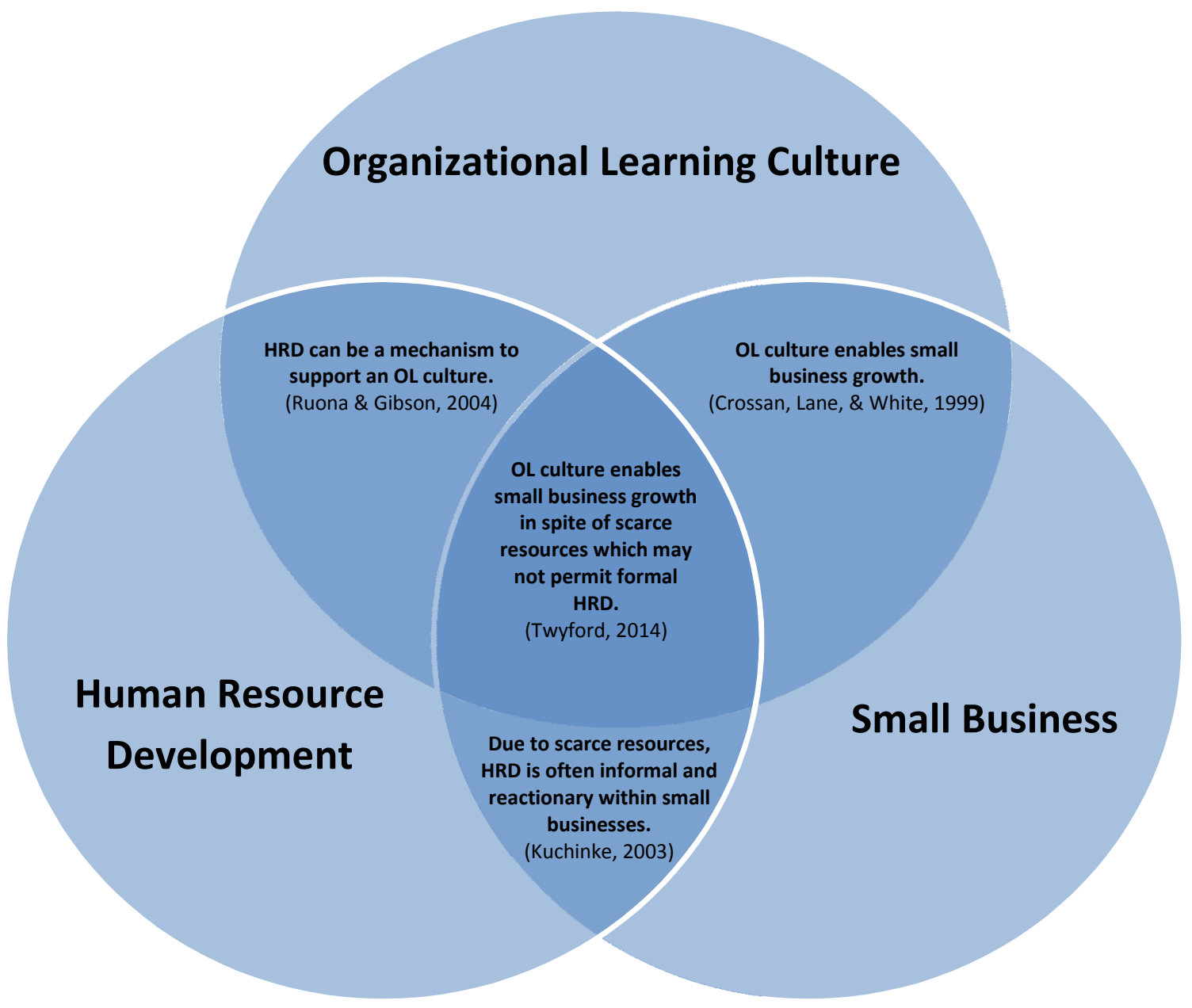

Figure (15). Small Business Organizational Learning Culture Conceptual Framework

\section{Case Support for the Conceptual Framework}

In the case of Castlewood Salon, it was not financial resources that necessarily

limited the implementation of HRD activities during the early years of the business.

Instead, Bill Smith exemplified the type of small business owner-manager described by

Hill (2004) in that he lacked understanding of the practice of HRD altogether. He also

had limited influence over the performance of his salon stylists which stymied his ability to implement any type of approach to employee learning. Thus, not only did Castlewood 
Salon not have the ideal type of approach described by Ruona and Gibson (2004) as strategically proactive, HRD practices were absent from the business context entirely. After experiencing two business failures during the early years, Bill made the decision to shift the course of Castlewood Salon. This shift ushered in the establishment and growth of an organizational learning culture. While Bill and other employees likely did not articulate the organization's early culture as a learning culture, the core values that were identified and upheld by Bill evidenced a commitment to learning. These core values underpinned the learning culture that emerged from the shift in how the business operated. Within this culture, employees began to increase their technical and business skills which resulted in business growth. The growth of Castlewood Salon could be seen in the increase in the client base, an increased pricing structure, and the salon's increased presence in local media (television and print ads). Evidence from this case study supports the claims of several HRD scholars who insist that an organizational learning culture can serve as a mechanism to enable small business growth (Crossan, Lane, \& White, 1999; Davenport \& Prusak, 2000; Macpherson \& Holt, 2007).

Soon, HRD activities began to emerge in Castlewood Salon as a support mechanism for the organizational learning culture. Perhaps the clearest example of this can be seen in the salon's apprentice training program. Interestingly, while Bill had no specific HRD knowledge or expertise, he was able to create the program based on his desire to build the knowledge and skill of his workforce. The apprentice training program can be considered a strategically proactive approach to HRD, as it embraces a more holistic view of employee learning. The program strives to produce highly skilled employees rather than simply serving as a means to an end to train newly hired 
employees. At the same time, the program produces opportunity for employees to assimilate the organizational culture. This results in increased employee support for the goals and mission of the business.

A commitment to learning and growth influenced Bill to implement HRD activities. In the case of Smith Enterprises, beginning with Castlewood Salon and evolution of subsequent businesses, an organizational learning culture enabled them to achieve business growth despite the limitations inherent to being a small business. The various HRD activities within the organization existed as an outward manifestation of, and as support for, this organizational learning culture. Thus, the case supports the core premise of the conceptual framework suggesting that an organizational learning culture enables small business growth in spite of scarce resources, which may not permit formal HRD activities.

\section{Research Conclusions}

The growth of Castlewood Salon, and the subsequent businesses generated as a result, demonstrated a commitment to learning. The salon, under Bill's leadership and ownership, experienced business failure early in its history. However, Bill treated the business failure as a learning experience. Several scholars suggest that when information is gathered about a change, translated, and then action taken to implement new learning, organizational learning occurs (Graham \& Nafukho, 2007; Skerlavaj, Stemberger, Skrinjar, \& Dimovski, 2006; Wyer, Mason, \& Theodorakopoulos, 2000). This commitment was an early indication of Bill's personal willingness to learn. This characteristic influenced the shape of the culture within the salon as he rebuilt the 
business from a place of personal reflection and implementation of the things that were learned from business failure.

\section{Leadership and Culture}

Schein (2006) suggested that "the only thing of real importance that leaders do is to create and manage culture" (p. 11). He distinguished the difference between leadership and management as the difference between creating and managing culture (leader) and acting within culture (management). In the beginning years of Castlewood Salon, Bill Smith created a very specific organizational culture, one that valued learning. He did not identify what he was doing as creating an organizational culture or as HRD practices. When he discusses this time in his leadership journey he talks simply about the values that he was committed to implementing in his business. He knew that he wanted the values to be embraced and lived out, but he was unable to identify this as creating an organizational culture. Yet, the process of identifying and articulating these values had to begin with Bill. He then had to work to identify employees who would support the values. Through the process of recruiting employees with whom the vales resonated, Bill built the organizational culture of Castlewood Salon and, subsequently, Smith Enterprises.

During the years before Bill shifted course to change the business structure of Castlewood Salon, stylists operated within a booth-rental structure. During this time, an unintentional culture emerged. Stylists viewed themselves as independent contractors who were not accountable to Bill. At this point, he was able to operate only in a management capacity. Rather than creating and managing a culture, he was acting within a culture. It was not until he made the decision to shift the course of the business, that he 
began doing the work of leadership by intentionally creating the culture. This included implementing a new business structure which allowed him more influence over the values of the organization.

Similar to Schein's (2006) assertion that management acts within culture while leadership creates and manages culture, Ellinger, Watkins, and Bostrom (1999) suggest that organizational leaders must transition from a role of manager to a role of facilitator of learning in order to create a learning organization. In Bill's case, he made the transition from manager to facilitator of learning early in his career as owner and operator of Castlewood Salon. Based on their research findings, Ellinger, et al. suggested that there are two clusters of behaviors that managers enacted when they viewed themselves as facilitators of learning. The two behavior clusters, empowering and facilitating, included several behaviors that can be seen in the case of Bill's leadership. Specifically, the empowering cluster refers to behaviors that encourage employees to assume personal responsibly for their learning. Bill's insistence that employees assume responsibility for their own learning and growth exemplifies this behavior. Ellinger, et al. suggested that within the facilitating cluster refers to behaviors that offer guidance and support to employees to foster learning and development. Considering those ideas, several behaviors align with Bill's leadership. Specifically, Bill Smith was observed as creating and promoting a learning environment, setting and communicating expectations, and providing feedback to employees.

\section{Commitment to Learning and Growth}

Crossan, Lane, and White's (1999) 4I Framework of Organizational Learning addresses the phenomenon of organizational renewal as it relates to learning. 
Specifically, the authors suggested that strategic renewal requires organizations to explore new ways of operating (feed-forward) while continuing to exploit what they have already learned (feedback). The case of Smith Enterprises is one in which organizational renewal appears to have occurred after the initial failure of the business. Through the process of exploring new ways of doing business, along with learning from the failed business attempt, Bill Smith was able to transform, or renew, the organization.

This experience of achieving success after two previous failures solidified Bill's commitment to learning. Due to the impact that this experiential learning had on Bill's personal and professional growth, the value of learning was evident to him. Thus, he began to appreciate learning in a way he had not prior to his business failure. As founder of the organization, Bill's influence on Castlewood Salon was strong (Spence \& Rutherfoord, 2001). Thus, his influence was powerful in shaping the organization's proclivity for learning (Kitching, 2007; Paige, 2002; Vera \& Crossan, 2004). The organizational learning culture was established by him, as leader, and sustained through his commitment to the core values that underpinned the culture.

Research conducted by Rigg and Trehan (2002) found that, among the study's sample of small businesses, there was a strong shared belief that improvement was a direct outcome of learning. The culture of Smith Enterprises was built upon the premise that learning would lead to improvement. Several times Bill referred to his philosophy of incremental improvement - the belief that, each day, employees' skills and ability should improve at least incrementally. This expectation influences employees to embrace and capitalize on opportunities for learning and improvement. It also leads employees to identify themselves as lifelong learners. While new employees agree to remain in a 
student learning role for their first year of employment in the apprentice training program, senior employees similarly identify themselves as students as they remain committed to the philosophy of incremental improvement.

Bill Smith's commitment to an organizational learning culture influenced the development of various learning programs and initiatives. Research conducted by Ellinger and Cseh (2007) identified several catalysts for facilitating learning in their case study of a manufacturing firm in the eastern U.S. One major contextual factor that their findings suggested positively influenced facilitation of employee learning included learning-committed leadership/management. The authors go on to suggest that leaders and managers who are committed to learning do two things: role model learning and development by example (walk the walk) and encourage, support, and reinforce the importance of developing others (talk the talk) (Ellinger \& Cseh, 2007, p. 448). This finding aligns with evidence presented in the case of Smith Enterprises. All of the learning initiatives within Smith Enterprises exist, not only as an outward manifestation of the organization's learning culture, but because of the personal commitment of the organization's leader to support learning through serving as a role model for learning.

\section{An Organizational Learning Culture Enables Business Growth}

Ellinger, Ellinger, Yang, and Howton's (1999) suggested that there is a payoff for those that implement learning organization strategies and practices. While their research was exploratory in nature, they were able to establish a positive connection between those firms embracing concepts consistent with learning organization literature and the firm's financial performance. In the case of Smith Enterprises, the organizational learning culture led to greater financial performance. This increased financial performance was the 
result of a highly skilled workforce. As employees' knowledge and skills improved, so too did the service they could provide to clients. The reputation of the business grew, evidenced by an increase of new clients referred to the salon by existing clients, producing greater demand. Based on growth of the salon business, Bill was able to expand into other industry areas such as hair care products, industry education, and business consulting. These opportunities benefitted not only Bill as owner-manager of Castlewood Salon, but also the employees.

Employees of Castlewood Salon continued to develop their business knowledge and technical skills. This allowed them, most at a young age, to surpass the knowledge and skill level of many older, more veteran stylists. There were few, if any, other stylists that could compete with the knowledge and skills of Castlewood Salon employees. Thus, opportunity was created for Castlewood Salon employees to educate other salons through the Beauty Factor and Bond for Men Product lines. The opportunity allowed salon employees to impart knowledge and skills amassed over the course of their time at Castlewood Salon to other salons seeking this information. Wilson (2005) proposed that one of the most important contributions that HRD can make within an organization is enabling that organization to learn more quickly than its peers. Smith Enterprises is an exemplar of this notion. The ability of the organization to learn more quickly than its peers has provided opportunity for salon employees to share this learning with other salons. Of the more than 500 salons within fifty miles of Castlewood Salon, Bill and his employees represent the only salon to offer education classes that are based on the technical skills and business knowledge that salon employees have gained over time. 
In particular, this benefit of Castlewood Salon's highly skilled workforce, which was developed over time through the organizational learning culture, allowed employees to contribute to the success of their industry by disseminating the practices of Castlewood Salon throughout their peer group. This offered benefit for everyone involved, from Bill to the employees. Income opportunities were provided to the salon as education classes were offered for a fee, while career growth opportunities were provided to employees. It also enabled the expansion of the Smith Enterprises, Incorporated as Castlewood Salon spawned additional businesses.

\section{Implications for Practice}

A learning culture begins with leadership commitment to the learning and development of employees (Graham \& Nafukho, 2008). This commitment may require delaying immediate rewards in order to gain long-term success. Because the small business environment is often characterized by limited resources (Hill, 2004), as well as the necessity for each decision to result in immediate benefit (Huang, 2001), this type of approach to business can seem counterintuitive and even risky. Yet it is this type of approach that allowed Castlewood Salon, and its subsequent business entities, to achieve business growth and success. It was the delaying of immediate income opportunities in favor of developing employees' skills and abilities that allowed the organization to achieve a greater level of competency than it would have otherwise.

\section{Apprenticeship Training Programs}

In the case of Smith Enterprises, Bill requires each new stylist employee of Castlewood Salon to spend a year exclusively in a learning role as an apprentice assistant. While he could allow new employees to begin serving clients - they have the necessary 
state licensing and training - he foregoes that option to invest in their learning and growth. This approach exemplifies the learning culture present within the organization. The shared belief that learning and growth are more important than short term gains underpins the culture and reminds employees of the expectations in place within the organization.

Bill's approach to establishing and maintaining a learning culture provides evidence that a commitment to employee learning does not always require significant investment of financial resources. The training and development that occurs within the apprentice training program is conducted in several ways that do not require any resource investment other than time. Approaches to learning such as on-the-job training, personal reading assignments, and a commitment to having employees share learning with one another do not require a financial investment from the organization. Instead, it is a commitment to employee learning that produces an expectation that employees should seek to learn at every opportunity.

For HRD practitioners, apprentice training programs, such as the type found within Castlewood Salon, can serve as a useful model for other small businesses looking to provide learning and development. In fact, these types of programs are becoming popular as a method of providing job training in various different industries. The U.S. Department of Labor, in partnership with the U.S. Department of Education, recently launched the Registered Apprenticeship-College Consortium. This new partnership provides graduates of Registered Apprenticeship programs with the opportunity to apply on-the-job and classroom training toward college credits. According to a recent Wall Street Journal article (2014), Apprenticeships Help Create Jobs. So Why Are They in 
Decline?, apprenticeships can provide a particular match between the skills employees require and the training that employees receive. In the same article, one small business owner states that the apprenticeship model within his company helps people see a career path as well as see the opportunities ahead and the clearly delineated ladder of skill acquisition and salary increases (Weber, 2014). This type of model, and its purpose, is similar to the one which has brought business success to Castlewood Salon.

\section{Philosophies, Behaviors, Practices, and Artifacts}

While a learning culture begins with leadership commitment, it is sustained through the philosophies, behaviors, practices, and artifacts that promote the culture (Schein, 2006). Torres and Preskill (2011) define culture as "patterns of behavior and thinking practiced and shared between those within an organization,” (p. 36). Building and maintaining an organizational culture requires that leaders clearly identify core values and then act in accordance with those values while also encouraging and holding accountable employees to do the same. It begins with building a workforce that represents those core values and nurturing employees as they grow to enable them to represent the core values of the culture. By building his workforce through intentional practices that illuminated those employees who would be a good "fit" for the organizational culture, a workforce was cultivated that was willing to embrace and nurture the culture.

One of the major ways in which this organization communicates the core value of learning is by asking employees to spend their first year of employment as "students" in a formal learning role. This commitment to learning and growth sets the tone for the employee's career at Castlewood Salon. It begins the process of what Bill describes as 
"beating the drum." In the beginning of an employee's career it is more likely that the core values of the culture need to be reinforced by leadership. However, over time as they develop more experience, they are able to operate without the need for external reinforcement. Once the employee embraces the culture, they are able to sustain it through living by the core values which underpin the organizational culture.

\section{Leadership and Employee Commitment}

HRD practitioners can help small business owner-managers understand that an organizational learning culture can contribute to business growth. However, this type of culture is only possible with a commitment from top leaders and employees. The case of Smith Enterprises provides evidence that the organizational learning culture began with a commitment from Bill Smith as owner-manager. It was not until he shifted the business model to provide himself greater influence as a leader that the type of culture he envisioned was embraced. Without his commitment and influence, the learning culture would not have been established and nurtured.

In addition to leadership commitment, it was the learning culture that provided opportunity for growth of the business, through growth of the employees. This is a significant opportunity for HRD practitioners to help small business owner-managers understand how they might leverage their own resources to achieve growth despite business environment limitations. For example, it is not necessary that a small business have access to financial resources above and beyond what it takes to operate their business in order to create and sustain a culture that leads to business growth. To provide this insight to small business owner-managers, as well as to coach them on the nuances of 
implementing such a culture, is a contribution that HRD practitioners stand to make in the small business sector.

\section{Limitations}

This research presents an instrumental case that exemplifies a small business within which a learning culture has been fostered and the results of which have influenced business growth. This is uncommon among the small business community which is known to typically conduct business from a reactionary stance, with little focus on long-term endeavors such as culture and employee development (Hill, 2004). From that standpoint, this research offers several valuable contributions. However, as is inevitable with any research project, limitations exist.

While Yin (2009) presents rationale for conducting a single-case study which suggests that single-case design is appropriate where the case represents an extreme or unique case, a single-case study also presents some limitation. Specifically, while instrumental case sampling facilitates logical generalization and maximum information application to other cases (Creswell, 2013), every case exists within a unique context. The findings from an instrumental case study are useful for researchers looking to better understand the phenomenon being studied, however it is prudent to acknowledge that the context of a single case, to some extent, limits a researcher's ability to generalize the findings from one case to another.

A second limitation of this study lies within the researcher's background as an organization development practitioner in a small business. This experience has the potential to bias not only how the researcher views the case but also the analysis and reporting of the data. This was acknowledged early in the research proposal phase in 
order to minimize the possibility that this bias would be present. Throughout the data collection and analysis phase of the research project the researcher maintained a journal which allowed thoughts, observations, and insights to be recorded. The content of the entries was shared with senior research advisors to test interpretations and minimize bias. To further mitigate the potential for bias, several different data collection methods including interviews, observations, and document analysis were employed to triangulate data.

Finally, the study participants within this case were all current employees of Smith Enterprises. During interviews, no employee mentioned anything negative regarding the organization's core values or the organizational culture. Likely this is due to the business success that the organization's core values and culture have fostered. However, because of the protective mechanism of the culture, it is possible that employees felt uncomfortable dissenting or may have left the organization without saying so. With nothing but positive comments in support of the culture, it is easy to question whether the comments were all completely authentic. Thus, without interviewing former employees, it is impossible to understand the potential shadow side of the organization's culture.

\section{Future Research}

This study aimed to explore the learning culture of a successful small business. According to Yin (2009), the exploratory nature of a study can lead to the development of pertinent assertions based on the case findings. The findings and assertions based on this exploratory case study provide evidence that, at least in this case, a learning culture can 
lead to growth for a small business. However, future research could serve to strengthen, validate, or even dispute this study's findings.

One area that could be valuable for investigation is with additional small businesses that identify having learning cultures. Findings from additional research in this area would serve to both strengthen and refine this study's conclusions. Alternatively, it might be valuable to understand those businesses that have tried and failed to implement a learning culture. While we understand how the learning culture of Smith Enterprises, Incorporated was established and nurtured, it would be useful to understand the story of another business wherein the establishment of a learning culture was not as successful. In addition to investigation of other small businesses with established learning cultures, it is suggested that future research focus on additional small businesses in different industries. Each business is inevitably influenced by the many contextual factors present within their industry. Kuchinke (2003) suggests that organizations are influenced by industry characteristics including technical, regulatory, institutional, and organizational size. This case study operated within the hairdressing industry which brings with it contextual factors such as negative stereotypes of those working within the industry. A small business in the hospitality industry might be influenced by much different contextual factors. Thus, looking at the phenomenon of learning cultures in small business across industries would be helpful.

While the phenomenon of an organizational learning culture turned out to be a positive characteristic of the case within this research, there is reason to investigate whether there is a shadow side to this type of culture. The feedback from study participants was overwhelmingly positive. So much so that it was necessary to take a step 
back and confer frequently with the study's senior research advisors to ensure that the case was being represented accurately and without bias. The overwhelming support for the organizational culture is likely due to Bill Smith's intentional approach to hiring and building his workforce to include only those individuals who believe in the type of culture that is present within the organization. However, what happens to those employees who do not agree with or fit into this type of culture? It would be valuable to investigate the experiences and perspectives of those employees who have been part of an organization with an established learning culture and who did not have a positive experience. Are there areas that are not necessarily positive that are being missed due to the overwhelmingly supportive nature of the majority of employees in this type of case?

Investigation using additional research approaches would be useful. It is suggested that the more that research seeks to explain how or why a phenomenon works, the more relevant the case study method is (Yin, 2009). However, case study research is not the only research approach that could provide value to understanding the phenomenon of organizational learning culture. Mixed methods research combining both qualitative and quantitative research approaches would be helpful in providing a more comprehensive view of this phenomenon in an organizational setting, while also using a qualitative, perhaps phenomenological, approach to understand employee experience of the culture, would be helpful to broadening this area of research.

Lastly, given the success of the apprentice training program in Castlewood Salon, it would be interesting to investigate the business metrics associated with this type of program. For example, by how much does a program of this nature reduce turnover? Or, what are the exact financial outcomes provided by this type of program? This case does 
not provide such information as Castlewood Salon does not measure program outcomes other than through employee skill attainment. It would be helpful in advocating for this type of program to be able to provide financial metrics regarding the benefit of an apprentice training program.

\section{Summary}

Graham and Nafukho (2008) suggest the need to move beyond traditional HRD practices to foster an environment that facilitates organizational learning. This case study provided evidence that an organizational learning culture can manifest HRD practices that transcend the need for substantial investment of a small business's resources. What is more, this case provided evidence that an organizational learning can enable small business growth. In this case, the organizational learning culture began with Bill Smith's vision to transform the perception of an entire industry. This transformation, he realized, could only be achieved by embracing a commitment to learning.

This commitment to learning represented the essence of the culture of Bill's organization. Subsequently, strategic recruiting and hiring helped build the type of workforce that embraced the learning culture. The agreement that employees enter as students and remain lifelong learners produced further support for the culture. From this emerged important learning practices including a formal mentorship program, weekly classroom training, assigned book reading, and on-the-job training. As employees' knowledge and skills improved, the business grew and additional business opportunities were presented. From this, Bill's initial vision came full circle as employees were able to give back through educating other salons regarding the knowledge and skills they had 
amassed over time. This transformed not only Bill's organization, but the perception of the industry as a whole. 


\section{REFERENCES}

Angrosino, M. V., \& Mays de Perez, K. A. (2000). Rethinking observation. In N. K. Denzin \& Y. S. Lincoln (Eds.), Handbook of Qualitative Research (pp. 673-702). Thousand Oaks, CA: SAGE Publications, Incorporated.

Argyris, C. (1977). Organizational learning and management information systems. Accounting, Organizations and Society, 2(2), 113-123.

Ayyagari, M., Beck, T., \& Demirguc-Kunt, A. (2007). Small and medium enterprises across the globe. Small Business Economics, 29(4), 415-434. doi: $10.1007 / \mathrm{s} 11187-006-9002-5$

Balcaen, S., \& Ooghe, H. (2006). 35 years of studies on business failure: an overview of the classic statistical methodologies and their related problems. The British Accounting Review, 38(1), 63-93. doi: 10.1016/j.bar.2005.09.001

Barrett, R., \& Mayson, S. (2007). Human resource management in growing small firms. Journal of Small Business and Enterprise Development, 14(2), 307-320. doi: $10.1108 / 14626000710746727$

Bates, T. (2005). Analysis of young, small firms that have closed: delineating successful from unsuccessful closures. Journal of Business Venturing, 20(3), 343-358. doi: 10.1016/j.jbusvent.2004.01.003 
Beaver, G., \& Hutchings, K. (2005). Training and developing an age diverse workforce in SMEs: the need for a strategic approach. Education+ Training, 47(8/9), 592604. doi: 10.1108/00400910510633134

Brockbank, W. (1999). If HR were really strategically proactive: Present and future directions in HR's contribution to competitive advantage. Human Resource Management, 38(4), 337-352. doi: 10.1002/(sici)1099050x(199924)38:4<337::aid-hrm8>3.0.co;2-5

Cangelosi, V. E., \& Dill, W. R. (1965). Organizational learning: Observations toward a theory. Administrative Science Quarterly, 175-203. doi: 10.2307/2391412

Cardon, M. S., \& Stevens, C. E. (2004). Managing human resources in small organizations: What do we know? Human resource management review, 14(3), 295-323. doi: 10.1016/j.hrmr.2004.06.001

Carspecken, P. F. (1996). Critical ethnography in educational research. New York: Routledge.

Cherubin, H. (2005). Community Reinvestment Act: Assessing the distributio of small and minority business in urban America, 2000. Retrieved from ProgQuest Digital Dissertations. (UMI Number: 3190019)

Choueke, R., \& Armstrong, R. (1998). The learning organisation in small and mediumsized enterprises: A destination or a journey? International Journal of Entrepreneurial Behaviour \& Research, 4(2), 129-140. doi:

$10.1108 / 13552559810224585$

Covin, J. G., Green, K. M., \& Slevin, D. P. (2006). Strategic process effects on the 
entrepreneurial orientation-sales growth rate relationship. Entrepreneurship Theory and Practice, 30(1), 57-81. doi: 10.5465/ambpp.2005.18778648

Creswell, J. W. (2013). Qualitative inquiry and research design: Choosing among five approaches. SAGE Publications, Incorporated.

Crossan, M. M., \& Berdrow, I. (2003). Organizational learning and strategic renewal. Strategic Management Journal, 24(11), 1087-1105. doi: 10.1002/smj.342

Crossan, M. M., Lane, H. W., \& White, R. E. (1999). An organizational learning framework: from intuition to institution. Academy of management review, 522537. doi: $10.2307 / 259140$

Crossan, M. M., Lane, H. W., White, R. E., \& Djurfeldt, L. (1995). Organizational learning: Dimensions for a theory. International Journal of Organizational Analysis, 3(4), 337-360. doi: 10.1108/eb028835

Crutzen, N., \& Van Caillie, D. (2008). The business failure process: An integrative model of the literature. Review of Business and Economics, 53(3), 287-316.

Dahlberg, K., Drew, N., \& Nyström, M. (2001). Reflective Lifeworld Research. Studentlitteratur, Lund.

Davenport, T. H., \& Prusak, L. (2000). Working knowledge: How organizations manage what they know. Harvard Business Press. doi: 10.1145/347634.348775

Devins, D., Gold, J., Johnson, S., \& Holden, R. (2005). A conceptual model of management learning in micro businesses: implications for research and policy. Education+ Training, 47(8/9), 540-551. doi: 10.1108/00400910510633099

Dobbs, M., \& Hamilton, R. T. (2007). Small business growth: Recent evidence and new 
directions. International Journal of Entrepreneurial Behaviour \& Research, 13(5), 296-322. doi: 10.1108/13552550710780885

Ellinger, A. D., \& Cseh, M. (2005). Contextual factors influencing informal learning in a workplace setting: The case of "reinventing itself company". Human Resource Development Quarterly, 16(3), 389-415. doi: 10.1002/hrdq.1145

Ellinger, A. D., Ellinger, A. E., Yang, B., \& Howton, S. W. (2002). The relationship between the learning organization concept and firms' financial performance: An empirical assessment. Human Resource Development Quarterly, 13(1), 5-22. doi: 10.1002/hrdq.1010

Ellinger, A. D., Watkins, K. E., \& Bostrom, R. P. (1999). Managers as facilitators of learning in learning organizations. Human Resource Development Quarterly, 10(2), 105-125. doi: 10.1002/hrdq.3920100203

Fink, D. (1998). Guidelines for the successful adoption of information technology in small and medium enterprises. International journal of information management, 18(4), 243-253. doi: 10.1016/s0268-4012(98)00013-9

Garavan, T. N., Morley, M., Gunnigle, P., \& Collins, E. (2001). Human capital accumulation: the role of human resource development. Journal of European Industrial Training, 25(2/3/4), 48-68. doi: 10.1108/eum0000000005437

Gaskill, L., Van Auken, H. E., \& Manning, R. A. (1993). A factor analytic study of the perceived causes of small business failure. Journal of Small Business Management, 31, 18-18.

Gergen, M. M., \& Gergen, K. J. (2000). Qualitative Inquiry: Tensions and transformations. In N. K. Denzin \& Y. S. Lincoln (Eds.), Handbook of Qualitative 
Research (pp. 1025-1046). Thousand Oaks, CA: SAGE Publications, Incorporated.

Glesne, C., \& Peshkin, A. (2010). Becoming qualitative researchers: An introduction. White Plains, NY: Longman.

Graham, C. M., \& Nafukho, F. M. (2008). Exploring Organizational Learning Mechanisms in Small-Size Business Enterprises. New Horizons in Adult Education and Human Resource Development, 22(1), 4-23. doi: 10.1002/nha3.10296

Graham, C. M., \& Nafukho, F. M. (2007). Culture, organizational learning and selected employee background variables in small-size business enterprises. Journal of European Industrial Training, 31(2), 127-144. doi: 10.1108/03090590710734354

Greiner, L. E. (1998). Evolution and revolution as organizations grow. Harvard business review, 50. doi: 10.1111/j.1741-6248.1997.00397.x

Gu, Q., Karoly, L. A., \& Zissimopoulos, J. M. (2008). Small business assistance programs in the United States: An analysis of what they are, how well they perform, and how we can learn more about them: RAND Institute for Civil Justice.

Hausman, A. (2005). Innovativeness among small businesses: Theory and propositions for future research. Industrial Marketing Management, 34(8), 773-782. doi: 10.1016/j.indmarman.2004.12.009

Headd, B. (2010). An analysis of small business and jobs. Retrieved from http://www.sba.gov/sites/default/files/files/an\%20analysis $\% 20$ of $\% 20$ small $\% 20 \mathrm{bu}$ siness $\% 20$ and $\% 20$ jobs $\% 281 \% 29 . p d f$ 
Hill, R. (2004). Why HRD in small organisations may have become a neglected field of study. In J. Stewart \& G. Beaver (Eds.), HRD in Small Organisations, Research and practice (pp. 8-25): Psychology Press.

Huang, T.-C. (2001). The relation of training practices and organizational performance in small and medium size enterprises. Education+ Training, 43(8/9), 437-444. doi: $10.1108 / 00400910110411620$

Huber, G. P. (1991). Organizational learning: The contributing processes and the literatures. Organization science, 2(1), 88-115. doi: 10.1287/orsc.2.1.88

Hudson, M., Smart, A., \& Bourne, M. (2001). Theory and practice in SME performance measurement systems. International Journal of Operations \& Production Management, 21(8), 1096-1115. doi: 10.1108/eum0000000005587

Hutchinson, P. (1999). Small enterprise: finance, ownership and control. International Journal of Management Reviews, 1(3), 343-365. doi: 10.1111/1468-2370.00018

Janesick, V. J. (2000). The choreography of qualitative inquiry design. In N. K. Denzin \& Y. S. Lincoln (Eds.), Handbook of Qualitative Research (pp. 379-399). Thousand Oaks, CA: SAGE Publications, Incorporated.

Kim, P. H., Aldrich, H. E., \& Keister, L. A. (2006). Access (not) denied: The impact of financial, human, and cultural capital on entrepreneurial entryin the United States. Small Business Economics, 27(1), 5-22. doi: 10.1007/s11187-006-0007-x

Kitching, J. (2007). Regulating employment relations through workplace learning: a study of small employers. Human Resource Management Journal, 17(1), 42-57. doi: 10.1111/j.1748-8583.2007.00019.x 
Kuchinke, K. P. (2003). Contingent HRD: Toward a theory of variation and differentiation in formal human resource development. Human Resource Development Review, 2(3), 294-309. doi: 10.1177/1534484303256885

Kvale, S., \& Brinkmann, S. (2008). Interviews: Learning the craft of qualitative research interviewing. Thousand Oaks, CA: SAGE Publications, Incorporated.

Lee, M. (2001). A refusal to define HRD. Human Resource Development International, 4(3), 327-341.doi: 10.1080/13678860126442

Lincoln, Y. S., \& Guba, E. G. (1985). Naturalistic inquiry. Thousand Oaks, CA: SAGE Publications, Incorporated.

Loan-Clarke, J., Boocock, G., Smith, A., \& Whittaker, J. (1999). Investment in management training and development by small businesses. Employee Relations, 21(3), 296-311. doi: 10.1108/01425459910273134

Lussier, R. N. (1996). Reasons why small businesses fail: How to avoid failure. The Entrepreneurial Executive, 1(2), 10-17.

Macpherson, A., \& Holt, R. (2007). Knowledge, learning and small firm growth: a systematic review of the evidence. Research Policy, 36(2), 172-192. doi: 10.1016/j.respol.2006.10.001

Mankin, D. (2009). Human resource development: Oxford university press.

Marsick, V. J., \& Watkins, K. E. (2001). Informal and incidental learning. New directions for adult and continuing education, 2001(89), 25-34. doi: 10.1002/ace.5

McLean, G. N., \& McLean, L. (2001). If we can't define HRD in one country, how can we define it in an international context? Human Resource Development International, 4(3), 313-326. doi: 10.1080/13678860110059339 
Miles, M. B., \& Huberman, A. M. (1994). Qualitative data analysis: An expanded sourcebook. Thousand Oaks, CA: SAGE Publications, Incorporated.

Morrison, A., \& Bergin-Seers, S. (2002). Pro-growth small businesses: learning “architecture”. Journal of Management Development, 21(5), 388-400. doi: $10.1108 / 02621710210426871$

Nadler, L. (1970). Developing human resources. Houston, Texas: Gulf Publishing Company.

Nafukho, F. M., Graham, C. M., \& Muyia, M. H. (2009). Determining the relationship among organizational learning dimensions of a small-size business enterprise. Journal of European Industrial Training, 33(1), 32-51. doi:

$10.1108 / 03090590910924360$

Paige, H. (2002). An exploration of learning, the knowledge-based economy, and ownermanagers of small bookselling businesses. Journal of Workplace Learning, 14(6), 233-244. doi: 10.1108/13665620210441199

Patton, D., Marlow, S., \& Hannon, P. (2000). The relationship between training and small firm performance; research frameworks and lost quests. International Small Business Journal, 19(1), 11-27. doi: 10.1177/0266242600191001

Rasheed, H. S. (2005). Turnaround strategies for declining small business: the effects of performance and resources. Journal of Developmental Entrepreneurship, 10(03), 239-252. doi: 10.1142/s1084946705000197

Rauch, A., Frese, M., \& Utsch, A. (2005). Effects of Human Capital and Long-Term Human Resources Development and Utilization on Employment Growth of 
Small-Scale Businesses: A Causal Analysis. Entrepreneurship Theory and Practice, 29(6), 681-698. doi: 10.1111/j.1540-6520.2011.00487.x

Rigg, C., \& Trehan, K. (2008). Critical reflection in the workplace: Is it just too difficult? Journal of European Industrial Training, 32(5), 374-384. doi: $10.1108 / 03090590810877094$

Robson, P. J., \& Bill, R. J. (2000). SME growth: the relationship with business advice and external collaboration. Small Business Economics, 15(3), 193-208.

Ruona, W. E., \& Gibson, S. K. (2004). The making of twenty-first-century HR: An analysis of the convergence of HRM, HRD, and OD. Human Resource Management, 43(1), 49-66. doi: 10.1002/hrm.20002

Ryan, G. W., \& Bernard, H. R. (2000). Data management and analysis methods. In N. K. Denzin \& Y. S. Lincoln (Eds.), Handbook of Qualitative Research (pp. 769-802). Thousand Oaks, CA: SAGE Publications, Incorporated.

Sadler-Smith, E., Down, S., \& Field, J. (1999). Adding value to HRD: evaluation, investors in people and small firm training. Human Resource Development International, 2(4), 369-390. doi: 10.1080/13678869900000039

Saru, E. (2007). Organisational learning and HRD: how appropriate are they for small firms? Journal of European Industrial Training, 31(1), 36-51. doi: $10.1108 / 03090590710721727$

Schein, E. H. (2006). Organizational culture and leadership (Vol. 356): John Wiley \& Sons.

SCORE (2014). Initiating Success for Small Businesses. Retrieved from http://www.score.org/SCORE_Initiatives 
Senge, P. M. (1997). The fifth discipline. Measuring Business Excellence, 1(3), 46-51. doi: $10.1108 / \mathrm{eb} 025496$

Senge, P. M., \& Sterman, J. D. (1992). Systems thinking and organizational learning: Acting locally and thinking globally in the organization of the future. European Journal of Operational Research, 59(1), 137-150. doi: 10.1016/03772217(92)90011-w

Škerlavaj, M., Štemberger, M. I., Škrinjar, R., \& Dimovski, V. (2007). Organizational learning culture—-the missing link between business process change and organizational performance. International Journal of Production Economics, 106(2), 346-367. doi: 10.1016/j.ijpe.2006.07.009

Spence, L. J., \& Rutherfoord, R. (2001). Social responsibility, profit maximisation and the small firm owner-manager. Journal of Small Business and Enterprise Development, 8(2), 126-139. doi: 10.1108/eum0000000006818

Stake, R. E. (2006). Multiple case study analysis. New York: Guilford Press.

Swanson, R. A., \& Holton, E. F. (2009). Foundations of Human Resource Development (2 ed.): Berrett-Koehler Publishers, 2009.

Torres, R. T., \& Preskill, H. (2001). Evaluation and organizational learning: Past, present, and future. American Journal of Evaluation, 22(3), 387-395. doi:

$10.1177 / 109821400102200316$

Tseng, Y.-F., \& Lee, T.-Z. (2009). Comparing appropriate decision support of human resource practices on organizational performance with DEA/AHP model. Expert Systems with Applications, 36(3), 6548-6558. doi: 10.1016/j.eswa.2008.07.066 
U.S. Small Business Administration (2014). Small Business Development Centers.

Retrieved from http://www.sba.gov/content/small-business-development-centerssbdes

Ulrich, D. (1997). Measuring human resources: an overview of practice and a prescription for results. Human Resource Management, 36(3), 303-320. doi: 10.1002/(sici)1099-050x(199723)36:3<303::aid-hrm3>3.0.co;2-\#

U.S. Small Business Administration (2014). Small Business Facts. Retrieved from http://www.sba.gov/advocacy/847/126001

Vera, D., \& Crossan, M. (2004). Strategic leadership and organizational learning. Academy of management review, 29(2), 222-240. doi: 10.2307/20159030

Wallsten, S. J. (2000). The effects of government-industry R\&D programs on private R\&D: the case of the Small Business Innovation Research program. RAND Journal of Economics, 31(1), 82-100. doi: 10.2307/2601030

Weber, L. (2014). Apprenticeships Help Create Jobs. So Why Are They in Decline? Wall Street Journal. Retrieved from http://stream.wsj.com/story/latest-headlines/SS-263399/SS-2-517596/ website:

Wiklund, J., Patzelt, H., \& Shepherd, D. A. (2009). Building an integrative model of small business growth. Small Business Economics, 32(4), 351-374. doi: $10.1007 / \mathrm{s} 11187-007-9084-8$

Wilson, J. P. (2005). Human resource development: Learning and training for individuals and organizations: Kogan Page Limited. 
Wyer, P., Mason, J., \& Theodorakopoulos, N. (2000). Small business development and the "learning organisation". International Journal of Entrepreneurial Behaviour \& Research, 6(4), 239-259. doi: 10.1108/13552550010355136

Yin, R. K. (2009). Case study research: Design and methods (Vol. 5). SAGE Publications, Incorporated. 


\section{APPENDIX A \\ INTERVIEW PROTOCOL}

\section{Interview questions for Leaders:}

\section{Employee Development \& Learning}

- How do employees develop their skills? (both formally and informally?)

- What influences the ways in which employees develop their skills?

- How is new learning applied?

- To what end is new learning applied?

- What outcome is hoped for when applying new learning?

- How do you integrate new learning into your existing ways of doing things?

- How does your organization learn from mistakes?

- Are behaviors and/or procedures changed in response to mistakes?

\section{Organizational Design \& Alignment}

- What are the intended desires or outcomes of the organization?

- How do you recognize when the direction of the organization is different from the desired outcome and follow the necessary steps to correct the misalignment?

\section{Organizational Change}

- When there is a change in how things are done (internally or industry-wide), how do you react?

- What is Bill's influence on the way you react to change?

\section{Interview questions for All Employees:}

\section{Organizational Culture}

- How would you describe your organization's culture?

- What is Bill's influence on the culture?

\section{Learning}

- When you learn something new, how do you communicate what you've learned to others at work? 
- Is it a priority to communicate to others when you learn something new?

- How do you integrate new learning into your existing ways of doing things?

- How does your organization learn from mistakes?

○ Does it change behaviors or procedures in response to mistakes?

\section{Organizational Change}

- When there is a change in how things are done, how do you react?

$\circ$ What is Bill's (and leadership's) influence on the way you react to change? 
APPENDIX B

OBSERVATION PROTOCOL

\begin{tabular}{|c|c|}
\hline $\begin{array}{c}\text { Smith Enterprises Organizational Learning Culture } \\
\text { Observational Protocol }\end{array}$ \\
\hline \multicolumn{2}{|c|}{ Length of Activity: 4 hours } \\
Org. Role: Stylist, Front Desk, Manufacturing/Distribution, Apprentice Assistant, \\
Education Evective Notes
\end{tabular}




\section{APPENDIX C \\ APPRENTICE TRAINING MODULES}

\section{Module 1-lasts 3-4 weeks}

- Orientation

○ New hire paperwork

○ Salon handbook

- Read through handbook together and discuss

- Discuss expectations

- Discuss the importance of their ability to be a great student and perform their technical skills. Also, stress the importance of having a positive attitude, working as a team, and goal setting.

- Discuss the salon sanitation responsibilities.

- All apprentices will be required to attend all weekly in-salon classes and educational events. When models are required, the apprentice is responsible for their supplying their own model.

- Orientation Checklist-tour section

- Making a Beverage Handout

- Laundry Handout

- Salon Sanitation

- Resting position

- This is how the salon looks when in perfect condition. The salon should be in resting position every night when we close and throughout the day to the best of our ability without interrupting the client's experience.

$\circ \quad$ Cleaning lists

- Eye for detail

- Product Knowledge

○ Product Knowledge Class

- Packet and video

○ Product Knowledge Certification

- BeautyFactor Quiz

- Certification Test

- Product Knowledge Certification Video

- Dialogue Training

$\circ$ Greeting

- Handout

- Demo 
- The educational director demonstrates a greeting to the

- Role Play apprentice.

- The educational director and apprentice go back and forth

- Salon tour introducing themselves to each other.

- Handout

- Demo

- The educational director gives the apprentice a couple tours and has them take notes.

- Practice giving tours

- The apprentice will give tours to the educational director and other designated members of the staff and receive feedback. The educational director is looking for good introduction, dialogue, confidence, voice inflection, and enthusiasm.

- Cleared to do tours on clients

- After consistently giving great tours to the educational director, the apprentice is cleared to tour guests.

- Sit-down conversation

- Educational director and apprentice discuss their first month

- Adaptation

- How has the apprentice fit into the new environment?

- Attitude

- How does the apprentice's attitude affect them and their fellow team members?

- Staying busy

- Has the apprentice kept busy?

\section{Module 2-lasts 3-4 weeks}

- Shampoos

○ Women

- Handout

○ Shampoo

$\circ$ Assisting Guidelines

- Demo

- The apprentice observes the educational director shampoo 2 clients. The educational director shampoos the apprentice twice. This enables the apprentice to not only see the process, but also feel it. The apprentice then shampoos the educational director as many times as necessary, at least 4, to get the process correct.

- Practice on staff members

- The whole shampoo process should last 4 to $4 \frac{1}{2} 2$ minutes. Each practice shampoo will be timed and recorded.

- Cleared to do shampoos on clients 
- Once the shampoo is the correct time and has a consistent flow, the apprentice will be cleared to shampoo female

○ Men guests.

- Handout

- Demo

- The apprentice observes the educational director shampoo 2 clients. The educational director shampoos the apprentice twice. This enables the apprentice to not only see the process, but also feel it. The apprentice then shampoos the educational director as many times as necessary, at least 4, to get the process correct.

- Practice on staff members

- The whole shampoo process should last 4 to 5 minutes. Each practice shampoo will be timed and recorded.

- Cleared to do shampoos on clients

- Once the shampoo is the correct time and has a consistent flow, the apprentice will be cleared to shampoo male guests.

- Introduction to color application

○ Handout

- Demo

- Educational director demos a color application on a mannequin. The apprentice also observes color being done on a client.

- Practice on mannequin with conditioner

- During all free time, the apprentice will practice applying color on a mannequin using conditioner. The apprentice will first practice new growth application, then pull through techniques.

○ Record times

- Every practice application will be timed and recorded. The apprentice must apply color on the mannequin in 10 minutes or less before being able to move on.

- Sit-down conversation

- Educational director and apprentice discuss the past month

- Progress

- Attitude

- Are they meeting expectations?

- How is their attitude affecting them and their fellow team members?

\section{Module 3-lasts 3-4 weeks}

- Color Mixing

- Handout

- Assist other team members with mixing

- Color Formulas

- Handout 
- Take-downs for color and highlights with Blue Viles and Toners

○ Handouts

- Demo

- Take-down on team member

- The apprentice must shampoo the color down with no assistance. The head and hair should be completely free of color and color residue. The take-down process should last 6-7 minutes (not including the toner and conditioning treatment processing times).

- Cleared to do take-downs on clients

- Assist with highlights

○ Handout

○ Demo

- The apprentice must observe another apprentice assisting a stylist with a highlight. The stylist and/or apprentice will also discuss the process verbally after the assisting is complete.

o Cleared to assist with highlights on client

- Cleared to apply color on guest

$\circ$ Efficient applications on mannequins

○ Test out-application on fellow team member

- When the application on a mannequin is at 9 minutes or less. The educational director will watch the apprentice apply color to a fellow team member. The application should include pulling color through the ends. The educational director is looking for time, even application, coverage, and cleanliness.

- Cleared to do color on clients

- Review

- Educational director and apprentice discuss Apprentice Training

- Strengths/ Weaknesses

- The educational director asks the apprentice to discuss their strengths and the areas in which they feel less comfortable

- Working with stylists and clients

- How is the apprentice working with clients?

- How much trust does the stylist have in the apprentice?

- Attitude

- How does the apprentice's attitude affect them and fellow team members?

- Apprentice is given assignment to return to educational director

- Create a list of goals: 2 month, 6 month, 1 year

\section{Module 4-lasts 3-4 weeks}

- Facial waxing

○ Handout

○ Demo

- Supervised waxes on fellow team members

- The educational director observes as the apprentice waxes 2 fellow team members. The apprentice must follow sanitation procedures, 
perform an acceptable wax, and display good dialogue. The apprentice will then be cleared to wax clients.

- Cleared to wax clients

- Perms

○ Handout

- Observe another perm being assisted

- The apprentice must observe a fellow apprentice assist with a perm:

- Rolling

- Solution application

- Complete Take-down

- Assist with perm and take-down with supervision

- Cleared to assist with perms

- Blowouts

- Blowout classes

- Practice on mannequin

- The apprentice uses free time to practice blowouts on different mannequins.

- Cleared to do blowouts on clients

- When the apprentice has mastered several techniques on a variety of hair, the apprentice is cleared to do blowouts on clients.

- Sit-down conversation

○ Discuss goals

- The educational director and apprentice discuss their goals and what needs to be done to achieve them.

- By the end of month 5, each apprentice is expected to be able to perform all of the above without any supervision. Now the apprentice enters Stylist Training.

- Month 7-Review

- Educational director and apprentice discuss Stylist Training

- Progress

- Attitude

- Going on the floor

- Apprentice is given an assignment to return to educational director

- Self-evaluation

- Make a list of all things confident performing on clients

- Make a list of all things that need to work on before performing on clients and what can be done to improve

○ Discuss list together

- One on one time takes place to work on the areas that need improvement

- Month 8-Introduction to the Floor

○ Apprentice is given one day each week to take appointments

- All appointments will be with clients that the apprentice has referred to the salon 
- The salon will not be giving clients to the apprentice until after the Final Presentation

- During this time, the services will be at designated pricing

- $\quad$ Month 12-Final Presentation 


\title{
CURRICULUM VITAE
}

\author{
Devon A. Twyford, Ph.D.
}

309 Bridlewood Avenue • Shelbyville, KY 40065

devont@gmail.com・(502) 321-4162

\begin{abstract}
Management Profile
Organization Development $\bullet$ Strategic Planning $\bullet$ Performance Management $\bullet$ Leadership Development $\bullet$ Individual/Team/Executive Coaching $\bullet$ Employee Training
\end{abstract}

Accomplished professional with experience in field of Organizational \& Human Resource Development poised to utilize background and expertise to excel in a management position. Ambitious with results expectation, well-developed interpersonal skills and the ability to motivate and direct others in achieving team and organizational goals. Offers expertise with Organization Development, Human Resource Training \& Development, Leadership Development, Strategic Planning, Performance Management and Coaching.

\section{Core Competencies}

- OrBnquiestional Axapyisin Development

- Workforce Training

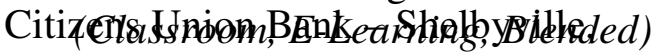

KY Employee \& Team²Delet3pithent
- Employee/Team/Executive Coaching

- Team Leadership

- Organizational Strategic Planning

- Group Facilitation \& Public Speaking

$1^{\text {st }}$ Vice President

Director of Organizational Development

Role included overseeing staff of trainers as well as designing and delivering formal training sessions in classroom, online and blended; Executive and Team job coaching; strategic planning, administration and oversight of Executive Leadership Development 
program; organizational change management, development and redesign of job descriptions for all staff and development of performance management processes.

\section{Key Contributions}

$>$ Led CUB Senior Management team through Strategic Planning process to determine important strategic objectives for 2011-2013 operating years. Provided oversight of plan to ensure completion of each strategic objective.

$>$ Due to major changes taking place within the organization's lending function, conducted Loan Officer Needs Assessment to determine source of unrest with current lending staff. Based on Needs Assessment, facilitated focus groups and other group processes to determine interventions to remedy sources of unrest. CEO and President implemented suggested interventions.

$>$ Conducted organizational analysis to determine source(s) contributing to lack of success for CUB in Jefferson County market. Based on findings, implemented Executive Job Coaching for both the Market President and Regional Manager. Saw immediate, improved results for Jefferson County market.

$>$ Conducted Executive job coaching for Market President and Regional Manager in Shelby County market in order to increase market share and performance. As a result, management capabilities and overall market performance increased.

$>$ Designed and delivered inaugural Management Training, "Monday Morning Mentoring."

$>$ Designed and delivered inaugural Sales Training Program, "Uncovering Opportunities", for ALL customer facing employees.

$>$ Established, planned and coordinated annual "Employee Development Conference" for 300+ employees for 5 years.

$>$ Built successful Training Department from scratch independently over the course of approximately 2 years.

Prior positions within Citizens Union Bank include Front Line Customer Service, Branch Management, AVP Branch Management Administration, VP Director of Training \& VP Director of Employee Performance \& Development

Education \& Credentials

Ph.D. Educational Leadership \& Organization Development University of Louisville - Louisville, KY

Master of Science in Human Resource Education University of Louisville - Louisville, KY

Bachelor of Science in Business Administration - Business Management

Sullivan University - Louisville, KY

Bachelor of Science in Business Administration - Marketing

Sullivan University - Louisville, KY 
Professional Development

Xavier University - Train the Trainer "Planning, Designing and Evaluating Training" Xavier University - Train the Trainer "Proven Classroom Techniques"

\author{
Professional Accomplishments \\ 2008 Graduate Leadership Shelby
}

2008 Citizens Union Bank Employee of the Year

2008 Graduate Citizens Union Bank Executive Development Leadership Program

2005 Citizens Union Bank "TIGERS" Core Values Award Recipient (Peer Nominated) 2005 Shelby County Business and Professional Women's Association "Young Careerist"

Award Recipient

Professional Associations

ASTD Kentuckiana Member

Academy of Human Resource Development Member

Community Leadership \& Activities

Big Brothers/Big Sisters of Kentuckiana Advisory Council Member Shelby County Cooperative Extension Office Advisory Council Member

Big Brothers/Big Sisters of Kentuckiana Big Sister Volunteer (3 years)

Habitat for Humanity Volunteer

Dave Ramsey "Financial Peace University for the Community" Facilitator (3 years)

\title{
Academic Papers \& Presentations
}

Rose, K., Shuck, B., Twyford, D., \& Bergman, M. (2014). Skunked: An integrative review exploring the consequences of dysfunctional leaders and implications for the employees who work for them. Manuscript submitted for publication to Human Resource Development Review.

Shuck, B., Twyford, D., Reio, T. G., Shuck. A. (2014). Human resource development practices and employee engagement: Examining the connection with employee turnover intentions. Manuscript submitted for publication to Human Resource Development Quarterly.

Twyford, D., \& Githens, R. (2014). Organizational learning in small business. In D. Chapman (Ed.), Proceedings of the Academy of Human Resource Development Conference, Houston, TX:

Shuck, B., Twyford, D., Shuck, A., \& Reio, T. G. (2013). Perceived investment in employee development and employee engagement: Examining the connection between employee turnover intentions. In D. Chapman (Ed.), Proceedings of the Academy of Human Resource Development Conference, Washington, DC: AHRD

Twyford, D., Shuck, B., \& Alagaraja, M. (2013). Human resource development in small business: An application of Brethower's performance principles to on the job training. In 
D. Chapman (Ed.), Proceedings of the Academy of Human Resource Development Conference, Washington, DC: AHRD

"HRD in Small Organizations" - University of Louisville Spring Research Conference 2012

Twyford, D., \& Githens, R. (2011). Human resource development in nonprofits. In D. Chapman (Ed.), Proceedings of the Academy of Human Resource Development

Conference, Chicago, IL: AHRD 